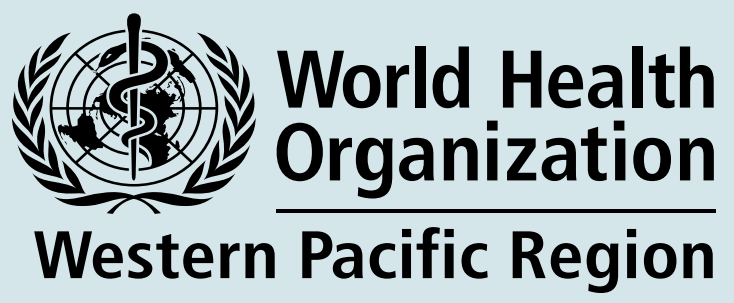

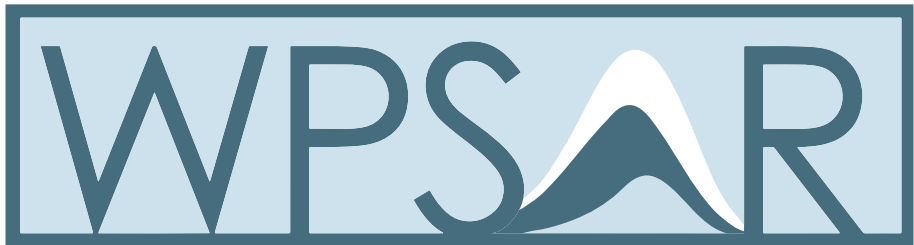

Western Pacific Surveillance and Response Journal

Volume 10, Number 1, 2018, Pages 1-42

p-ISSN: 2094-7321 e-ISSN: 2094-7313

\section{IN THIS ISSUE}

Outbreak Investigation Report

Is your drinking water safe? A rotavirus outbreak linked to water refilling stations in the Philippines, 2016

Rebato N, de los Reyes VC, Sucaldito MN and Marina G

Original Research

Rapid increase of syphilis in Tokyo: an analysis of infectious disease surveillance data from 2007 to 2016

Sugishita Y, Kayebeta A, Soejima $K$ and Yauchi $M$

Dengue-like illness surveillance: a two-year longitudinal survey in suburban and rural communities in the Lao People's Democratic Republic and in Thailand

Vannavong N, Seidu R, Stenström TA, Dada N and Overgaard HJ

A case series of fatal meningoencephalitis in Mongolia: epidemiological and molecular characteristics of tick-borne encephalitis virus Baasandavga U, Badrakh B, Burged N, Davaajav O, Khurelsukh T, Barnes A, Ulaankhuu U and Nyamdorj T

Missed detections of influenza A(H1)pdm09 by real-time RT-PCR assay due to haemagglutinin sequence mutation, December 2017 to March 2018, northern Viet Nam

Phuong $H$, Ung $T$, Nguyen $H$, Nguyen T, Le T, Nguyen S, Nguyen $A$, Tran $H$, Vuong $C$ and $L e M$

\section{Brief Report}

Preparation for mass gathering events from the perspective of a non-host country: the experience of Japan during the 2018 PyeongChang Olympics and Paralympic Winter Games

Jindai K, Yamagishi T, Fukusumi M, Nishiki S, Kobayashi Y, Matsui Y, Matsui T and Oishi K

\section{Western Pacific Surveillance and Response}

Open access journal with continuous publication

Western Pacific Surveillance and Response (WPSAR) is anopen access journal dedicated to the surveillance of and response to public health events. The goal of the journal is to create a platform for timely information sharing both within our region and globally to enhance surveillance and response activities. WPSAR is a continuous publication which means articles will be published online as soon as they have completed the review and editing process. Every three months articles will be batched for a print issue. It is a publication managed by the World Health Organization Regional Office for the Western Pacific.

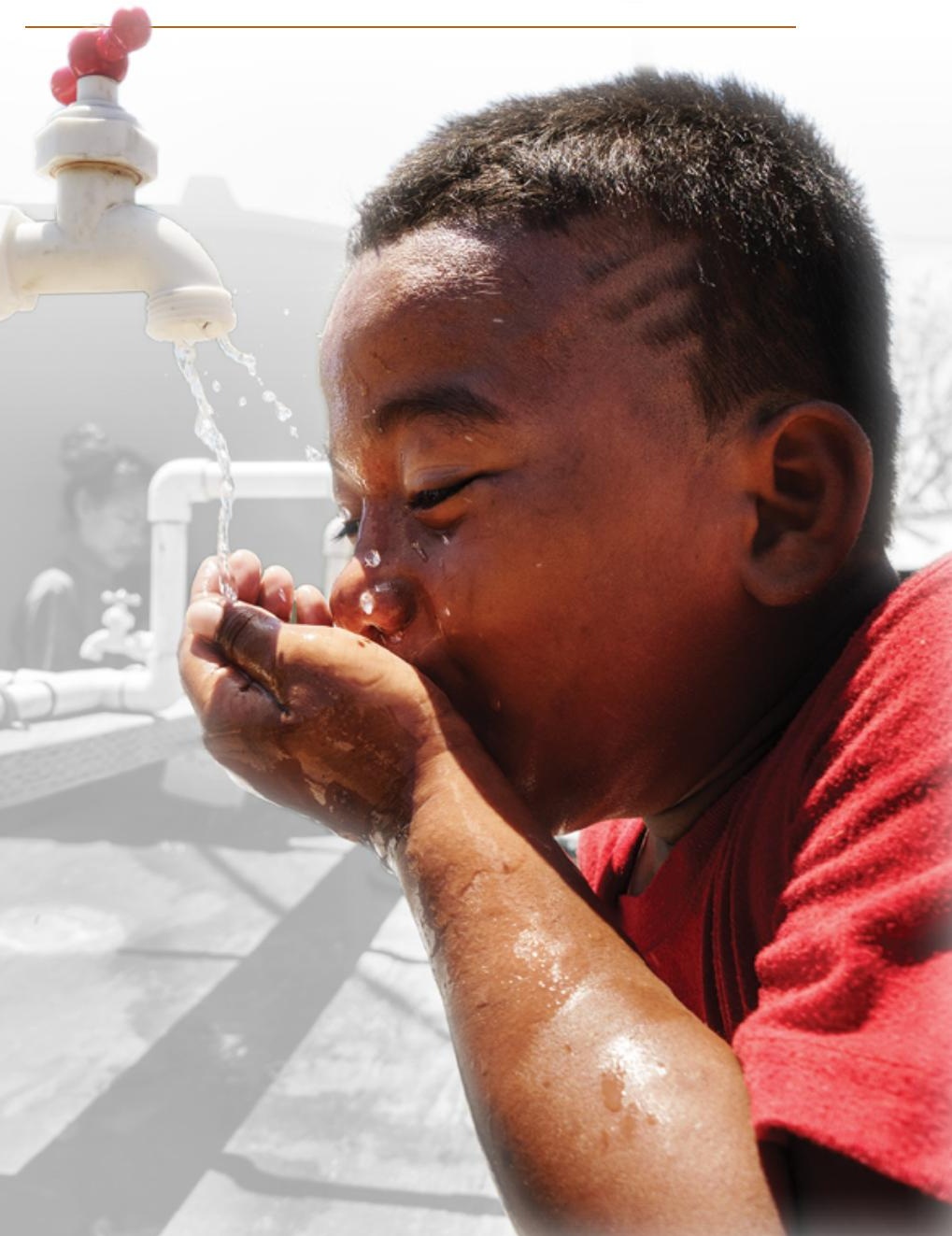




\section{EDITORIAL TEAM}

\author{
Ailan Li \\ Executive Editor \\ Amelia Kasper \\ Chi Hung Czarina Leung \\ Consulting Editors
}

Antonio Perez

Editorial Assistant

Associate Editors

Rabindra Abeyasinghe
James Heffelfinger
Chin-Kei Lee
Nobuyuki Nishikiori
Heather Papowitz
Boris Pavlin

To contact us:

\author{
Western Pacific Surveillance and Response \\ World Health Organization \\ Office for the Western Pacific Region \\ United Nations Avenue \\ 1000 Manila, Philippines \\ wpsar@who.int \\ https://ojs.wpro.who.int/
}

\section{Copyright notice}

Rights and permissions (c) World Health Organization 2019. Some rights reserved.

p-ISSN: 2094-7321

e-ISSN: 2094-7313

The articles in this publication are published by the World Health Organization and contain contributions by individual authors. The articles are available under the Creative Commons Attribution 3.0 IGO license (CC BY 3.0 IGO http:// creativecommons.org/licenses/by/3.0/igo/legalcode), which permits unrestricted use, distribution and reproduction in any medium, provided the original work is properly cited. In any use of these articles, there should be no suggestion that WHO endorses any specific organization, products or services. The use of the WHO logo is not permitted.

Attribution: please cite the articles as follows: [Author names]. [Article title]. Western Pac Surveill Response J. [Year]; [Volume] ([Issue]). [doi number]. License: Creative Commons BY 3.0 IGO

The World Health Organization does not necessarily own each component of the content contained within these articles and does not therefore warrant that the use of any third-party-owned individual component or part contained in the articles will not infringe on the rights of those third parties. The risk of claims resulting from such infringement rests solely with you. If you wish to re-use a component of the articles attributed to a third party, it is your responsibility to determine whether permission is needed for that re-use and to obtain permission from the copyright owner. Examples of components can include, but are not limited to, tables, figures or images.

Any mediation relating to disputes arising under this license shall be conducted in accordance with the WIPO Mediation Rules (www.wipo.int/amc/en/mediation/rules). Any inquiries should be addressed to publications@wpro.who.int.

\section{Disclaimer}

The designations employed and the presentation of the information in this publication do not imply the expression of any opinion whatsoever on the part of the World Health Organization concerning the legal status of any country, territory, city or area or of its authorities, or concerning the delimitation of its frontiers or boundaries.

The mention of specific companies or of certain manufacturers' products does not imply that they are endorsed or recommended by the World Health Organization in preference to others of a similar nature that are not mentioned. Errors and omissions excepted, the names of proprietary products are distinguished by initial capital letters. 


\title{
Is your drinking water safe? A rotavirus outbreak linked to water refilling stations in the Philippines, 2016
}

\author{
Niño D Rebato, ${ }^{a}$ Vikki Carr D de los Reyes, ${ }^{a}$ Ma Nemia L Sucaldito a and Gretchen R Marina \\ Correspondence to Niño Rebato (email: ninorebato@gmail.com)
}

Introduction: In April 2016, the Department of Health in Zamboanga Peninsula reported an increase in the number of acute gastroenteritis cases reported from Zamboanga City. An epidemiologic investigation was conducted to verify the existence of an outbreak, determine source/mode of transmission and recommend control measures.

Methods: A line list of cases was compiled from the 11 hospitals within Zamboanga City and a case-series study was conducted. Suspected cases were any persons from Zamboanga City who had three or more episodes of acute diarrhoea within 24 hours from 15 March to 29 May 2016. Confirmed cases were suspected cases with active symptoms during the investigation who had a stool sample collected with rotavirus detected. Water samples were also collected for viral detection.

Results: There were 2936 suspected cases with 22 deaths (case fatality rate: $0.75 \%$ ), an age range of 8 days to 89 years (median: 2 years), with those aged less than 5 years the most affected age group (1903/2936, 65\%). The majority were males (1549/2936, 53\%). From the 138 active case patients included in the case-series study, the majority reported contact with a family member who had diarrhoea $(89 / 138,64 \%)$ and using water refilling stations as their major source of drinking water $(88 / 134,64 \%)$. Of the 93 stool specimens collected, $56(60 \%)$ were positive for rotavirus. Five samples from water refilling stations where case patients reported collecting drinking water were all positive for rotavirus.

Discussion: Strict regulation of water refilling stations and boiling drinking water in households were implemented, immediately controlling the outbreak. After complying with all the requirements set by the Department of Health, a water safety certificate was awarded to Zamboanga City in September 2018.

O n 6 April 2016, the Regional Epidemiology and Surveillance Unit of the Department of Health in Zamboanga Peninsula reported an increase in acute gastroenteritis cases in Zamboanga City to the national event-based surveillance system. Zamboanga City is a highly urbanized city located in Mindanao in the southern Philippines with a population of 861799 people. ${ }^{1}$ It is the sixth most populous and third largest city in the Philippines. $^{2}$ Water production within Zamboanga City Water District serves only $48 \%$ of the total population with most people relying on water refilling stations. These water refilling stations sell purified water, mostly in 5-gallon containers that are delivered to the consumers' homes.

According to Zamboanga City Health Office, the city had a rotavirus outbreak in 2010 due to water contamination, affecting around 500 individuals. In 2012, rotavirus vaccine was added to the national vaccination schedule of all infants aged between 1.5 and 3.5 months. According to Zamboanga City Health Office, the immunization coverage in Zamboanga City is around 30\%, far from the national target of $90 \%{ }^{3}$

The Epidemiology Bureau of the Department of Health sent a team from 28 April to 2 May 2016 to conduct an epidemiologic investigation to verify the existence of an outbreak, determine the cause, identify the likely source and mode of transmission and recommend control and prevention measures.

\section{METHODS}

\section{Case-series study}

A line list of suspected cases was constructed from records on suspected case patients admitted to the 11 hospitals within Zamboanga City. A suspected case was defined as any previously well individual in Zamboanga City who had three or more watery stools per day from 15 March to 29 May 2016. 
A case-series study was then conducted for those suspected cases that were still symptomatic and admitted to hospital at the time the investigation team was present (active cases). These active case patients were interviewed for information on demographics, exposure history, medical history and other relevant information. Stool samples were collected from these active case patients with a confirmed case defined as a suspected case that had rotavirus detected in stool sample.

Data analysis was performed using Microsoft Excel 2013.

\section{Environmental investigation}

The Philippine drinking-water standards require all water sources to adhere to standard parameters and values for drinking-water quality. There should be no Escherichia coli; coliform or other bacteria present in every $100 \mathrm{ml}$ water sample should not exceed the permissible level of biological organisms, organic and inorganic constituents (antimony, arsenic, etc.); and the chemical, disinfectant, disinfectant by-products and radiological constituents should be within standard values. ${ }^{4}$

Sixty-six water sources consisting of 39 water refilling stations, 17 water district and 10 deep wells in Zamboanga City were inspected by the city sanitation office to determine possible cross-contamination and non-compliance to the Philippine drinking-water standards. ${ }^{4}$

\section{Laboratory examination}

Stool specimens from active case patients were collected and sent to the Research Institute for Tropical Medicine (RITM) in Manila for rotavirus, norovirus and adenovirus detection using reverse transcriptase polymerase chain reaction (RT-PCR). To rule out other potential causes of the outbreak, rectal swab specimens were also tested for bacterial pathogens according to RITM standard procedures and previously published methods. ${ }^{5}$

Water samples were tested for bacterial analysis using the Colilert (IDEXX Laboratories, Inc., Westbrook, Maine, USA) rapid test. RT-PCR and conventional PCR were used for detection of pathogen based on the World Health Organization's manual for rotavirus detection. ${ }^{6}$

\section{RESULTS}

\section{Suspected cases}

A total of 2936 suspected cases were identified with onset dates from 28 March 2016. There was a peak of cases on 3-5 April 2016 (Fig. 1). The age of all suspected cases ranged from 8 days to 89 years (median: 2 years), with the majority of suspected cases aged less than 5 years $(1903 / 2936,65 \%)$. Just over half the suspected cases were male (1549/2936, 53\%). There were 22 deaths reported, giving a case fatality rate of $0.75 \%$. The age of fatal cases ranged from 2 months to 50 years (median: 11 months) and 13 (59\%) were male.

\section{Case series}

There were 138 active case patients included in the case series. Eighty-eight (64\%) were aged less than 5 years. All had diarrhoea; others reported vomiting (112/138, 81\%), abdominal pain $(84 / 138,61 \%)$ and fever $(83 / 138,60 \%)$.

The majority of active case patients reported close contact with family member who had diarrhoea before their illness onset $(89 / 138,64 \%)$. The major source of drinking water reported among these case patients was from water refilling stations $(88 / 138,64 \%$; only $44 / 138$ or $32 \%$ reported that they drank boiled water. Before eating and after using toilet, 53\% (73/138) reported using hand sanitizer and $62 \%(86 / 138)$ reported using detergent or bath soap regularly (Table 1 ).

\section{Environmental survey}

There were more than 200 water refilling stations in Zamboanga City, but only 125 had a sanitary permit. Non-compliant establishments were issued closure orders by the City Health Office due to possible contamination. Violations of the Philippine drinking-water standards were observed in some establishments due to presence of bacteria in water sample and biological organisms more than the permissible limit in every $100 \mathrm{ml}$ sample.

Five water distribution pipes from Zamboanga City Water District were inspected. Water handlers were mostly children. Hand pumps are attached to the water distribution pipes to add pressure to the faucet. Pipes are also submerged in the sewers. These sources also did not meet the water-quality standards and were immediately rehabilitated. 
Fig. 1. Diarrhoea cases by date of onset and case category, Zamboanga City, 28 March to 29 May 2016 $(n=2936)$

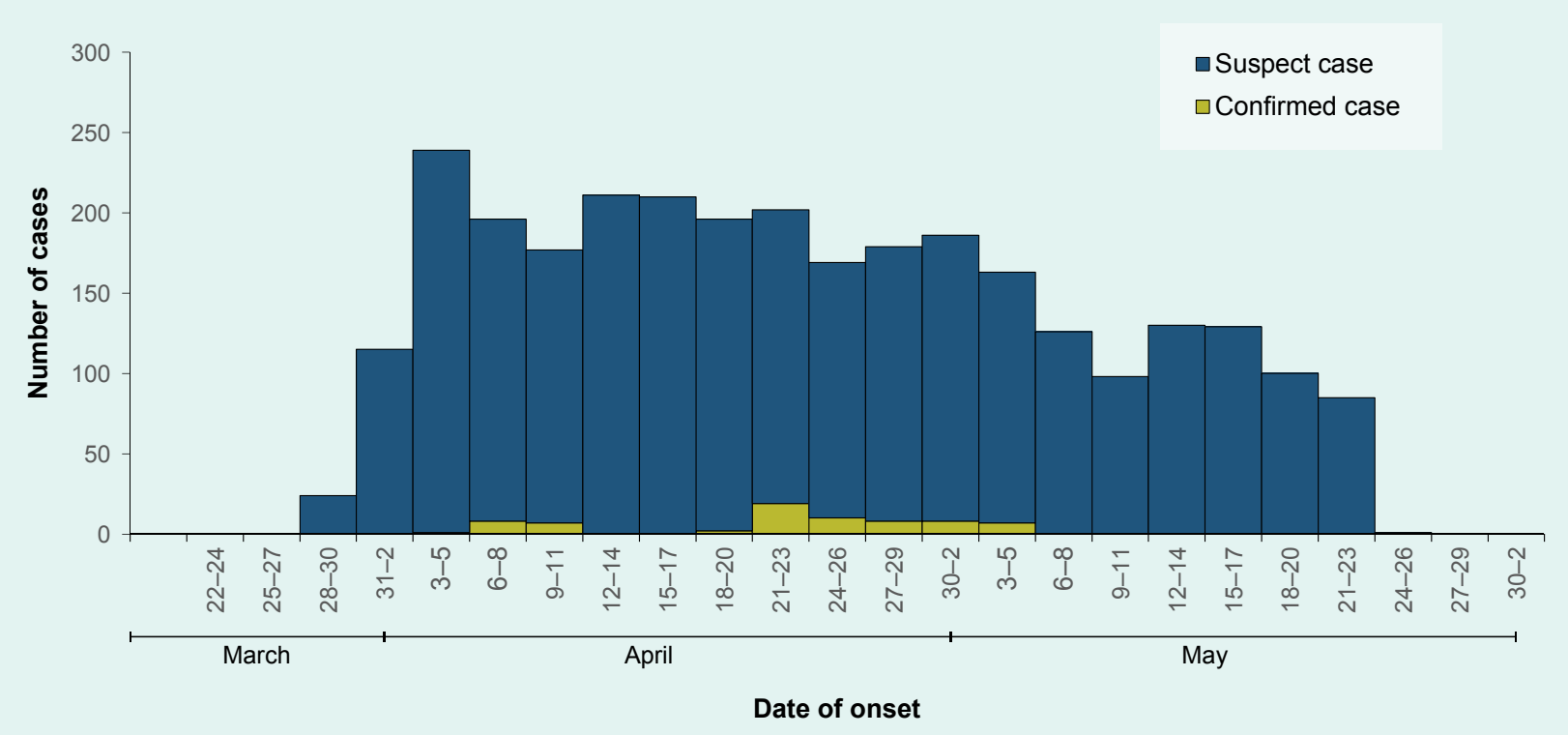

Table 1. Profile of active rotavirus cases, Zamboanga City, 28 April to 2 May $2016(n=138)$

\begin{tabular}{|c|c|c|c|}
\hline Factors & $\begin{array}{c}<5 \text { years } \\
n(\%)\end{array}$ & $\begin{array}{c}\geq 5 \text { years } \\
n(\%)\end{array}$ & $\begin{array}{l}\text { Total } \\
n(\%)\end{array}$ \\
\hline Total & $88(100 \%)$ & $50(100 \%)$ & $138(100 \%)$ \\
\hline \multicolumn{4}{|l|}{ Sex } \\
\hline Male & $48(55 \%)$ & $21(42 \%)$ & $69(50 \%)$ \\
\hline Female & $40(45 \%)$ & $29(58 \%)$ & $69(50 \%)$ \\
\hline \multicolumn{4}{|l|}{ Symptoms } \\
\hline Diarrhoea & $88(100 \%)$ & $50(100 \%)$ & $138(100 \%)$ \\
\hline Vomiting & $80(91 \%)$ & $32(64 \%)$ & $112(81 \%)$ \\
\hline Abdominal pain & $50(57 \%)$ & $34(68 \%)$ & $84(61 \%)$ \\
\hline Dehydration & $56(64 \%)$ & $37(74 \%)$ & $93(67 \%)$ \\
\hline Fever & $58(66 \%)$ & $25(50 \%)$ & $83(60 \%)$ \\
\hline Hospitalized & $88(100 \%)$ & $50(100 \%)$ & $138(100 \%)$ \\
\hline Close contact with sick family member & $55(55 \%)$ & $34(68 \%)$ & $89(64 \%)$ \\
\hline Drinking-water source from water refilling stations & $74(84 \%)$ & $14(28 \%)$ & $88(64 \%)$ \\
\hline Boil drinking water & $31(35 \%)$ & $13(26 \%)$ & $44(32 \%)$ \\
\hline Use hand sanitizer & $45(51 \%)$ & $28(56 \%)$ & $73(53 \%)$ \\
\hline Use soap after toilet use & 56 (64\%) & 30 (60\%) & 86 (62\%) \\
\hline
\end{tabular}




\section{Laboratory examination}

There were 93 stool specimens from active case patients submitted to RITM for viral detection with $56(60 \%)$ positive for rotavirus. Six case patients $(6 \%)$ had coinfection of rotavirus and adenovirus, and three $(3 \%)$ had co-infection of rotavirus and norovirus. All specimens were negative for any bacterial pathogens.

Of the 66 water samples, excess total coliforms were detected in 19/39 (49\%) water refilling stations, 9/17 (53\%) Zamboanga City Water District samples and 4/10 (40\%) samples from deep wells. Escherichia coli were present in water samples collected from water refilling stations (4/39, 10\%), Zamboanga City Water District $(2 / 17,12 \%)$ and deep wells $(5 / 10,50 \%)$.

Of the 15 water samples sent to RITM for rotavirus confirmation (five each from water refilling stations, the Zamboanga City Water District and deep wells) only the five refilling-station samples were positive for rotavirus RNA.

\section{DISCUSSION}

The evidence collected during this outbreak investigation suggests that rotavirus was the cause of this outbreak. Sixty per cent of cases that were laboratory tested were positive for rotavirus; water samples taken from water refilling stations, the most commonly reported water source used by active case patients, were also positive for rotavirus. The symptoms reported were consistent with rotavirus, ${ }^{7}$ as was the age distribution with most cases aged less than 5 years. Rotavirus was the most common cause of diarrhoeal deaths globally in children under 5 years old, accounting for 215000 child deaths in 2013 based on the estimates of the World Health Organization. ${ }^{8}$ This underscores the need for prevention in this particular age group.

Rotavirus is the major cause of hospital admissions, emergency department visits and clinic visits in the Philippines among infants with diarrhoea. ${ }^{9}$ Rotavirus vaccine was introduced in 2012 as part of the Expanded Program on Immunization, but because of inadequate supply, some areas, including Zamboanga City, have not received the vaccine since 2014 . Vaccination could help prevent rotavirus outbreaks.
Rotavirus infection can easily spread from an infected person to another by close contact. ${ }^{7}$ Most case patients were exposed first to a family member with vomiting and diarrhoea before onset of their symptoms. Rotavirus is highly communicable; a small infectious dose of less than 100 virus particles can cause the fast spread of the illness. ${ }^{10}$

The majority of active case patients reported obtaining their drinking water from water refilling stations. This was the first rotavirus outbreak in the Philippines with viral isolation of rotavirus from water refilling stations. The presence of rotaviruses in drinking water has been reported in several studies ${ }^{11,12}$ and has been the source of several epidemics originating from contaminated water. ${ }^{13,14}$ In parallel with person-to-person contamination, drinking water might play a role in the occurrence of sporadic cases. This, and the fact that many of the water refilling stations did not have sanitary permits, emphasize the need for routine inspections and water testing of water refilling stations.

RITM's protocol ${ }^{5}$ indicates that only stool specimens from cases whose onset of diarrhoea was three days before the specimen collection date could be tested. Because specimen collection was only done during the time of field investigation, cases that fell outside the collection period were not sampled, hence, only $93 / 2936$ or $3 \%$ of stool specimens were collected. This sampling method could overestimate sample positivity. However, the higher prevalence of rotavirus in younger children demonstrated by this study is similar to other rotavirus investigations in other settings. ${ }^{12,13,14}$

Risk factors for this outbreak were not statistically tested due to the descriptive design of the study. Also, we were not able to elicit information on the rotavirus vaccination history of the active case patients interviewed as it was not included in our questionnaire. This is a limitation of the study, although it is expected that the vaccination rate would be low based on reported vaccination rates in the city.

In May 2016, as a result of this investigation, the government of Zamboanga City advised households to boil drinking water and also created a technical working group focusing on water safety with emphasis on the strict regulation of water refilling stations to control the outbreak. Multiagency activities were conducted to come 
up with the city water safety plan, and in September 2018, more than two years after the outbreak, a water safety certificate was awarded to Zamboanga City after complying with all the requirements set by the Department of Health. ${ }^{15}$ No further outbreaks of rotavirus have been reported in Zamboanga. To prevent outbreaks of this magnitude in the future, these water safety measures need to be sustained and continued.

\section{Acknowledgements}

The authors would like to thank the Regional Health Emergency Management, Surveillance and Disaster Response Unit (RHEMSDRU) of Zamboanga Peninsula headed by Mr Maxell Bermas and his staff for the assistance given during the entire outbreak investigation. We are also grateful to Ms Rowena Capistrano of Research Institute for Tropical Medicine (RITM), the management of 11 Zamboanga City hospitals, to Dr Ivy Itturalde of the City Health Office, Zamboanga Peninsula Pediatrics Society, and to the local government of Zamboanga City for the technical and laboratory support, and to Ms Michelle McPherson for her diligent effort in helping get this paper published.

\section{Funding}

This study was funded by the Department of Health, Philippines.

\section{Conflict of interest}

None.

\section{References}

1. Total population by city, municipality, and barangay of Region IX Zamboanga Peninsula, Manila: Philippine Statistics Authority; 2015 (https://www.psa.gov.ph/sites/default/files/attachments/ hsd/pressrelease/R09.xlsx, accessed 21 November 2018).

2. Population of the Philippines. Manila: National Statistics Office; 2010 (https://www.psa.gov.ph/content/highlights-philippine-population-2015-census-population, accessed 15 June 2016).
3. Field Health Services Information System ver. 2012. Manila: Department of Health (Philippines); 2012 (https://chogensantos. files.wordpress.com/2016/04/fhsis.pdf).

4. Philippine national standards for drinking water 2017. Manila: Department of Health (Philippines); 2017 (http://dmas.doh.gov. ph:8080/Relatedlssuances?id=337128\&ist=Administrative\%20 Order\&isn=2017-0010)

5. Guidelines for specimen collection, transport and referral during infectious disease outbreak response. Manila: Research Institute for Tropical Medicine; 2014.

6. Manual of rotavirus detection and characterization methods Geneva: World Health Organization, 2009 (http://apps.who.int/ iris/bitstream/handle/10665/70122/WHO IVB 08.17 eng.pdf; sessionid=DF854894A00E16C1A3F7CC29DFD3EE02?sequen $\mathrm{ce}=1$, accessed 21 February 2017).

7. Payne DC, Wikswo M, Parashar UD. Chapter 13: Rotavirus. In: VPD surveillance manual, 5th edition. Atlanta, GA: Centers for Disease Control and Prevention; 2013 (https://www.cdc.gov/vaccines/pubs/surv-manual/chpt13-rotavirus.pdf, accessed 28 April 2016).

8. Estimated rotavirus deaths for children under 5 years of age: 2013 , 215 000. Geneva: World Health Organization; 2016 (http://www. who.int/immunization/monitoring surveillance/burden/estimates/ rotavirus/en/, accessed 15 June 2016).

9. Carlos CC, Inobaya MT, Bresee JS, Lagrada ML, Olorosa AM, Kirkwood CD, et al. The burden of hospitalizations and clinic visits for rotavirus disease in children aged $<5$ years in the Philippines. J Infect Dis. 2009 Nov 1;200(s1) Suppl 1:S174-81. doi:10.1086/605044 pmid:19817598

10. Rotavirus. Atlanta, GA: Centers for Disease Control and Prevention; 2016 (https://www.cdc.gov/rotavirus/, accessed 21 February 2017).

11. Rutjes SA, Lodder WJ, van Leeuwen AD, de Roda Husman AM. Detection of infectious rotavirus in naturally contaminated source waters for drinking water production. J Appl Microbiol. 2009 Jul;107(1):97-105. doi:10.1111/j.1365-2672.2009.04184.x pmid:19302334

12. Sobsey MD, Kellogg JS. De Leon Ricardo, Carol Shieh YS. Enteric virus detection in water by nucleic acid methods. Denver, CO American Water Works Association Research Foundation; 1996 (https://books.google.com.ph/books/about/Enteric Virus Detection_in_Water_by_Nucl.html?id=bfXtlwFOd4oC\&redir_esc $=y$, accessed 21 February 2017).

13. Verheyen J, Timmen-Wego M, Laudien R, Boussaad I, Sen S, Koc A, et al. Detection of adenoviruses and rotaviruses in drinking water sources used in rural areas of Benin, West Africa. Appl Environ Microbiol. 2009 May;75(9):2798-801. doi:10.1128/ AEM.01807-08 pmid:19270143

14. Hopkins RS, Gaspard GB, Williams FP Jr, Karlin RJ, Cukor G, Blacklow NR. A community waterborne gastroenteritis outbreak: evidence for rotavirus as the agent. Am J Public Health. 1984 Mar;74(3):263-5. doi:10.2105/AJPH.74.3.263 pmid:6320684 


\title{
Rapid increase of syphilis in Tokyo: an analysis of infectious disease surveillance data from 2007 to 2016
}

\author{
Yoshiyuki Sugishita, ${ }^{a}$ Aya Kayebeta, ${ }^{a}$ Kumiko Soejima ${ }^{a}$ and Mariko Yauchi ${ }^{a}$ \\ Correspondence to Yoshiyuki Sugishita (email: yoshiyuk@gmail.com)
}

The objective of this study was to examine the trends of primary and secondary syphilis in Tokyo between 2007 and 2016 using national infectious disease surveillance data. We analysed all 3269 cases reported during these 10 years. A statistically significant increase in cases was observed after 2010 with a more rapid rate of increase after 2014 mainly in urban areas in Tokyo. The notification rates per 100000 population in 2010, 2014 and 2016 were $0.9(n=113)$, $2.2(n=295)$ and $8.7(n=1190)$, respectively. Domestic syphilis transmission was suspected in $92.6-99.3 \%$ of cases during the period 2007-2016.

Until 2013, the increase was mainly observed among men who have sex with men (MSM); however, heterosexual transmission became more dominant and eventually surpassed transmission among MSM in 2015. In 2016, the notified cases of infections through heterosexual contact were 22.3 and 40.4 times higher in men and women, respectively, compared to those in 2010. The median ages of affected heterosexual men and women were 37 (interquartile range: 28-46) and 26 (interquartile range: 22-32) years, respectively. Reports of oropharyngeal lesions have been increasing among both men and women with syphilis. The number of congenital syphilis cases reported in Tokyo was 0 to 3 cases per year during the study period.

More information and further analysis are needed to explain the reason for this increase.

$\mathrm{S}$ yphilis is a common sexually transmitted infection. In 2012, an estimated 5.6 million new syphilis infections among people aged 15 to 49 years were reported globally. ${ }^{1}$ In Japan, a venereal disease prevention law passed in 1948 mandated a syphilis patient notification system. The Ministry of Health, Labour and Welfare consolidates data using the National Epidemiological Surveillance of Infectious Disease (NESID) system. ${ }^{2,3}$ Although syphilis cases nationwide decreased from 216617 in 1948 to 621 in 2010, they rebounded afterwards, reaching 4546 in $2016 .^{2,3}$

\section{METHODS}

\section{Surveillance}

Medical institutions report cases to NESID through public health centres. In 2015, 31 public health centres and approximately 13600 medical institutions served the 13.5 million residents of Tokyo. ${ }^{4,5}$ Syphilis diagnosis and treatment are widely available throughout the metropolitan area, including at community medical facilities. Free and anonymous syphilis and HIV testing is also offered by most municipal public health centres and the Tokyo Metropolitan Testing and Counselling Offices.

Physicians are required to report cases of early symptomatic (primary and secondary [P\&S]) syphilis, late symptomatic syphilis, asymptomatic syphilis and congenital syphilis (CS) via facsimile to public health centres using a designated paper notification form. Public health centre staff then register cases online to NESID. Demographic and clinical information, date of diagnosis and epidemiological information (e.g. location of disease transmission, sexual history) are consolidated in NESID. All registered syphilis cases are verified by surveillance officers in the Tokyo Metropolitan Infectious Disease Surveillance Center (TMIDSC), which publishes weekly surveillance reports. ${ }^{6}$

\section{Data collection}

We extracted cases of P\&S syphilis and CS in Tokyo from 1 January 2007 to 31 December 2016 from NESID. Tokyo consists of 23 special wards (central), the Tama area (suburban) and the islands (suburban) (Fig. 1). We used 
Fig. 1. Map of Tokyo (includes 23 special wards, Tama area, and islands)

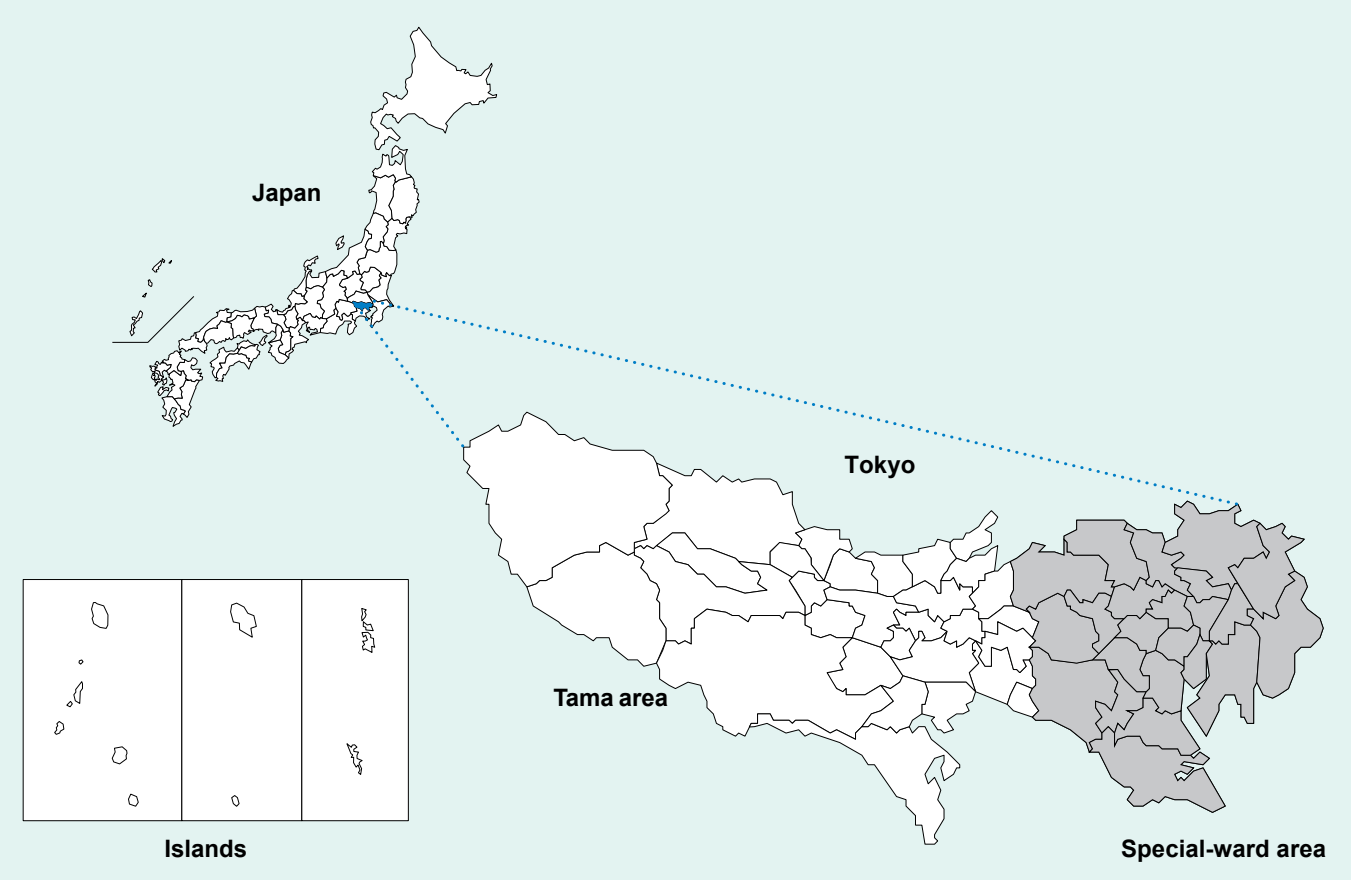

NESID surveillance definitions to define early symptomatic syphilis and CS. Early symptomatic syphilis was defined as an individual who tested positive in both nontreponemal and specific treponemal tests with at least one clinical sign or symptom (primary: painless chancre; secondary: painless inguinal lymphadenopathy, syphilitic roseola, papular syphilide or condyloma lata). ${ }^{2,3}$ CS was defined as a live infant with signs or symptoms of CS or a positive serological examination. ${ }^{2,3}$

\section{Descriptive analysis}

We performed descriptive analysis of early symptomatic syphilis cases considering sex, age, diagnosis date, syphilis stage, symptoms, sex of partner, suspected location of disease transmission (Tokyo, other prefectures in Japan, outside of Japan or unknown) and location of the reporting medical facility (central or suburban Tokyo). Sex partner preferences were categorized as men who have sex with men (MSM), men who have sex with women only (MSW), men who have sex with men and women (MSMW), women who have sex with men only (WSM), women who have sex with women (WSW), women who have sex with women and men (WSWM) or sexual contact type unknown. The notification rate was calculated to indicate the annual number of newly diagnosed and notified cases per 100000 population using the annual population estimates from the 2010 and 2015 Census in Tokyo.

Descriptive analysis of CS was performed considering date of diagnosis.

\section{Regression analysis}

We focused on P\&S syphilis to analyse trends in cases using a generalized linear model. We offset a Poisson regression model by the estimated annual population and compared every pair of adjacent years by two-sample tests for equality of proportion. For comparison, we employed the notified cases of P\&S syphilis and the estimated annual population of Tokyo.

All statistical analyses were done with $\mathrm{R}$ software version R-3.4.1 (R Foundation for Statistical Computing, Vienna, Austria). A $p$ value of $<0.05$ was considered statistically significant. We performed Bonferroni corrections for multiple comparisons. The number of tests that compared adjacent years was nine, so the significance level for each test was set to 0.0056 . 
Fig. 2. Notification rates per 100000 population of primary and secondary syphilis by sex and area, Tokyo, 2007 to 2016

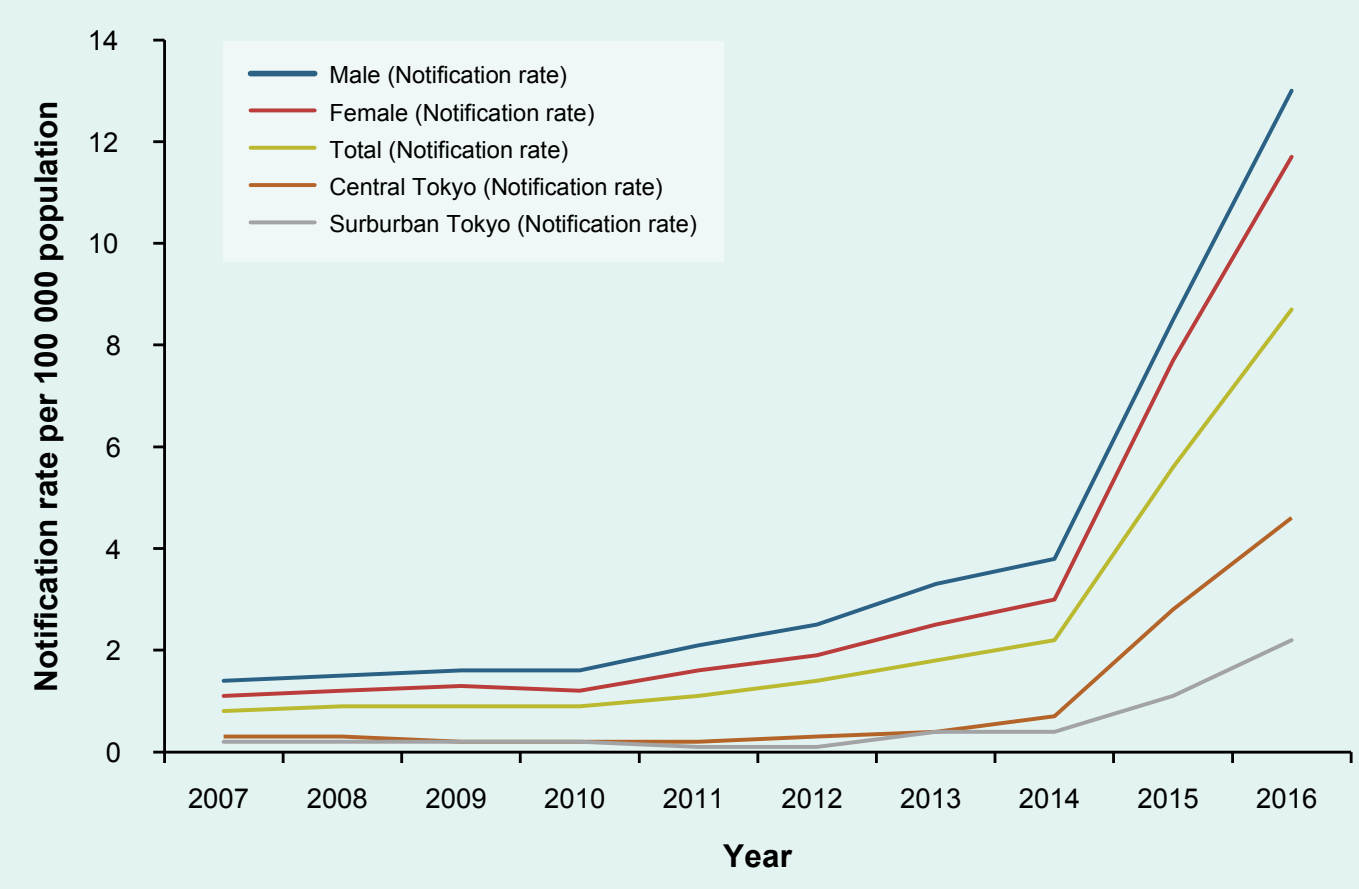

\section{Ethics statement}

This study was exempt from ethical review committee review since the data were surveillance data conducted under the provisions of Japanese law. The data collected in this study do not contain personal information.

\section{RESULTS}

\section{Notifications and rates}

\section{Overall and by sex}

The notification rate of P\&S syphilis was 8.7 per 100000 population $(n=1190)$ in 2016, 9.7 times higher compared to $0.9(n=113)$ in 2010 and a fourfold increase compared to 2.2 ( $n=295$ ) in 2014 (Fig. 2). The annual notification rate for men exceeded that for women throughout the period of 2007 to 2016 . Both men and women had the highest notification rate in 2016, which was $13.0(n=875)$ for men and $4.6(n=315)$ for women.

\section{Sources of notification reports}

Annual notification rates from central Tokyo exceeded those from the suburbs (Fig. 2). In central Tokyo, the notification rate was 1.1 per 100000 population in 2007, increased to 3.0 in 2014 and climbed to 11.7 in 2016. In the Tokyo suburbs from 2007 to 2012, the notification rate ranged from 0.1 to 0.2 , then climbed to 2.2 by 2016 .

\section{Trend analysis}

The model shows that cases trended upward throughout the study period $(P<0.001)$ (Fig. 3$)$. There was a statistically significant increase in the number of cases from 2012-2013, 2014-2015 and 2015-2016 $(P<0.0056)$.

\section{Suspected location of disease transmission}

The proportions of cases with suspected transmission within Japan ranged from $92.6 \%$ to $99.3 \%$ during the study period. The proportions of domestically acquired infections stemming from Tokyo ranged from $87.6 \%$ to $96.3 \%$. 
Fig. 3. Generalized linear model fitting and comparison of adjacent years by two-sample test for equality of proportions, by use of the number of primary and secondary syphilis notifications and estimated population of the residents in Tokyo

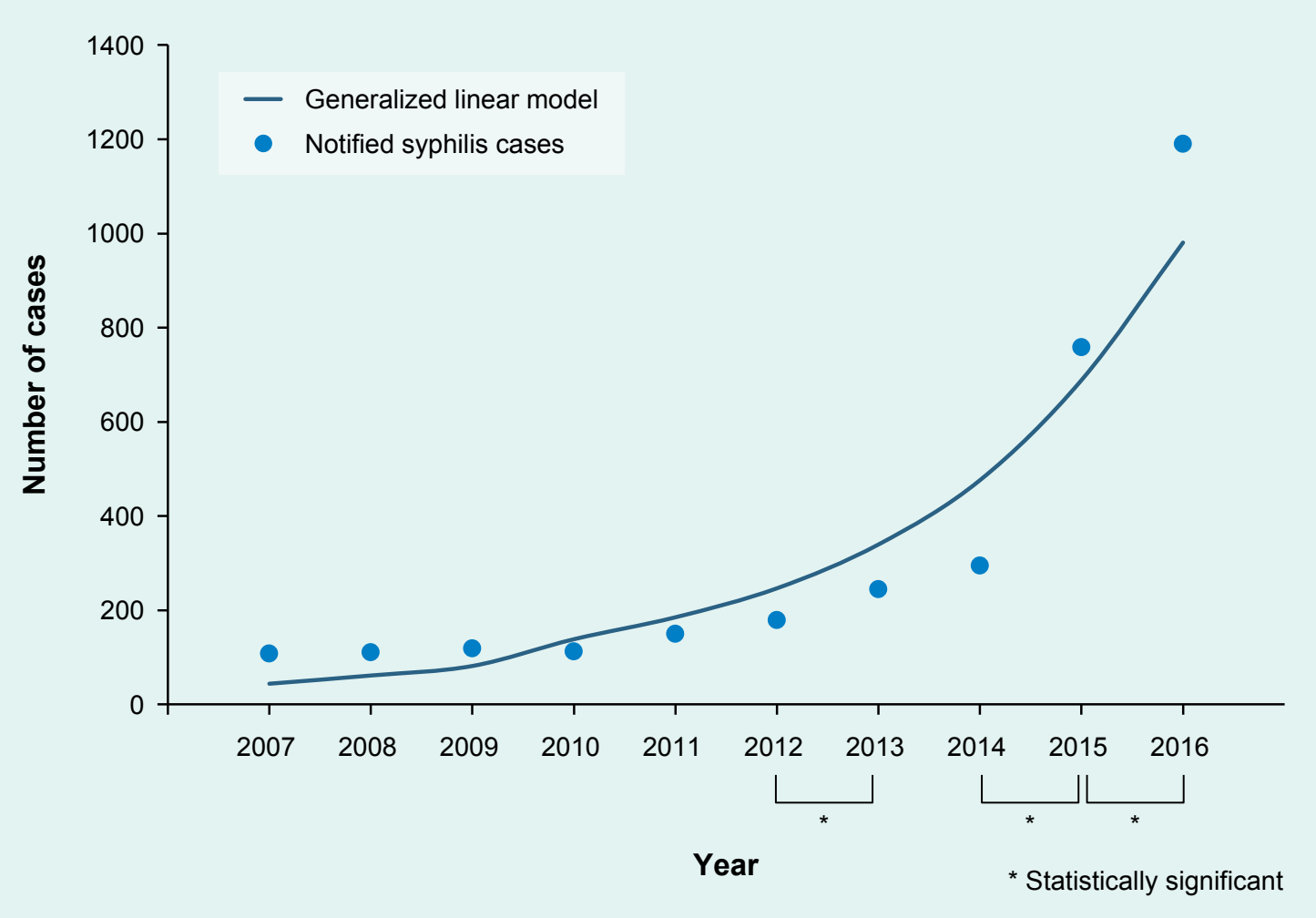

\section{Disease stage}

A total of 1198 primary cases and 2071 secondary cases were reported from 2007 to 2016 (Fig. 4). The number of primary syphilis cases had been declining; they started increasing again after 2010. The number of secondary syphilis cases has consistently increased since 2007. In 2016 , the number of primary cases was 533 , a 31 -fold increase since 2010. The number of secondary cases was 657 , a sevenfold increase during the same period.

\section{Sex of partner}

\section{Men who have sex with men}

Infections among MSM steadily increased from 2007 to 2016 (Fig. 5). The number of cases among MSM was 4.2 times higher in 2016 than in 2010. The proportion of MSM cases increased annually from 2007 to 2013, peaked at $62.9 \%$ in 2013 and then decreased to $21.6 \%$ in 2016. The median age of MSM during 2007-2016 was 36 (interquartile range [IQR]: 29-43) years (Fig. 6A). During the period 2012-2016, the incidence of oropharyngeal lesions increased (Fig. 7) and affected a greater percentage of MSM with syphilis (2.7\% in 2016 to $6.1 \%$ in 2014 .)

\section{Men who have sex with women only}

The number of cases among MSW decreased from 2007 to 2010 , then increased in 2014 , and markedly increased during the years 2015-2016 (Fig. 5). The cases among MSW $(n=283)$ exceeded those among MSM $(n=170)$ in 2015 and was 22.3 times higher in 2016 compared to 2010. The proportion of cases among MSW was $50.9 \%$ in 2007, decreased to $15.5-21.3 \%$ from 2010 to 2013 and increased again in 2014 to $37.5 \%$ in 2016 . The median age of MSW during 2007-2016 was 37 (IQR: 28-46) years (Fig. 6B). Affected MSW with oropharyngeal lesions sharply increased in 2015 and 2016 (Fig. 7); the proportion was 3.5\% in 2015 and $3.4 \%$ in 2016.

\section{Men who have sex with men and women}

The notified cases in MSMW were 0 to 3 cases per year in 2007 to 2015. In 2016, six cases were reported. 
Fig. 4. Cases of notified syphilis by stage, Tokyo, 2007 to 2016

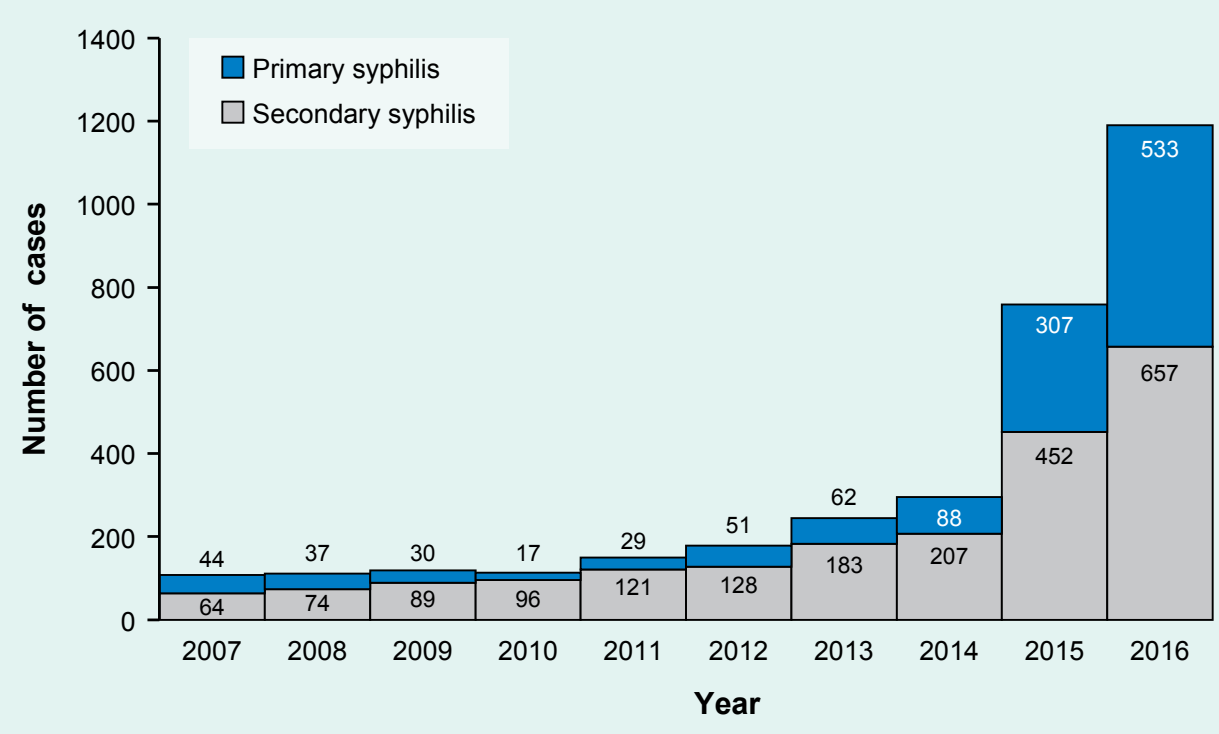

Fig. 5. Changes in the number of the notifications of primary and secondary syphilis cases by sex of partner, Tokyo, 2007 to 2016

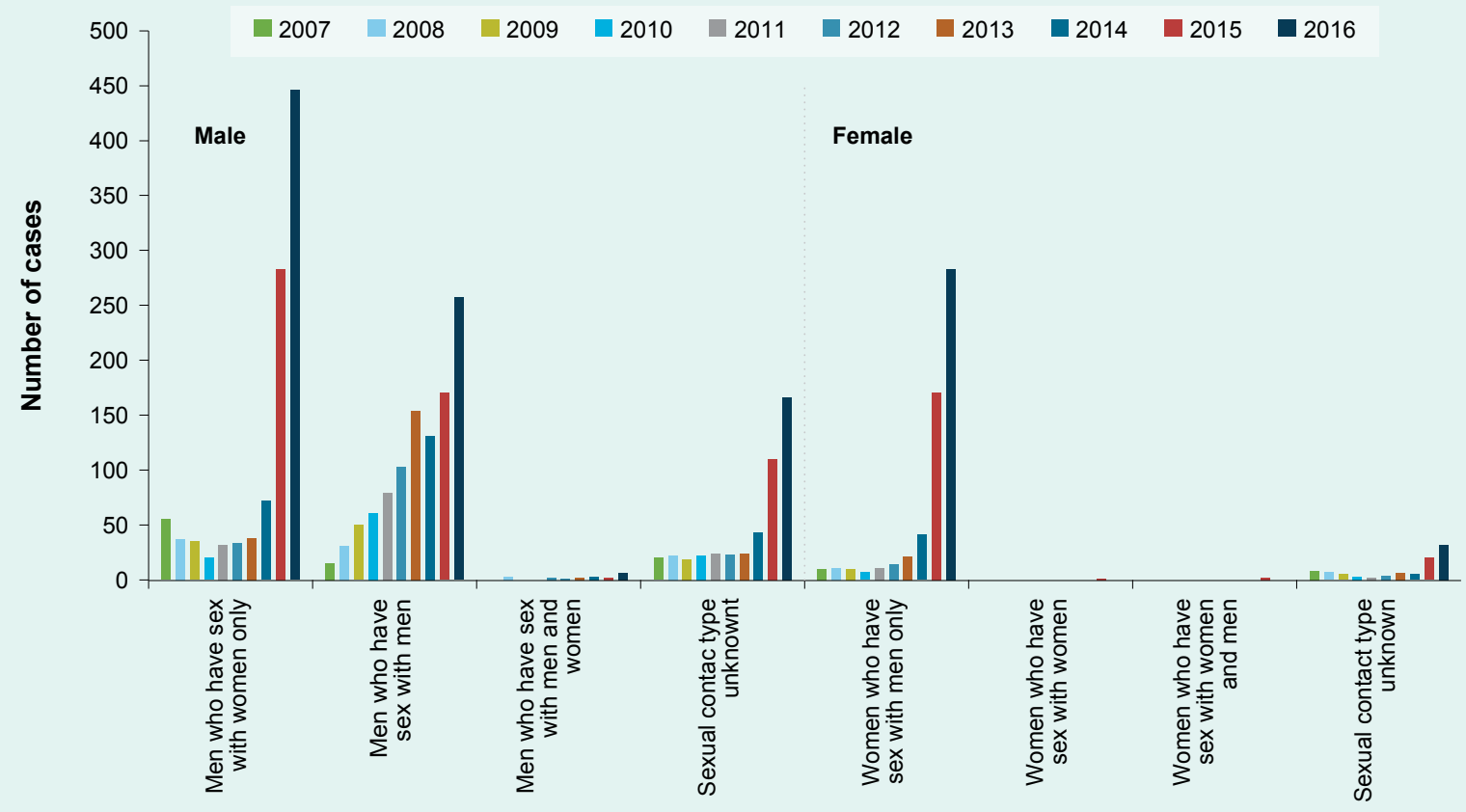

Sex of partner

\section{Women who have sex with men only}

The notified cases in WSM were stable between 2007 and 2012; however, they increased in 2013 to 2014 and markedly increased in 2015 and 2016, mirroring the trend seen in the MSW population (Fig. 5). There were 40.4 times more cases in 2016 compared to 2010. The proportion of WSM cases ranged from $6.2-9.9 \%$ in 2007 to 2013; it increased in 2014, reaching $23.8 \%$ in 2016. From 2007 to 2016, the median age of affected WSM was 26 (IQR: 22-32) years; in 2016, 59.7\% of the affected WSM were in their 20s (Fig. 6C). Oropharyn- 
Fig. 6. Age distribution of primary and secondary syphilis cases among men who have sex with men, men who have sex with women only, and women who have sex with men only, Tokyo, 2007 to 2016
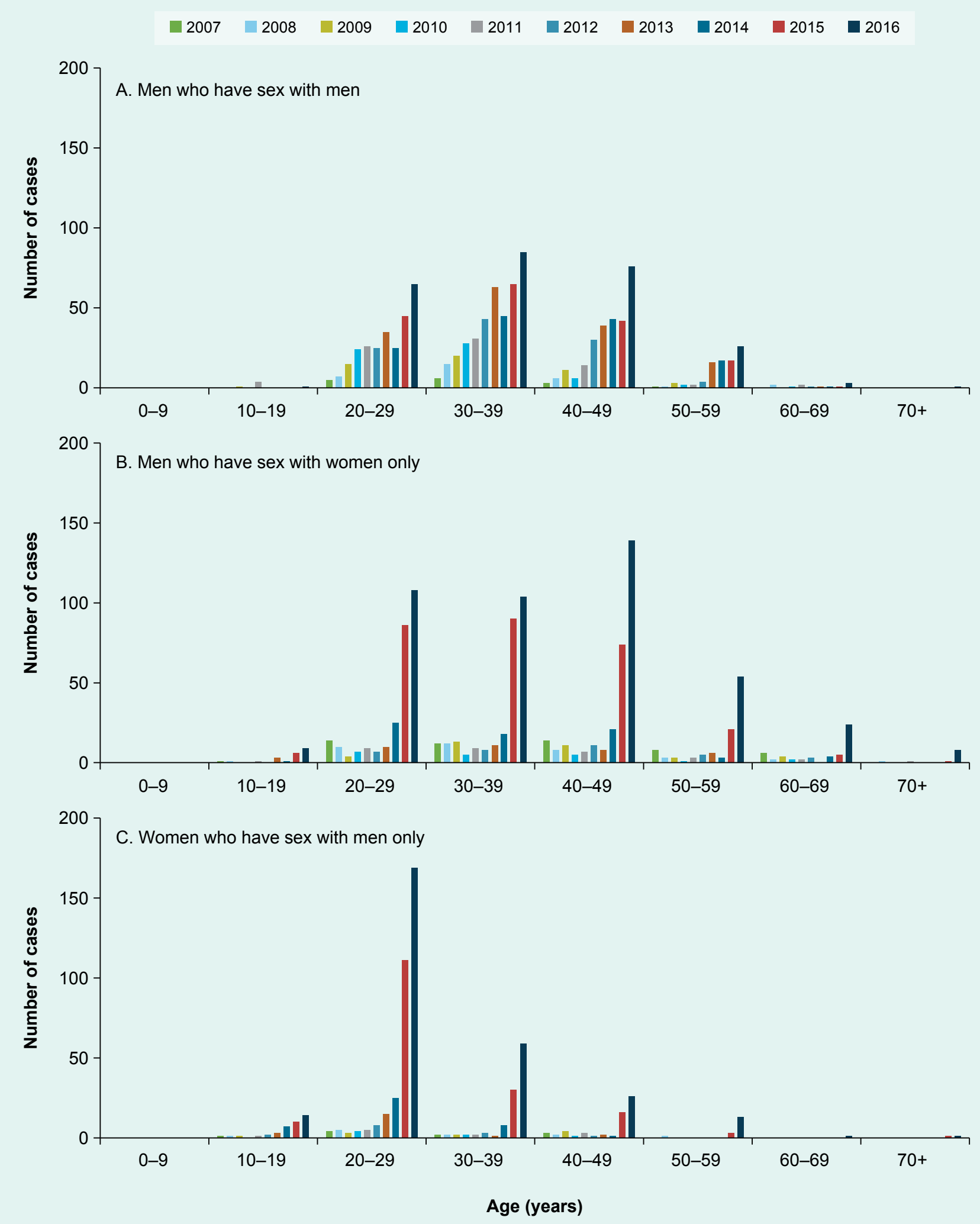
Fig. 7. Changes in the number of cases with oropharyngeal lesions among primary and secondary syphilis cases by sex of partner, Tokyo, 2007 to 2016

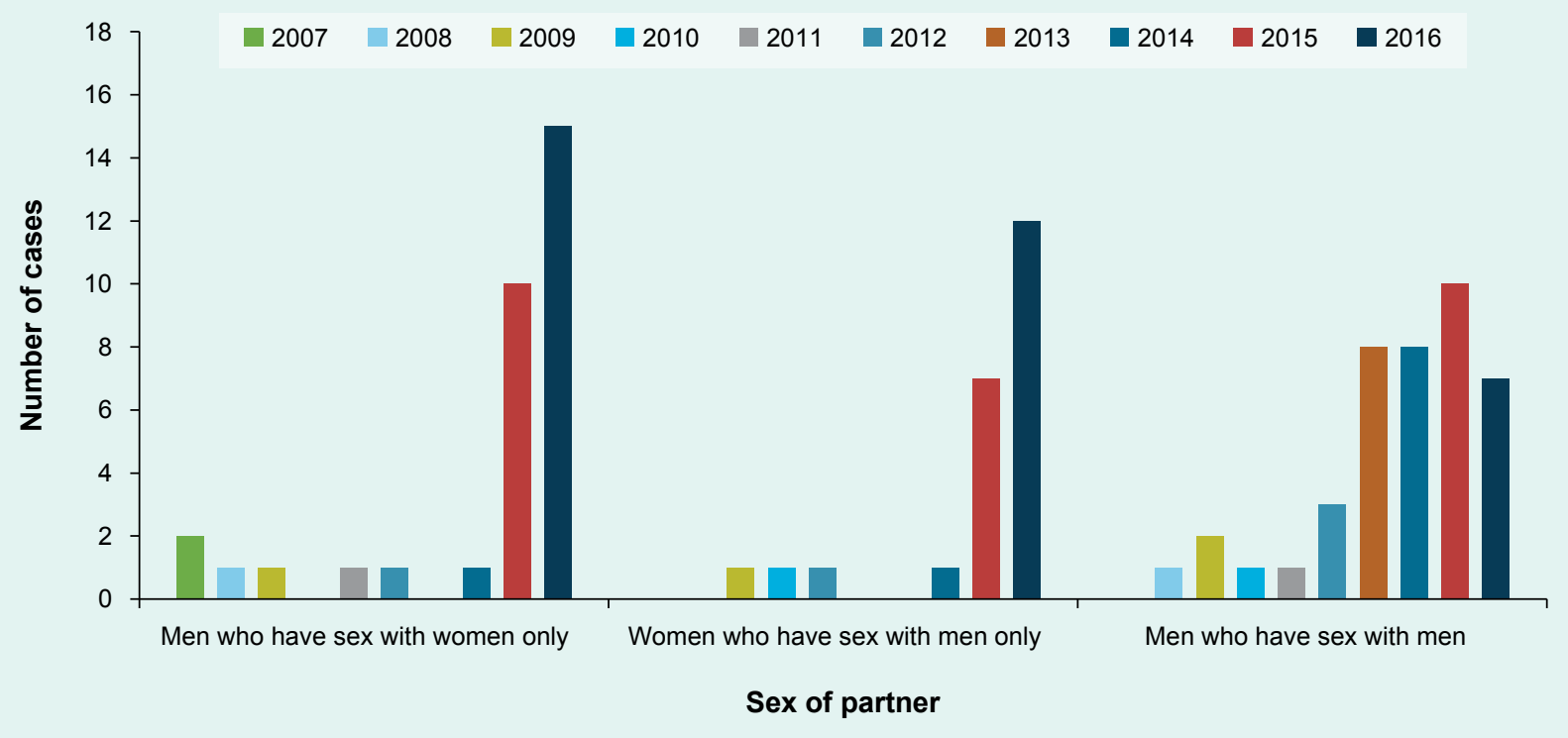

geal lesions increased among WSM in 2015 and 2016 (Fig. 7); the proportion was $4.1 \%$ in 2015 and $4.2 \%$ in 2016.

\section{Women who have sex with women}

Only one case of syphilis, reported in 2015, involved WSW.

\section{Women who have sex with women and men}

Two cases, reported in 2015, were in WSWM.

\section{Congenital syphilis}

Twelve cases ( $0-3$ cases per year) of CS were reported in Tokyo. The number of cases was one in 2008, two in 2009, three in 2012, one in 2014, two in 2015 and three in 2016

\section{DISCUSSION}

We found that P\&S syphilis cases in Tokyo generally increased from 2007 to 2016 and has been sharply increasing since 2015. During the period 2007-2010, an increase in infections among MSM was offset by a decrease of infections among MSW. As transmission among MSM continued to rise, the number of cases overall increased from 2011 to 2013. Cases among MSW and WSM increased rapidly after 2014, resulting in a larger number of cases transmitted through heterosexual contact than among MSM in 2015. We conclude that heterosexual transmission is a significant driver of the increase in syphilis cases in Tokyo with a contributing increase of cases among MSM.

The disproportionate increase in primary-stage syphilis may be due to increased ascertainment from prompt health-care seeking and improved recognition among clinicians. However, secondary syphilis also increased sevenfold, suggesting that the increase in primary syphilis cases may be due to increased incidence. Reports of oropharyngeal lesions increased among both men and women with syphilis. The proportion of those with oropharyngeal lesions did not vary considerably among MSM, MSW and WSM. The oral cavity can be a point of entry for syphilis, and an oropharyngeal lesion can be a source of syphilis infection. ${ }^{7}$ Providers and the public should be aware that syphilis can be transmitted through oral sex.

We are concerned about the increase of syphilis in young women. An increase of syphilis among women occurred in the 2010s in the United States of America that resulted in increased CS incidence. ${ }^{8}$ CS is preventable; pregnant women and their partners should be encouraged to seek appropriate prenatal care, including routine prenatal screening and treatment of syphilis. 
The notification rate in central Tokyo exceeded that in the suburbs. One potential explanation is that there are more medical facilities with infectious disease departments in central Tokyo. Though the notification rate in suburban areas is low, it has increased, highlighting that syphilis is not a public health problem limited to urban areas.

During the study period, trends in syphilis cases at the national level were like those in Tokyo. National syphilis cases started increasing in 2011. Most cases were from large metropolitan areas such as Tokyo and Osaka. Cases among MSM and heterosexual men and women increased during the years 2011-2016. ${ }^{2,3}$

Syphilis has been increasing globally since the $2000 s,{ }^{9}$ including in countries neighbouring Japan. ${ }^{10,11}$ Global travel contributes to the spread of sexually transmitted infections; one study found that $20.4 \%$ of travellers have casual sexual contact during foreign trips. ${ }^{12}$ As the Tokyo Metropolitan Government (TMG) is hosting the Olympic and Paralympic Games in 2020, it is expected that more people will visit Tokyo. Foreign visitors may introduce or acquire syphilis in Japan, potentially spreading syphilis both in Japan and their home countries.

\section{Limitations}

We used census and surveillance data collected by government departments. Identifying the reasons behind the increased number of syphilis cases in Tokyo is beyond the scope of this study since NESID data do not contain risk factor information. Other studies outside of Japan have cited increased health-care access and utilization, improved diagnostic testing or increased high-risk sexual behaviour as reasons for increasing syphilis incidence. ${ }^{13,14}$ Physicians may have increased reporting in response to heightened awareness that syphilis is a notifiable disease and the availability of the syphilis case reporting form on the TMIDSC website. ${ }^{6}$ Not all cases of syphilis are diagnosed; patients often do not seek medical care for an initial lesion, which is painless and disappears spontaneously. Since the clinical presentation is non-specific, syphilis testing may not be performed for those who do seek care. Some diagnosed cases are likely never reported. Also, the Prevention of Infectious Diseases and Medical Care for Infectious Patients Act has no express provision for contact tracing, ${ }^{15}$ which is necessary to detect and treat sexual contacts. The number of CS cases may also be underestimated since only live births are classified as CS.
In response to the increase in syphilis cases, TMG provided clinician training sessions on testing and treatment, expanding syphilis testing opportunities, adding home address and nationality to surveillance information and updating public educational materials (including an e-learning curriculum).

Targeted interventions are needed to curb the rising number of syphilis cases. Continued surveillance and additional analysis are needed to identify and mitigate factors causing the increase. Public health strategies to prevent and treat infections in young women are imperative to preventing CS. Curbing syphilis cases in Tokyo depends on increased awareness and the collaborative efforts of health-care providers, educators, media, academia and the public.

\section{Acknowledgements}

We would like to thank all the members of the surveillance staff at public health centres and all physicians who reported syphilis cases in Tokyo for their contribution to syphilis surveillance.

\section{Funding information}

None of the authors have any financial ties to disclose.

\section{Conflicts of interest}

None of the authors have any conflicts of interest to disclose.

\section{References}

1. Newman L, Rowley J, Vander Hoorn S, Wijesooriya NS, Unemo $\mathrm{M}$, Low N, et al. Global estimates of the prevalence and incidence of four curable sexually transmitted infections in 2012 based on systematic review and global reporting. PLoS One. 2015 Dec 8;10(12):e0143304. doi:10.1371/journal.pone.0143304 pmid:26646541

2. National Institute of Infectious Diseases and Tuberculosis and Infectious Diseases Control Division, Ministry of Health, Labour and Welfare. Syphilis 2008-2014. Infectious Agents Surveillance Report. 2015 Feb;36(2):17-8.

3. Takahashi T, Arima Y, Yamagishi T, Nishiki S, Kanai M, Ishikane $M$, et al. Rapid increase in reports of syphilis associated with men who have sex with women and women who have sex with men, Japan, 2012 to 2016. Sex Transm Dis. 2018 Mar;45(3):139-43. doi:10.1097/OLQ.0000000000000768 pmid:29420439

4. Tokyo statistical yearbook: 19 Medical care, sanitation, and environment: 19-1 Medical facilities by district [online database]. Tokyo: Statistics Division, Bureau of General Affairs, Tokyo Metropolitan Government; 2016 (http://www.toukei.metro.tokyo.jp/ tnenkan/tn-eindex.htm, accessed 26 May 2018). 
5. Tokyo statistical yearbook: 2 Population and households: 2-1 Changes in population [online database]. Tokyo: Statistics Division, Bureau of General Affairs, Tokyo Metropolitan Government; 2015 (http://www.toukei.metro.tokyo.jp/tnenkan/tn-eindex.htm, accessed 26 May 2018).

6. Tokyo Metropolitan Infectious Disease Surveillance Center [Internet]. Tokyo: Tokyo Metropolitan Institute of Public Health 2019 (http://idsc.tokyo-eiken.go.jp/epid_en/, accessed 6 February 2019).

7. Saini R, Saini S, Sharma S. Oral sex, oral health and orogenital infections. J Glob Infect Dis. 2010 Jan;2(1):57-62. doi:10.4103/0974-777X.59252 pmid:20300419

8. Bowen V, Su J, Torrone E, Kidd S, Weinstock H. Increase in incidence of congenital syphilis - United States, 2012-2014. MMWR Morb Mortal Wkly Rep. 201511 13;64(44):1241-5. doi:10.15585/mmwr.mm6444a3 pmid:26562206

9. Abara WE, Hess KL, Neblett Fanfair R, Bernstein KT, Paz-Bailey G. Syphilis trends among men who have sex with men in the United States and Western Europe: a systematic review of trend studies published between 2004 and 2015. PLoS One. 2016 07 22;11(7):e0159309. doi:10.1371/journal.pone.0159309 pmid:27447943

10. Tucker JD, Chen XS, Peeling RW. Syphilis and social upheaval in China. N Engl J Med. 2010 May 6;362(18):1658-61. doi:10.1056/NEJMp0911149 pmid:20445179
11. Kang SH, Lee JH, Choi SH, Lee J, Yoon HS, Cha SH, et al. Recent change in congenital syphilis in Korea: Retrospective 10 year study. Pediatr Int. 2015 Dec;57(6):1112-5. doi:10.1111/ ped.12663 pmid:25916174

12. Vivancos R, Abubakar I, Hunter PR. Foreign travel, casual sex, and sexually transmitted infections: systematic review and meta-analysis. Int J Infect Dis. 2010 Oct;14(10):e842-51. doi:10.1016/j. ijid.2010.02.2251 pmid:20580587

13. Savage EJ, Marsh K, Duffell S, Ison CA, Zaman A, Hughes G. Rapid increase in gonorrhoea and syphilis diagnoses in England in 2011. Euro Surveill. 2012 Jul 19;17(29):20224. pmid:22835469

14. Baigalmaa J, Erdenechimeg C, Narantuya J, Bulbul A, Tugsjargal $\mathrm{J}$, Dolgion $\mathrm{E}$, et al. Increasing syphilis notifications in Mongolia: results from national surveillance for 2001-2011. West Pac Surveill Response. 2012 Dec 21;3(4):86-93. doi:10.5365/ wpsar.2012.3.2.008 pmid:23908947

15. National Institute of Infectious Diseases, and Tuberculosis and Infectious Diseases Control Division, Ministry of Health, Labour and Welfare. The National Epidemiological Surveillance of Infectious Diseases in compliance with the enforcement of the new Infectious Diseases Control Law. Infectious Agents Surveillance Report. 1999 April; 20(4). 


\title{
Dengue-like illness surveillance: a two- year longitudinal survey in suburban and rural communities in the Lao People's Democratic Republic and in Thailand
}

\author{
Nanthasane Vannavong, ${ }^{a, b}$ Razak Seidu, ${ }^{c}$ Thor Axel Stenström, ${ }^{d}$ Nsa Dada a and Hans Jørgen Overgaard ${ }^{a}$ \\ Correspondence to Nanthasane Vannavong (email: anandafeł@gmail.com)
}

\begin{abstract}
Objective: This study aimed to determine the incidences of dengue-like illness (DLI), dengue virus (DENV) infection, and serotypes and to identify socio-demographical and entomological risk factors of DLI in selected suburban and rural communities in the Lao People's Democratic Republic and in Thailand.
\end{abstract}

Methods: A two-year longitudinal study was conducted in four villages during the inter-epidemic period between 2011 and 2013. Entomological surveys, semi-structured interviews of household heads and observations were conducted. Occurrences of DLI were recorded weekly using the World Health Organization's dengue definition along with blood samples; results were compared with national surveillance dengue data. Risk factors of DLI were assessed using logistic regression.

Results: Among the 2007 people in the study, 83 DLI cases were reported: 69 in suburban Lao People's Democratic Republic, 11 in rural Thailand, three in rural Lao People's Democratic Republic and none in suburban Thailand. Four were confirmed DENV: two from suburban Lao People's Democratic Republic (both DENV-1) and two from rural Thailand (both DENV-2). Although the number of detected DLIs during the study period was low, DLI incidence was higher in the study compared to the dengue surveillance data in both countries. DLI in suburban Lao People's Democratic Republic was associated with age and occupation, but not with the number of pupae per person.

Discussion: This study highlights the importance of continuous clinical and vector surveillance for dengue to improve early detection of dengue and other mosquito-borne diseases in the region.

D engue is a mosquito-borne viral infection prevalent throughout the tropics and subtropics. In SouthEast Asia, one of the largest outbreaks ever recorded occurred in 2010,1-3 during which 22929 cases and 46 deaths were recorded in the Lao People's Democratic Republic, $^{2}$ and 116947 cases and 139 deaths in Thailand. ${ }^{4}$ The incidence in the Lao People's Democratic Republic was 367 cases per 100000 persons, ${ }^{1}$ and in Thailand, 177 cases per 100000 persons-higher than recorded in neighbouring Viet Nam (150 cases per 100000 persons) or Cambodia (93 cases per 100000 persons). ${ }^{2}$ The most recent outbreak in Thailand occurred in 2015 with 144952 cases and 148 deaths; ${ }^{5}$ it was the most prevalent circulating strains of dengue virus (DENV) were DENV-4 (33.1\%) and DENV-3 (32.6\%). ${ }^{6}$ In the Lao People's
Democratic Republic, the most recent large outbreak occurred 2013, with 15 out of 17 provinces reporting dengue at epidemic levels, causing 95 deaths from a total of 44171 cases; $^{7}$ DENV-3 and DENV-2 were the most common serotypes. ${ }^{8}$

In the Lao People's Democratic Republic and in Thailand, the number of cases peak during the rainy season, generally between May and October. ${ }^{1,4}$ Dengue vector control in affected settings mainly relies on integrated vector management as recommended by the World Health Organization (WHO). ${ }^{9}$ A widely occurring challenge for effective mosquito control using the larvicide temephos is the widespread belief that it is harmful due to its smell. ${ }^{10}$ Another challenge is insecticide resistance in Aedes aegypti, the main dengue vector, ${ }^{11}$ which has been

\footnotetext{
Faculty of Science and Technology, Norwegian University of Life Sciences, As, Norway.

Champasak Provincial Health Office, Pakse, Lao People's Democratic Republic.

Water and Environmental Engineering Group, Institute for Marine Operations and Civil Engineering, Norwegian University of Science and Technology,

Ålesund, Norway.

SARChl Chair, Institute for Water and Waste Water Technology, Durban University of Technology, Durban, South Africa.

Submitted: 5 October 2017; Published: 19 February 2019

doi: 10.5365/wpsar.2017.8.4.001
} 
identified in Thailand ${ }^{11}$ and the Lao People's Democratic Republic. ${ }^{12}$ A review of space spraying for the control of adult mosquitoes revealed that this intervention was unsustainable and did not lead to a reduction in dengue incidence. ${ }^{13} \mathrm{~A}$ dengue vaccine is approved for public use in Thailand; however, those without a history of DENV infection before vaccination have been found to have a risk of developing severe disease. ${ }^{14}$

Patients with dengue-like illnesses (DLI) have acute febrile illnesses (AFI) with similar clinical manifestations to dengue ${ }^{3}$ but without laboratory confirmation of dengue infection. DLI can be defined even in settings without laboratory facilities or rapid diagnosis test kits for confirming dengue infection. ${ }^{9,15}$ An etiological study done in the southern Lao People's Democratic Republic in 2003-2004 found that 30\% (69/229) of patients presenting with nonmalarial febrile illnesses during inter-epidemic periods of dengue had dengue infections confirmed by enzyme-linked immunosorbent assay (ELISA). ${ }^{16}$ In Thailand, dengue was the third leading cause of AFI in rural areas. ${ }^{17}$

Active surveillance of dengue and DENV serotypes in non-outbreak settings is rarely conducted in the Lao People's Democratic Republic or in Thailand. Identifying $D E N V$ infection is necessary to reduce the dengue burden by improving the early response and implementing control measures. The aims of this study were to assess the incidence and risk factors of DLI and to identify dengue infections in relation to socio-demographic characteristics and mosquito pupal indices in selected study sites of both countries during an inter-epidemic period.

\section{METHODS}

\section{Study areas and design}

A two-year longitudinal study with active case detection was conducted in Salavan province, southern Lao People's Democratic Republic and in Khon Kaen province, northeastern Thailand. One suburban and one rural village were selected in each country (Fig. 1). The two villages in the Lao People's Democratic Republic and the two villages in Thailand are located six and nine kilometres apart, respectively. These villages were selected based on previously described criteria. ${ }^{18}$ The study was conducted in both dry and wet seasons within the time period of March 2011 to April 2013 with slight deviations of the start and end dates between the sites.

\section{Participants}

The total number of households in each village was 215 in suburban and 130 in rural Lao People's Democratic Republic, and 272 in suburban and 139 in rural Thailand. Rural Lao People's Democratic Republic had the lowest number of households (130), and we chose this number as the sample size across all selected villages. For each of the other three villages with more than 130 households, we systematically sampled households by first identifying a random house and then selecting additional houses based on a fixed interval derived by dividing the total number of households by 130 . All individuals residing in the selected households were included. Fig. 1 shows the total number of households and people included. During the course of the study, individuals were lost to follow-up because they went to study elsewhere, moved out after marriage or died; households were lost to follow-up due to families moving and settling in other villages or choosing to leave the study. Migrants and newborn children were included as newly enrolled participants. The final number of individuals included in the analysis was 2007.

\section{Identification of dengue-like illnesses}

Each of the selected households was visited weekly by trained village health volunteers. DLI was defined using the WHO dengue definition, i.e. presence of AFI for 2-7 days with two or more nonspecific symptoms such as headache, retro-orbital pain, myalgia, arthralgia, rash, and haemorrhagic manifestations. ${ }^{19}$ We used an individual questionnaire to obtain case information (Table 1) from patients or guardians of patients less than 15 years old.

\section{Confirmation of dengue cases}

From each identified DLI case, we took a blood sample by finger prick and blotting onto two pieces of filter paper (Blood Sampling Paper, NOBUTO, Chemoscience (Thailand) Co., Ltd), according to the manufacturer's instructions. After the blood was absorbed, the paper was dried at room temperature for 1-2 hours and thereafter sealed in sterile bags (Whirl-Pak Bags, Chemoscience (Thailand) Co., Ltd). The samples were stored at $-20{ }^{\circ} \mathrm{C}$ until transport. All samples were periodically brought to Thailand where they were analysed by real-time polymerase chain reaction (PCR) for DENV RNA detection and 
Fig. 1. Number of participants and households included in the cross-sectional survey carried out during two years of follow-up from 2011 to 2012 in four villages in the Lao People's Democratic Republic and in Thailand

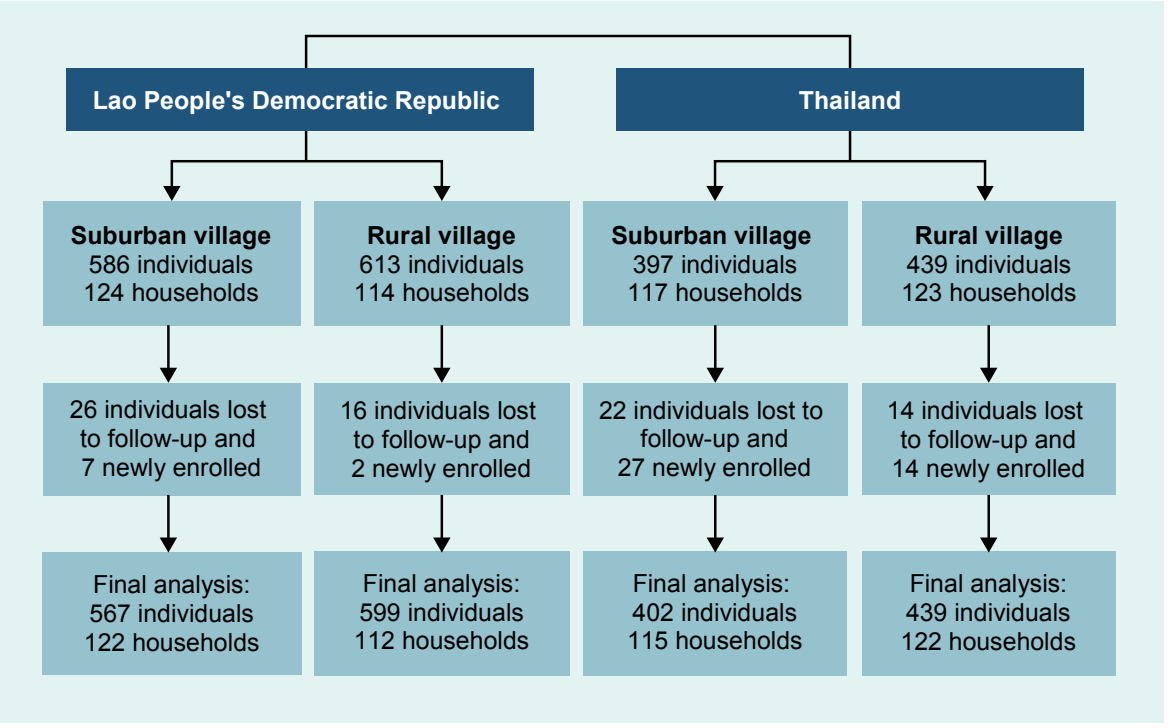

serotyping using previously described techniques. ${ }^{20}$ We obtained secondary data reported during 2010-2013 from the national surveillance system in both countries to compare with data from our study.

\section{Socio-demographic characteristics and entomological survey}

Household information was obtained from household heads using a semi-structured household questionnaire. Data collected are displayed in Table 1. The entomological survey was conducted once per household in 2011 from the beginning of March to the beginning of June. In suburban and rural Thailand, the survey was conducted in March-April 2011, while for the Lao People's Democratic Republic villages, the survey was done in May-June 2011. All household water storage containers were examined for Ae. aegypti pupae, and the number of pupae present were counted and recorded. Pupae were identified to species using a dissecting microscope and illustrated keys as described elsewhere. ${ }^{18}$

\section{Data analysis}

Descriptive analysis of socio-demographic characteristics and entomological data was conducted for each study village. Room occupancy rate was estimated using the United Nation's definition. ${ }^{21}$ The socioeconomic status (SES) of each household was estimated and ranked into rich, intermediate and poor using principal components analysis. ${ }^{22}$ Variables used in the SES ranking have been described elsewhere. ${ }^{23}$ Two entomological indices derived from the entomological survey, pupae per household and pupae per person (number of pupae divided by number of persons in each house) were used as potential risk factors for DLI. ${ }^{24}$ National surveillance system data on dengue incidences in both countries were compared with the DLI data obtained in this study. Comparisons within and between countries were conducted using descriptive analysis. Univariable and multivariable logistic regression models were used to find significant relationships between the presence of DLI and various risk factors in each village. Variables with a significance level of $P \leq 0.25$ derived from the univariable analysis were included in the multivariable model. A backward stepwise selection procedure was used to obtain significant risk factors $(P<0.05)$ from the multivariable analysis. Statistical analyses were done using STATA (version 10, STATA Corporation, College Station, TX, USA).

\section{Ethics}

All participants and guardians of children signed informed consent forms to participate in the study. The study was approved by the National Ethics Committee for Health Research, Ministry of Health, Vientiane, Lao People's Democratic Republic (No. 03) and by the Ethical Committee of Phramongkutklao College of Medicine, Bangkok, Thailand (S033h/53). 
Table 1. General information of individuals, households, mosquito infestation and disease information (denguelike illness (DLI) and dengue) in suburban and rural villages in the Lao People's Democratic Republic and in Thailand (percentages in parentheses)

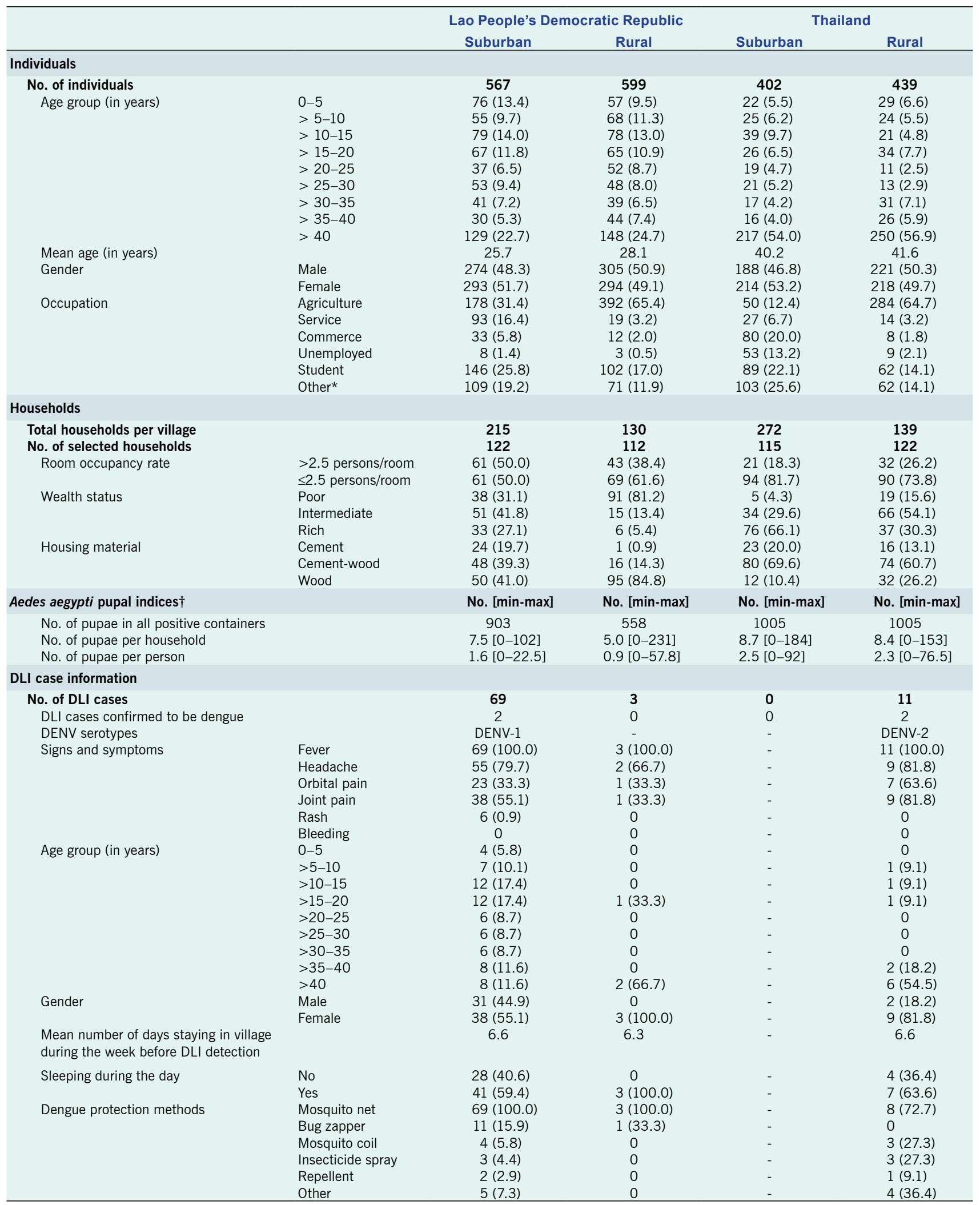

$\dagger$ Aedes aegypti pupal indices applied from Dada et al. (2013). ${ }^{18}$ Number of Aedes aegypti pupae was not available in one household of suburban Lao People's Democratic Republic and in two households of rural Thailand

*Other: retired and children, Min-max: minimum-maximum 


\section{RESULTS}

\section{Socio-demographic characteristics}

Information on the study villages is shown in Table 1 . The mean ages of people from suburban and rural Lao People's Democratic Republic were 26 and 28 years, while the Thai villagers were older, mean 40 and 42 years, respectively. The main occupation reported was agriculture, especially in the rural villages of both countries, where $65 \%$ of individuals were farmers. The population densities in the Lao People's Democratic Republic villages based on the room occupancy were more than 2.5 persons per habitable room, which was higher than the Thai sites. Generally, Thai villages had higher SESs than those in the Lao People's Democratic Republic.

\section{Entomological survey}

Water containers were infested with Ae. aegypti pupae in all study villages (Table 1). Aedes aegypti pupal indices were higher in Thailand than in the Lao People's Democratic Republic; suburban Thailand had the highest numbers of pupae per household (8.7) and pupae per person (2.5). Similar figures were recorded in rural Thailand. With 5.0 pupae per household and 0.9 pupae per person, rural Lao People's Democratic Republic had the lowest Ae. aegypti pupal indices recorded in this study.

\section{Dengue-like illnesses and confirmed dengue cases}

A total of $83 \mathrm{DLI}$ cases were reported during the study period with 69 (mean age: 25 years) in suburban Lao People's Democratic Republic, three in rural Lao People's Democratic Republic (mean age: 49 years) and 11 in rural Thailand (mean age: 42 years). There were no cases recorded in suburban Thailand (Table 1). Of the 83 cases, four were confirmed DENV positive (4.8\%): two from suburban Lao People's Democratic Republic (both DENV1) and two from rural Thailand (both DENV-2). Each of these four DENV-positive cases was reported as a DLI case just one time during the study period, and all had sought care at local hospitals. The time from reported date of illness onset to specimen collection was 5 and 9 days, respectively, for the two cases in suburban Lao People's Democratic Republic and 2 and 7, respectively, days for the cases in Thailand.
In suburban Lao People's Democratic Republic, DLI cases were recorded during the entire study period in both 2011 (34 cases) and 2012 (34 cases). The majority of the cases in rural Thailand (10 cases) were recorded in 2011 (Fig. 2A). Most of the cases were found during the end of the rainy seasons (August to October in 2011 and October to November in 2012). The confirmed dengue cases were identified around these time periods. In rural Thailand, the confirmed dengue cases were found in November and December 2011.

Secondary dengue data collected from the Thai national surveillance system provided by the Manchakhiri district hospital surveillance unit showed only five and two confirmed dengue cases in 2011 from the suburban and rural village, respectively. Of these seven cases, only one from the rural village was enrolled in our study and was also confirmed as positive for DENV infection. The other six cases were not in the selected households. In the Lao People's Democratic Republic, no dengue surveillance data at the village level were available.

District-level secondary dengue data obtained from both national surveillance systems showed at least a three-fold higher dengue incidence in the Lakhonpheng district (Lao People's Democratic Republic) than in the Manchakhiri district (Thailand) (Fig. 2B). In the Lakhonpheng district, the incidence of dengue in 2010 was more than three times higher than in 2011 or 2012 and slightly higher than in 2013. In the Manchakhiri district, dengue incidence was low ( $<240$ cases/100 000 population) during 2010-2013.

\section{Risk factors and dengue-like illnesses}

The results from the univariable (Table 2 ) and multivariable (Table 3) analyses were similar, and no correlation was found with Ae. aegypti pupal indices (Table 3). The univariable analysis showed that risk factors associated with DLI in suburban Lao People's Democratic Republic were age, education and occupation. Only age and occupation remained significantly significant in the multivariable analysis. In the 15-20 years age group, the odds of having DLI symptoms were almost five times higher than the odds of those under 5 years of age. The odds of DLI in service and "other" (retired and children) occupations were about three times higher than the odds for farmers. In rural Thailand, the multivariable analysis showed no significant associations between DLI and any risk factor (Table 3). 
Fig. 2A. Temporal distribution of dengue-like illness (DLI) and confirmed dengue cases in suburban and rural villages in Lakhonpeng district, Lao People's Democratic Republic $(D L I=72)$ and Manchakhiri district, Thailand $(\mathrm{DLI}=11)$.

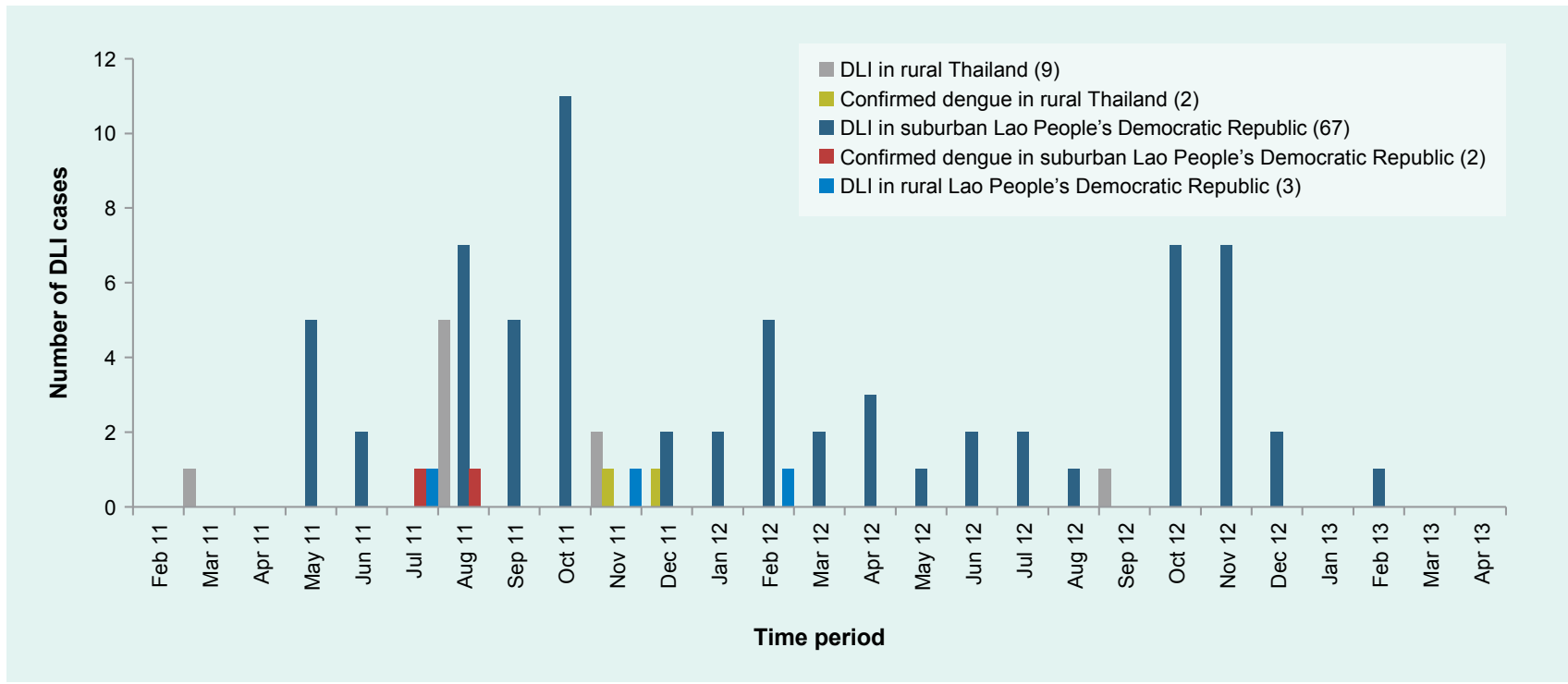

* Figures in parentheses indicate number of cases

Fig. 2B. Dengue incidence in Lakhonpheng district, Lao People's Democratic Republic and in Manchakhiri district, Thailand, 2010-2013.

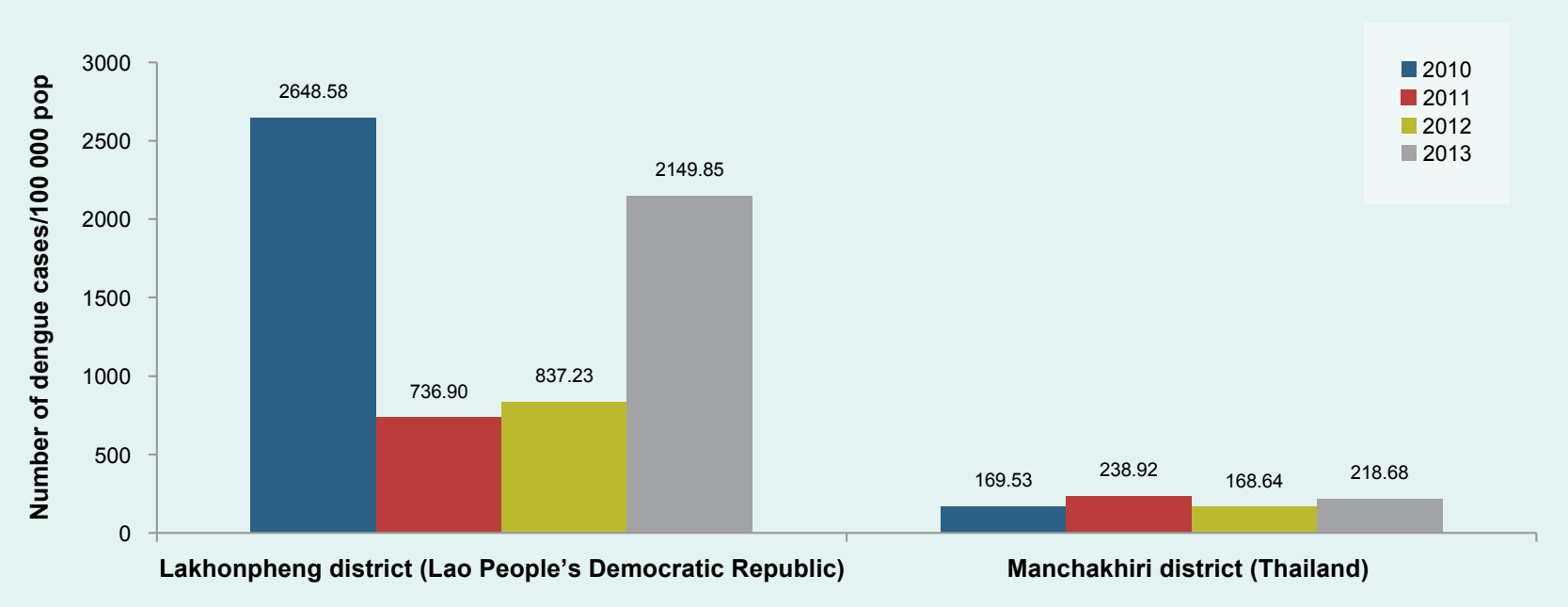

Figures represent the number of dengue cases per 100000 populations reported in the districts in the Lao People's Democratic Republic and in Thailand where the study villages are located (secondary data derived from the national surveillance system).

Several methods for dengue protection were used by DLI cases (Table 1): indoor aerosol insecticide spray, mosquito coils, repellents, etc.; however, they were rarely recorded. Mosquito nets were thought to be protective, and they were used by $100 \%$ of cases in suburban and rural Lao People's Democratic Republic and by $73 \%$ of cases in rural Thailand.

\section{DISCUSSION}

\section{Dengue and dengue-like illnesses}

Eighty-three DLI cases were recorded among 2007 inhabitants during the two-year study period (Table 1). Only one case, recorded in suburban Lao People's Democratic Republic, was from a participant newly enrolled during 
Table 2. Univariable analyses of risk factors associated with dengue-like illnesses (DLI) in suburban Lao People's Democratic Republic and in rural Thailand (Odds ratio (OR) ([95\% confidence intervals, $\mathrm{Cl}] \mathrm{p}$-value). Numbers in bold indicate significant associations $(P<0.05)$

\begin{tabular}{|c|c|c|c|c|c|c|c|c|c|}
\hline & & \multicolumn{4}{|c|}{$\begin{array}{l}\text { Lao People's Democratic Republic - } \\
\text { Suburban village }(n=567)\end{array}$} & \multicolumn{4}{|c|}{$\begin{array}{l}\text { Thailand - Rural village } \\
\qquad(n=402)\end{array}$} \\
\hline & & $\%$ & OR & $95 \% \mathrm{Cl}$ & p-value & $\%$ & OR & $95 \% \mathrm{Cl}$ & $p$-value \\
\hline \multicolumn{10}{|l|}{ Socio-demography } \\
\hline \multirow[t]{6}{*}{ Age group } & $0-5$ & 13 & 1 & & & 7 & 1 & & \\
\hline & $>5-10$ & 10 & 1.6 & {$[0.5-4.8]$} & 0.390 & 5 & NA & & \\
\hline & $>10-15$ & 14 & 2.1 & {$[0.8-5.5]$} & 0.136 & 5 & NA & & \\
\hline & $>15-20$ & 12 & 2.7 & {$[1.0-6.9]$} & 0.046 & 8 & NA & & \\
\hline & $>20-25$ & 6 & 1.0 & {$[0.3-4.1]$} & 0.970 & 2 & NA & & \\
\hline & $>25$ & 45 & 1.3 & {$[0.5-3.2]$} & 0.560 & 73 & NA & & \\
\hline \multirow[t]{2}{*}{ Sex } & Male & 48 & 1 & & & 50 & 1 & & \\
\hline & Female & 52 & 1.1 & {$[0.7-1.8]$} & 0.572 & 50 & 4.6 & [0.9-21.1] & 0.052 \\
\hline \multirow[t]{2}{*}{ Education } & $\leq$ Primary school & 53 & 1 & & & 77 & 1 & & \\
\hline & $>$ Primary school & 47 & 2.3 & {$[1.4-3.8]$} & 0.001 & 23 & 1.9 & {$[0.6-6.5]$} & 0.311 \\
\hline \multirow[t]{6}{*}{ Occupation } & Agriculture & 31 & 1 & & & 65 & 1 & & \\
\hline & Service & 16 & 2.2 & {$[1.0-4.8]$} & 0.041 & 3 & NA & & \\
\hline & Commerce & 6 & 1.3 & {$[0.4-4.8]$} & 0.643 & 2 & NA & & \\
\hline & Unemployed & 2 & 3.7 & {$[0.8-16.6]$} & 0.086 & 2 & 4.5 & [0.6-36.8] & 0.158 \\
\hline & Student & 26 & 2.6 & {$[1.3-5.2]$} & 0.005 & 14 & 1.3 & {$[0.3-6.3]$} & 0.734 \\
\hline & Other* & 19 & 1.6 & {$[0.7-3.6]$} & 0.229 & 14 & 0.7 & {$[0.1-5.3]$} & 0.694 \\
\hline \multirow[t]{2}{*}{ Room occupancy rate } & $>2.5$ persons/room & 56 & 1 & & & 30 & 1 & & \\
\hline & $\leq 2.5$ persons/room & 44 & 0.8 & {$[0.5-1.3]$} & 0.391 & 70 & 1.2 & {$[0.3-4.4]$} & 0.827 \\
\hline \multirow[t]{3}{*}{ Housing material } & Cement & 18 & 1 & & & 12 & 1 & & \\
\hline & Cement-wood & 42 & 1.1 & {$[0.6-2.2]$} & 0.737 & 63 & NA & & \\
\hline & Wood & 40 & 0.9 & {$[0.5-1.8]$} & 0.788 & 25 & NA & & \\
\hline \multirow[t]{3}{*}{ Wealth status } & Poor & 29 & 1 & & & 14 & 1 & & \\
\hline & Intermediate & 42 & 1.3 & {$[0.7-2.4]$} & 0.375 & 53 & 0.3 & {$[0.1-1.1]$} & 0.065 \\
\hline & Rich & 29 & 1.5 & {$[0.8-2.8]$} & 0.227 & 33 & 0.3 & {$[0.1-1.5]$} & 0.144 \\
\hline \multicolumn{10}{|l|}{ Aedes aegypti pupal indices } \\
\hline No. of pupae per household & & 100 & 1.0 & {$[0.9-1.0]$} & 0.917 & 100 & NA & & \\
\hline \multirow{3}{*}{ No. of pupae per person } & $0-0.49$ & 67 & 1 & & & 51 & 1 & & \\
\hline & $0.5-1.5$ & 9 & 0.7 & {$[0.2-1.9]$} & 0.474 & 21 & 0.6 & {$[0.1-2.6]$} & 0.450 \\
\hline & $>1.5$ & 24 & 1.2 & {$[0.7-2.0]$} & 0.580 & 28 & NA & & \\
\hline
\end{tabular}

* Other: retired and children; NA: not applicable

Table 3. Multivariable analyses of risk factors associated with dengue-like illnesses (DLI) in suburban Lao People's Democratic Republic and rural Thailand (Odds ratio (OR) ([95\% confidence intervals, $\mathrm{Cl}] \mathrm{p}$-value). Numbers in bold indicate significant associations $(P<0.05)$

\begin{tabular}{|c|c|c|c|c|c|c|c|c|c|}
\hline & & \multicolumn{4}{|c|}{$\begin{array}{l}\text { Lao People's Democratic Republic - } \\
\text { Suburban village }(n=567)\end{array}$} & \multicolumn{4}{|c|}{$\begin{array}{l}\text { Thailand - Rural village } \\
\qquad(n=402)\end{array}$} \\
\hline & & $\%$ & OR & $95 \% \mathrm{Cl}$ & $p$-value & $\%$ & OR & $95 \% \mathrm{Cl}$ & $p$-value \\
\hline \multirow[t]{6}{*}{ Age group } & $0-5$ & 13 & 1 & & & 7 & 1 & & \\
\hline & $>5-10$ & 10 & 2.1 & {$[0.6-6.9]$} & 0.251 & 5 & NA & & \\
\hline & $>10-15$ & 14 & 3.4 & {$[0.8-14.8]$} & 0.097 & 5 & NA & & \\
\hline & $>15-20$ & 12 & 4.8 & [1.2-19.6] & 0.029 & 8 & NA & & \\
\hline & $>20-25$ & 6 & 2.1 & [0.4-11.9] & 0.406 & 2 & NA & & \\
\hline & $>25$ & 45 & 2.8 & [0.8-10.5] & 0.122 & 73 & NA & & \\
\hline \multirow[t]{2}{*}{ Sex } & Male & & & & & 50 & 1 & & \\
\hline & Female & & & & & 50 & 4.2 & [0.9-19.3] & 0.068 \\
\hline \multirow[t]{6}{*}{ Occupation } & Agriculture & 31 & 1 & & & & & & \\
\hline & Service & 16 & 2.4 & {$[1.1-5.4]$} & 0.028 & & & & \\
\hline & Commerce & 6 & 1.4 & {$[0.4-5.0]$} & 0.606 & & & & \\
\hline & Unemployed & 2 & 3.2 & {$[0.7-14.7]$} & 0.136 & & & & \\
\hline & Student & 26 & 2.3 & {$[0.8-6.1]$} & 0.104 & & & & \\
\hline & Other* & 19 & 3.5 & [1.1-11.0] & 0.031 & & & & \\
\hline \multirow[t]{3}{*}{ Wealth status } & Poor & & & & & 14 & 1 & & \\
\hline & Intermediate & & & & & 53 & 0.3 & {$[0.1-1.2]$} & 0.081 \\
\hline & Rich & & & & & 33 & 0.3 & {$[0.1-1.4]$} & 0.129 \\
\hline
\end{tabular}

* Other: retired and children; NA: not applicable 
the study period. Most of the cases were recorded during the rainy season, consistent with previous findings. ${ }^{1,4}$ The incidence of DLI in the Lao People's Democratic Republic was two times higher than in Thailand, which corresponds with the district-level dengue surveillance data reported from the same study periods in both countries (Fig. 2B). We also found that dengue incidence in Lakhonpheng district (Lao People's Democratic Republic) was three to four times higher than in Manchakhiri district (Thailand).

No DLI was reported in suburban Thailand, although the national surveillance system reported five dengue cases from this village. The affected households were not included in our study. Fewer DLIs were recorded in rural Lao People's Democratic Republic (three in total). One factor that could contribute is that the study village has no health facility; therefore, people may not seek health care.

Only four of the $83 \mathrm{DLI}$ cases (4.8\%) were confirmed as dengue in this study. Non-confirmed DLIs could have resulted from false negative dengue or from other diseases that present with similar clinical manifestations. ${ }^{9}$ A study of a cohort of 1500 healthy children aged 2-14 years in Indonesia, Malaysia, the Philippines, Thailand, and Viet Nam found that the most common causes of AFI $\left(\geq 38^{\circ} \mathrm{C}\right.$ for $\geq 2$ days) were chikungunya, scrub typhus, and dengue. ${ }^{25}$ Co-circulating arboviruses, such as Zika and chikungunya, pose challenges for disease diagnosis and early response to outbreaks ${ }^{26}$ since they are often indistinguishable clinically. ${ }^{27,28}$ In South-East Asia, Zika virus was first reported in Malaysia in 1966, and subsequent cases were also reported in many countries including in Thailand (2014). ${ }^{29}$ Recently, a previous Zika outbreak in the region was recorded in Singapore (2016). ${ }^{28}$ In the Lao People's Democratic Republic and in Thailand, the first chikungunya outbreaks were reported in $1958^{30}$ and $2012,^{31}$ respectively. Other infections that cause DLIs in the study region include scrub typhus, influenza, Japanese encephalitis and leptospirosis. ${ }^{16,32}$

The unexpectedly low number of confirmed dengue infections could be due to sample degradation from inadequate temperature control from intermittent power supplies or the use of only one laboratory method to detect infections. Although real-time PCR testing has a reported sensitivity of $93 \%,{ }^{20}$ some samples could have been false negatives. Using both viral detection and serological tests, such as IgM ELISA, would improve diagnostic accuracy.
This study revealed circulation of DENV-1 in the Lao People's Democratic Republic and DENV-2 in Thailand, a finding corroborated by national surveillance data. DENV1 was detected in the Lao People's Democratic Republic during 2007-2011 and accounted for the highest proportion of dengue serotypes (38\%) during the 2010 outbreak, followed by DENV-2 (30\%). ${ }^{1}$ In Thailand, $54.6 \%$ of the DENV serotypes isolated in 2010 were DENV-2, followed by DENV-1 $(25.5 \%){ }^{4}$

\section{Risk factors of dengue-like illnesses}

Significant risk factors for DLI were found only in the suburban village of the Lao People's Democratic Republic, where DLI was associated with age and occupation. Individuals aged $15-20$ years old were more likely to have DLI than those $0-5$ years old, which is in line with a previous study conducted in Brazil. ${ }^{33}$ In the 2010 dengue outbreak in the Lao People's Democratic Republic, the most affected age group was 10-19 years, ${ }^{1}$ similar to the findings of this study. In Thailand, the highest incidence rates of dengue reported between 2000 and 2011 were in 10-14 year olds. ${ }^{4}$ Similar findings occurred during a 2009 chikungunya outbreak in Thailand where the most affected age group was 10-14 years. $^{34}$

Employment in a service occupation was associated with DLI (Table 3), and $80 \%$ of these employees had an educational level higher than high school. A previous study found that attainment of secondary or higher educational degrees was significantly associated with dengue infection. ${ }^{35}$ This may relate to travel or work patterns away from home, thus increasing their chances of contracting dengue infections compared with those who travel less. Human movement as a result of socieconomic development favours the spread of dengue and other vector-borne diseases. ${ }^{36,37}$

Clustering of DLI cases could be influenced by household risk within the same household; however, a household-level spatial analysis of DLI cases was not conducted in this study. Furthermore, dengue transmission is not limited to within households. Schools, workplaces, markets, hospitals, parks, and other public places may play a role in dengue transmission. Dengue control interventions that focus on households may be insufficient for community-wide disease control. 
Although pupal indices are accepted as better indicators of dengue transmission than the traditional Stegomyia indices (i.e. House, Container, and Breteau indices), ${ }^{38-40}$ a high density ( $>1.5$ pupae per person) of Ae. aegypti was not associated with DLI in the household (Table 2), even though the pupal densities found in three of the four study villages (Table 1 ) were above proposed transmission thresholds of 0.5-1.5 pupae per person. ${ }^{24}$ Similarly, a study conducted in the Republic of Palau found that DLI infections were not associated with the pupal index; however, households reporting DLIs were significantly more likely to harbour potential mosquito breeding sites than those without. ${ }^{15} \mathrm{~A}$ systematic review of the correlation between vector indices and dengue transmission also found no robust relationships to predict dengue outbreaks. ${ }^{40}$ More reliable mosquito indices are needed. Adult mosquito collections may provide more useful information of disease risk, since infectious adult mosquitoes are more epidemiologically relevant than larvae or pupae. ${ }^{9}$

Although our study focused only on dengue, other febrile illnesses, such as chikungunya and Zika, are also endemic in these locations. Our findings corroborate those from the national dengue surveillance programmes, highlighting the importance of continued clinical and vector surveillance and indicating the need to expand surveillance to include other mosquito-borne diseases associated with AFI. This would have significant impact on accurate and timely detection and reporting AFI-related outbreaks.

\section{Acknowledgements}

We would like to thank the Research Council of Norway and the Norwegian University of Life Sciences, Ås, Norway for financial support. The Water and Environmental Engineering Group at the Norwegian University of Science and Technology is also acknowledged for the office space and logistical support in writing this paper. Thanks to all of the following organizations and individuals for the great support of this work: Dr Sibounhom Archkhawongs from the Ministry of Health in the Lao People's Democratic Republic, Professor Theeraphap Chareonviriyaphap from the Department of Entomology, Kasetsart University, Bangkok, Thailand and Dr Ram Rangsin from the Phramongkutklao College of Medicine, Bangkok, Thailand. Finally, sincere thanks to local authorities, fieldworkers and volunteers in both countries for all their help and assistance.

\section{Funding}

The project was funded by the Research Council of Norway (Project no. 191652) and through a PhD grant to Nanthasane Vannavong from the Faculty of Science and Technology, Norwegian University of Life Sciences.

\section{Conflicts of interest}

The authors declare that they have no competing interests.

\section{References}

1. Khampapongpane B, Lewis HC, Ketmayoon P, Phonekeo D, Somoulay $\mathrm{V}$, Khamsing $A$, et al. National dengue surveillance in the Lao People's Democratic Republic, 2006-2012: epidemiological and laboratory findings. Western Pac Surveill Response J. 31 Mar 2014;5(1):7-13. pmid:24734212

2. Arima Y, Chiew M, Matsui T; Emerging Disease Surveillance and Response Team, Division of Health Security and Emergencies, World Health Organization Regional Office for the Western Pacific. Epidemiological update on the dengue situation in the Western Pacific Region, 2012. West Pac Surveill Response. 20 Apr 2015;6(2):82-9. doi:10.5365/wpsar.2014.5.4.002 pmid:26306221

3. Dengue virus infections. Atlanta, GA: Centers for Disease Control and Prevention; 2015 (https://wwwn.cdc.gov/nndss/conditions/denguevirus-infections/case-definition/2015/, accessed 19 July 2017).

4. Limkittikul K, Brett J, L'Azou M. Epidemiological trends of dengue disease in Thailand (2000-2011): a systematic literature review. PLoS Negl Trop Dis. 6 Nov 2014;8(11):e3241. doi:10.1371/journal. pntd.0003241 pmid:25375766

5. Dengue haemorrhagic fever. Mueang Nonthaburi: Bureau of Epidemiology, Thailand; 2017 (http://www.boe.moph.go.th/boedb/ surdata/disease.php?dcontent $=$ old\&ds $=262766$, accessed 3 June 2017).

6. Dengue diseases. Annual Epidemiology Surveillance Report 2015. Mueang Nonthaburi: Bureau of Epidemiology, Thailand; 2015 (http://www.boe.moph.go.th/Annual/AESR2015/sum_aesr.php, accessed 18 September 2017).

7. Dengue. Vientiane: WHO Lao People's Democratic Republic; 2017 (http://www.wpro.who.int/laos/topics/dengue/en/, accessed 31 March 2017).

8. Phommanivong V, Kanda S, Shimono T, Lamaningao P, Darcy AW, Mishima $\mathrm{N}$, et al. Co-circulation of the dengue with chikungunya virus during the 2013 outbreak in the southern part of Lao PDR. Trop Med Health. 4 Aug 2016;44(1):24. doi:10.1186/s41182-0160020-y pmid:27524929

9. Dengue guidelines for diagnosis, treatment, prevention and control. Geneva: World Health Organization; 2009 (http://www.who.int/ $\mathrm{tdr} /$ publications/documents/dengue-diagnosis.pdf, accessed 8 July 2018).

10. Phuanukoonnon S, Bough M, Bryan JH. Household practices of temephos use for dengue larval control, Khon Kaen Province, North-east Thailand. Dengue Bull. 2006;30:251-9.

11. Ponlawat A, Scott JG, Harrington LC. Insecticide susceptibility of Aedes aegypti and Aedes albopictus across Thailand. J Med Entomol. Sep 2005;42(5):821-5. doi:10.1093/jmedent/42.5.821 pmid:16363166

12. Sebastien M, Ian S, Paul B. Vector mapping, characterization of insecticide resistance of Aedes populations, and entomology capacity development in Lao PDR, 2014 (http://www.pasteur.la/?s=Vect 
or+mapping\%2C+characterization+of+insecticide+re, accessed 4 June 2017).

13. Esu E, Lenhart A, Smith L, Horstick O. Effectiveness of peridomestic space spraying with insecticide on dengue transmission; systematic review. Trop Med Int Health. May 2010;15(5):619-31. pmid:20214764

14. Aguiar M, Halstead SB, Stollenwerk N. Consider stopping dengvaxia administration without immunological screening. Expert Rev Vaccines. Apr 2017;16(4):301-2. doi:10.1080/14760584.2017.1276 831 pmid:28010152

15. Umezaki M, Sengebau-Kinzio MJ, Nakamura K, Ridep E, Watanabe M, Takano T. Household risk factors associated with denguelike illness, Republic of Palau, 2000-2001. Biosci Trends. Aug 2007;1(1):33-7. pmid:20103864

16. Mayxay $M$, Sengvilaipaseuth $O$, Chanthongthip $A$, Dubot-Pérès A, Rolain JM, Parola P, et al. Causes of fever in rural Southern Laos. Am J Trop Med Hyg. Sep 2015;93(3):517-20. doi:10.4269/ ajtmh.14-0772 pmid:26149859

17. Suttinont C, Losuwanaluk K, Niwatayakul K, Hoontrakul S, Intaranongpai W, Silpasakorn S, et al. Causes of acute, undifferentiated, febrile illness in rural Thailand: results of a prospective observational study. Ann Trop Med Parasitol. Jun 2006;100(4):363-70. doi:10.1179/136485906X112158 pmid:16762116

18. Dada N, Vannavong $N$, Seidu R, Lenhart A, Stenström TA Chareonviriyaphap T, et al. Relationship between Aedes aegypti production and occurrence of Escherichia coli in domestic water storage containers in rural and sub-urban villages in Thailand and Laos. Acta Trop. Jun 2013;126(3):177-85. doi:10.1016/j.actatropica.2013.02.023 pmid:23499713

19. Dengue haemorrhagic fever: diagnosis, treatment, prevention and control. 2nd edition. Geneva: World Health Organization; 1997 (http://www.who.int/csr/resources/publications/dengue/ Denguepublication/en/, accessed 31 March 2017).

20. Prado I, Rosario D, Bernardo L, Álvarez M, Rodríguez R, Vázquez $\mathrm{S}$, et al. PCR detection of dengue virus using dried whole blood spotted on filter paper. J Virol Methods. Apr 2005;125(1):75-81. doi:10.1016/j.jviromet.2005.01.001 pmid:15737419

21. Demographic and social statistics. New York, NY: Statistics Division, United Nations; 2016 (http://unstats.un.org/unsd/demographic/ sconcerns/housing/housingmethods.htm\#Ea, accessed 6 January 2017).

22. Vyas S, Kumaranayake L. Constructing socio-economic status indices: how to use principal components analysis. Health Policy Plan. Nov 2006;21(6):459-68. doi:10.1093/heapol/czl029 pmid:17030551

23. Vannavong N, Seidu R, Stenström TA, Dada N, Overgaard HJ. Effects of socio-demographic characteristics and household water management on Aedes aegypti production in suburban and rural villages in Laos and Thailand. Parasit Vectors. 4 Apr 2017;10(1):170. doi:10.1186/s13071-017-2107-7 pmid:28376893

24. Focks DA, Brenner RJ, Hayes J, Daniels E. Transmission thresholds for dengue in terms of Aedes aegypti pupae per person with discussion of their utility in source reduction efforts. Am J Trop Med Hyg. Jan 2000;62(1):11-8. doi:10.4269/ajtmh.2000.62.11 pmid:10761719

25. Capeding MR, Chua MN, Hadinegoro SR, Hussain II, Nallusamy $R$, Pitisuttithum $P$, et al. Dengue and other common causes of acute febrile illness in Asia: an active surveillance study in children. PLoS Negl Trop Dis. 25 Jul 2013;7(7):e2331. doi:10.1371/journal. pntd.0002331 pmid:23936565

26. Velasco JM, Valderama MT, Lopez MN, Chua D Jr, Latog R 2nd, Roque $\mathrm{V} \mathrm{Jr}$, et al. Chikungunya virus infections among patients with dengue-like illness at a tertiary care hospital in the Philippines, 2012-2013. Am J Trop Med Hyg. Dec 2015;93(6):1318-24. doi:10.4269/ajtmh.15-0332 pmid:26416109
27. Pessôa R, Patriota JV, Lourdes de Souza M, Felix AC, Mamede $\mathrm{N}$, Sanabani SS. Investigation into an outbreak of dengue-like illness in Pernambuco, Brazil, revealed a cocirculation of Zika, Chikungunya, and dengue virus type 1. Medicine (Baltimore). Mar 2016;95(12):e3201. doi:10.1097/MD.0000000000003201 pmid:27015222

28. Ho ZJM, Hapuarachchi HC, Barkham T, Chow A, Ng LC, Lee $J M V$, et al. Outbreak of Zika virus infection in Singapore: an epidemiological, entomological, virological, and clinical analysis. Lancet Infect Dis. Aug 2017;17(8):813-821. doi:10.1016/S14733099(17)30249-9

29. Wiwanitkit V. The current status of Zika virus in Southeast Asia. Epidemiol Health. Jun 2016;38:e2016026. doi:10.4178/epih. e2016026 pmid:27336445

30. Soulaphy C, Souliphone P, Phanthavong K, Phonekeo D, Phimmasine $\mathrm{S}$, Khamphaphongphane $\mathrm{B}$, et al. Emergence of chikungunya in Moonlapamok and Khong Districts, Champassak Province, the Lao People's Democratic Republic, May to September 2012. West Pac Surveill Response. 18 Mar 2013;4(1):46-50. doi:10.5365/ wpsar.2012.3.4.017 pmid:23908956

31. Hammon WM, Rudnick A, Sather GE. Viruses associated with epidemic hemorrhagic fevers of the Philippines and Thailand. Science. 15 Apr 1960;131(3407):1102-3. doi:10.1126/science.131.3407.1102 pmid:14399343

32. Mayxay $M$, Castonguay-Vanier J, Chansamouth $V$, Dubot-Pérès $A$, Paris DH, Phetsouvanh R, et al. Causes of non-malarial fever in Laos: a prospective study. Lancet Glob Health. Jul 2013;1(1):e46-54. doi:10.1016/S2214-109X(13)70008-1 pmid:24748368

33. Braga C, Luna CF, Martelli CM, de Souza WV, Cordeiro MT, Alexander N, et al. Seroprevalence and risk factors for dengue infection in socio-economically distinct areas of Recife, Brazil. Acta Trop. Mar 2010;113(3):234-40. doi:10.1016/j.actatropica.2009.10.021 pmid:19896921

34. Chikungunya fever. Annual epidemiological surveillance report 2009. Mueang Nonthaburi: Bureau of Epidemiology, Thailand; 2009 (http://www.boe.moph.go.th/Annual/Annual\%202552/ AESR52 Part1/Annual MenuPart1 52 CD.html, accessed 18 September 2017).

35. Koyadun S, Butraporn P, Kittayapong P. Ecologic and sociodemographic risk determinants for dengue transmission in urban areas in Thailand. Interdiscip Perspect Infect Dis. 2012;2012:907494. doi:10.1155/2012/907494 pmid:23056042

36. Maidana NA, Yang HM. Describing the geographic spread of dengue disease by traveling waves. Math Biosci. Sep 2008;215(1):64-77. doi:10.1016/j.mbs.2008.05.008 pmid:18590749

37. Stoddard ST, Morrison AC, Vazquez-Prokopec GM, Paz Soldan V, Kochel TJ, Kitron $U$, et al. The role of human movement in the transmission of vector-borne pathogens. PLoS Negl Trop Dis. 21 Jul 2009;3(7):e481. doi:10.1371/journal.pntd.0000481 pmid:19621090

38. Focks DA, Chadee DD. Pupal survey: an epidemiologically significant surveillance method for Aedes aegypti: an example using data from Trinidad. Am J Trop Med Hyg. Feb 1997;56(2):159-67. doi:10.4269/ajtmh.1997.56.159 pmid:9080874

39. Strengthening implementation of the global strategy for dengue fever/dengue haemorrhagic fever prevention and control. Report of the Informal Consultation 18-20 October 1999, Geneva WHO/ CDS/(DEN)/IC/ 2000.1. Geneva: World Health Organization; 2000 (http://www.who.int/csr/resources/publications/dengue/whocdsdenic20001.pdf, accessed 31 March 2017).

40. Bowman LR, Runge-Ranzinger S, McCall PJ. Assessing the relationship between vector indices and dengue transmission: a systematic review of the evidence. PLoS Negl Trop Dis. 8 May 2014;8(5):e2848. doi:10.1371/journal.pntd.0002848 pmid:24810901 


\section{A case series of fatal meningoencephalitis in Mongolia: epidemiological and molecular characteristics of tick-borne encephalitis virus}

Uyanga Baasandavga, a Burmaajar Badrakh, ${ }^{b}$ Natsagdorj Burged, a Otgonsuren Davaajav, ${ }^{c}$ Tungalag Khurelsukh, Amber Barnes, ${ }^{d}$ Unursaikhan Ulaankhuv ${ }^{a}$ and Tsogbadrakh Nyamdorj ${ }^{a}$

Correspondence to Uyanga Baasandavga (email: uyanga24@yahoo.com)

In Mongolia, the incidence and fatality rates of tick-borne encephalitis (TBE) have been increasing. We aimed to identify the epidemiological and molecular characteristics of tick-borne encephalitis virus (TBEV) associated with fatal meningoencephalitis in Mongolia.

We conducted a descriptive study of 14 fatal cases of TBE that occurred between 2008 and 2017 in Mongolia. Reverse transcription polymerase chain reaction (RT-PCR) was used to detect viral RNA in brain tissue. RT-PCR products from six patients who died from TBE between 2013 and 2017 were directly sequenced and analysed phylogenetically. Ticks collected from Selenge and Bulgan provinces were also tested for TBEV by RT-PCR.

Between 2008 and 2017, there were 14 fatal TBE cases in hospitals in Mongolia. The 14 patients who died reported receiving tick bites in Bulgan or Selenge province; $71.4 \%$ of deaths resulted from tick bites in Bulgan province. The TBE case fatality rate was $28.6 \%$ for patients in Bulgan province and $2.7 \%$ for those in Selenge province. All of the fatalities were men; the median age was $45 \pm 12.6$ years. Tick bites occurred between April and June in forested areas. In 2013, a 388 base pair fragment of the envelope (E) gene was obtained from a hospitalized patient. The closest relatives of this virus are Far-Eastern TBEV isolates.

The case fatality rate differed between two provinces where tick bites occurred. A higher number of TBE cases and the virulent Far-Eastern subtype occurred in patients in Bulgan province. This province should increase vaccination coverage, training, education and investigations.

$\mathrm{T}$ ick-borne encephalitis virus (TBEV) is a member of the genus Flavivirus of the Flaviviridae family. The virion consists of a single-stranded RNA molecule enclosed by the core membrane and the envelope (E) protein. The three genetically and antigenetically closely related TBEV subtypes (Western, Siberian and FarEastern) are not subject to significant antigenic variation. ${ }^{1}$

Tick-borne encephalitis (TBE) is a viral infectious disease that is transmitted by a bite from an infected tick and can progress to death. In Europe and Asia, between 10000 and 15000 TBE cases are reported annually. ${ }^{1}$ Reported case fatality rates (CFR) differ based on virus subtypes: $20-40 \%$ for the Far-Eastern subtype, $6-8 \%$ for the Siberian subtype and $1-2 \%$ for the European subtype. $^{2}$

TBEV can be transmitted to humans during the bite of several species of infected ticks, including Ixodes scapularis, Ixodes ricinus and Ixodes persulcatus; however, the main vector of TBEV is /xodes persulcatus. ${ }^{2}$ Researchers isolated TBEV from Ixodes persulcatus collected in Selenge and Bulgan provinces in the northern part of Mongolia., 3

TBE has recently attracted attention because of the increasing incidence and consequent significant harm to humans. Since 2005, vaccination and educational cam-

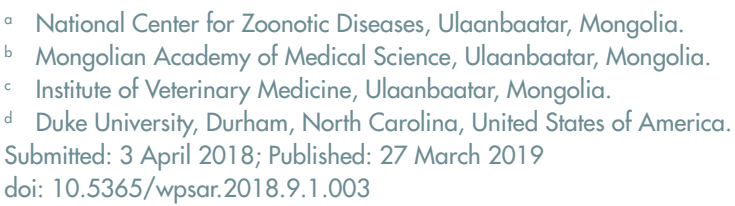


paigns have been administered throughout the affected areas of Mongolia, but human cases and fatalities from TBE continue to increase. The goal of this study was to identify the epidemiological and molecular characteristics of TBEV associated with fatal meningoencephalitis in Mongolia. Greater understanding of the virulence of TBEV in Mongolia and its distribution is urgently needed for the prevention of TBE.

\section{METHODS}

\section{Epidemiological characteristics of fatal cases}

Data on fatal TBE cases were documented by the National Center for Zoonotic Diseases (NCZD), which has registered tick-borne diseases since $2005 .^{5}$ We used data of all cases that were confirmed at the National Reference Laboratory of NCZD by enzyme-linked immunosorbent assay (ELISA), immunofluorescence assay (IFA) and polymerase chain reaction (PCR). Confirmatory diagnostic definitions were:

- Clinical criteria: Patient with at least two of the following signs or symptoms without other known reasons: fever $>37.5{ }^{\circ} \mathrm{C}$, headache, stiff neck, vomiting, paralysis or loss of consciousness.

- Laboratory criteria: IgM positive or IgG fourfold increase in pair serum OR detection of TBEV nucleic acid in any clinical specimen.

- Exposure history: Exposure is defined as a person who travelled or lived in forested areas with tick bites.

- Suspected cases: Patients with exposure history who fulfilled clinical criteria during the surveillance period.

- Confirmed cases: Suspected cases + laboratory confirmation.

A descriptive epidemiological study was conducted of 14 TBE patients who died in Mongolia between 2008 and 2017. All patients who died were bitten by ticks in areas of Bulgan and Selenge provinces. We collected clinical information on age, sex, occupation, province, clinical symptom onset dates, hospitalization dates and range of symptoms from the medical files. The CFR rate was calculated by the proportion of deaths among the laboratory-confirmed TBE cases in the province.
Tick collection, processing and viral RNA extraction

A total of 65 ticks (Ixodes persulcatus) were collected by flagging in Selenge province (17 ticks) and Bulgan province (48 ticks) in 2017.

Ticks were collected from Bulgan and Selenge provinces in the areas the patients recalled being bitten by a tick. Ticks were sampled in July 2017 using flagging methods according to the guidance of NCZD. For tick collection, a tick drag method was conducted using a white cloth sized $60 \times 100 \mathrm{~cm}$. Ticks were stored alive in a $50 \mathrm{ml}$ Falcon tube until they were investigated. Tick species were visually identified using a tick identification guide. ${ }^{6}$

Viral RNA was isolated from ticks using a Pure Link RNA Mini Kit (Thermo Fisher, Waltham, MA, USA) according to the manufacturer's protocol. The ticks were frozen in liquid nitrogen then ground using a sterile mortar and pestle. The resulting homogenate was transferred to a $1.5 \mathrm{ml}$ tube and mixed with $0.6 \mathrm{ml}$ lysis buffer before viral RNA extraction.

Post-mortem sample collection, processing and viral RNA extraction

Post-mortem tissue samples from seven of the TBE patients were stored at $-70{ }^{\circ} \mathrm{C}$ in the NCZD laboratory; tissue samples of seven other deceased patients were not available because the families declined autopsies. We excluded one patient's sample since results of the laboratory analysis of this sample were previously published in $2010 .^{7}$ Samples of cerebellum, cerebral cortex and spinal cord of the remaining six patients who died from TBE between 2013 and 2017 were selected.

Viral RNA was extracted from the supernatant of post-mortem nervous tissue using a Pure Link RNA Mini Kit (Thermo Fisher, Waltham, MA, USA) according to the manufacturer's protocol. The extracted RNA was eluted from a spin cartridge column in a volume of $100 \mu \mathrm{L}$ RNase-free water.

\section{RT-PCR with TBEV E gene specific primers}

Reverse transcription (RT) was done using Super Script III (Thermo Fisher, USA) according to the manufacturer's instruction. PCR was performed using taq-polymerase and sets of primers EncE-L (5'-GACCAGAGTGATC- 
GAGGCTG-3') and 1643-R (5'-GCCAGATCATTRAACCAGTC-3'), which flank the 388 bp fragment inside the $E$ gene of the TBEV genome.

An RT-PCR master mixture was prepared using $2 x$ Reaction mix $25 \mu \mathrm{l}$, Super Script $\AA$ III (Thermo Fisher, USA) RT/Platinum ${ }^{\circledR}$ Taq Mix $2 \mu \mathrm{l}, \mathrm{F}$ and R primers each $1 \mu \mathrm{l}$, molecular water $19 \mu \mathrm{l}$ and template RNA 2 $\mu$ l (final volume $50 \mu /$ sample; Super Script $\circledast$ III One-Step RT-PCR System with Platinum ${ }^{\circledR T a q}$ DNA Polymerase, \#12574-026, (Thermo Fisher, USA). The RT-PCR conditions were: 1 cycle of $50{ }^{\circ} \mathrm{C}$ for 45 minutes and $94{ }^{\circ} \mathrm{C}$ for 5 minutes; 40 cycles of denaturation at $94^{\circ} \mathrm{C}$ for 1 minute, annealing at $58^{\circ} \mathrm{C}$ for 1 minute, and extension at $72{ }^{\circ} \mathrm{C}$ for 2 minutes; and final extension at $72{ }^{\circ} \mathrm{C}$ for 7 minutes. The PCR products were detected in UV light as ethidium bromide-stained 388-base pair bands electrophoresed with a marker on $1.5 \%$ agarose gel. A band detected on the gel was purified using the quick PCR Purification Kit (Qiagen, Hilden, Germany).

\section{Sequence analysis}

Sequence analyses of the PCR products were conducted at the Institute of Veterinary Medicine of Mongolia using Genetic Analyser 3100 XI with Bigdye v3.1 (Thermo Fisher, USA) according to the manufacturer's protocol. Raw data sequences were analysed to create FASTA files with Sequence analyser v5.2 and Codoncode alignment v7.1. The sequence results were checked using the BLAST website of the National Center for Biotechnology Information. ${ }^{8}$ Phylogenic analyses of the PCR products sequences were performed using Crustal $X$ v2.0 and MEGA 7.0.

\section{Ethical statement}

Post-mortem tissue samples were collected and stored at the NCZD laboratory. Ethical clearance was not required as NCZD is responsible for analysis of zoonotic diseases.

\section{RESULTS}

\section{Epidemiological characteristics of fatal cases}

Fourteen patient fatalities were registered in Mongolia between 2008 and 2017 for a CFR of 4.9\% (14/287). Seven $(50 \%)$ of the documented patients lived in Bul- gan province, three $(21.4 \%)$ in Selenge province, three (21.4\%) in Orkhon province and one (7.1\%) in DarkhanUul province (Fig. 1). By the tick bite area, total CFR was $28.6 \%(10 / 35)$ in Bulgan, and 2.7\% (4/150) in Selenge province. The CFR range was $18.2-50 \%$ in Bulgan and 5.7-10\% in Selenge province between 2008 and 2017.

All of the TBE fatalities were men who reported tick bites during the months of April through June (April: 1/14 [7.1\%], May: 9/14 [64.3\%], and June: 4/14 [28.6\%]). The most common activities associated with tick bites were collecting plants $(5 / 12,41.6 \%)$, preparing wood $(4 / 12,33.3 \%)$, collecting animal horns $(2 / 12,16.7 \%)$ and herding livestock in forested areas $(1 / 12,8.3 \%)$. The median age of the fatal cases was $45 \pm 12.6$ years; the employments of the fatal cases included herder, driver, self-employed and unemployed (Table 1).

The median incubation period was $16 \pm 11.4$ days. Generally, fatalities occurred $8.1 \pm 5.2$ days after clinical symptoms developed. The median incubation period of fatal cases in Selenge province was 9 days with symptom onset dates from 1 May to 25 June. The median days between symptom onset and death was 10.7 days. The median incubation period of fatal cases in Bulgan province was 12.6 days with symptom onset dates between 24 May and 28 June. The median number of days between symptom onset and death was 6.7 days.

Patients with TBEV from a tick bite in Selenge province had a 1.4 times shorter incubation period than those in Bulgan province $(P=0.15)$. The number of days between symptom onset and death in Selenge province was 1.5 times longer than in Bulgan province $(P<0.05)$.

The most common clinical signs and symptoms were fever (12/14, [85.7\%]); paralysis (12/14, [85.7\%]); headache (11/14, [78.6\%]); vomiting (10/14, [71.5\%]); loss of consciousness $(8 / 14,[71.5 \%])$; stiff neck $(8 / 14$, [71.5\%]); muscle ache (8/14, [71.5\%]); and coxalgia, rash, blindness, and cough with bloody mucus (each reported by $1 / 14,[7.1 \%]$ ) (Table 2). All patients who died were not vaccinated against TBE.

Molecular epidemiology of fatal cases and infected ticks

TBEV RNA was detected in two ticks (11.7\%) from Selenge province and six brain tissue samples from 
Fig. 1. Distribution of 14 fatal TBE cases

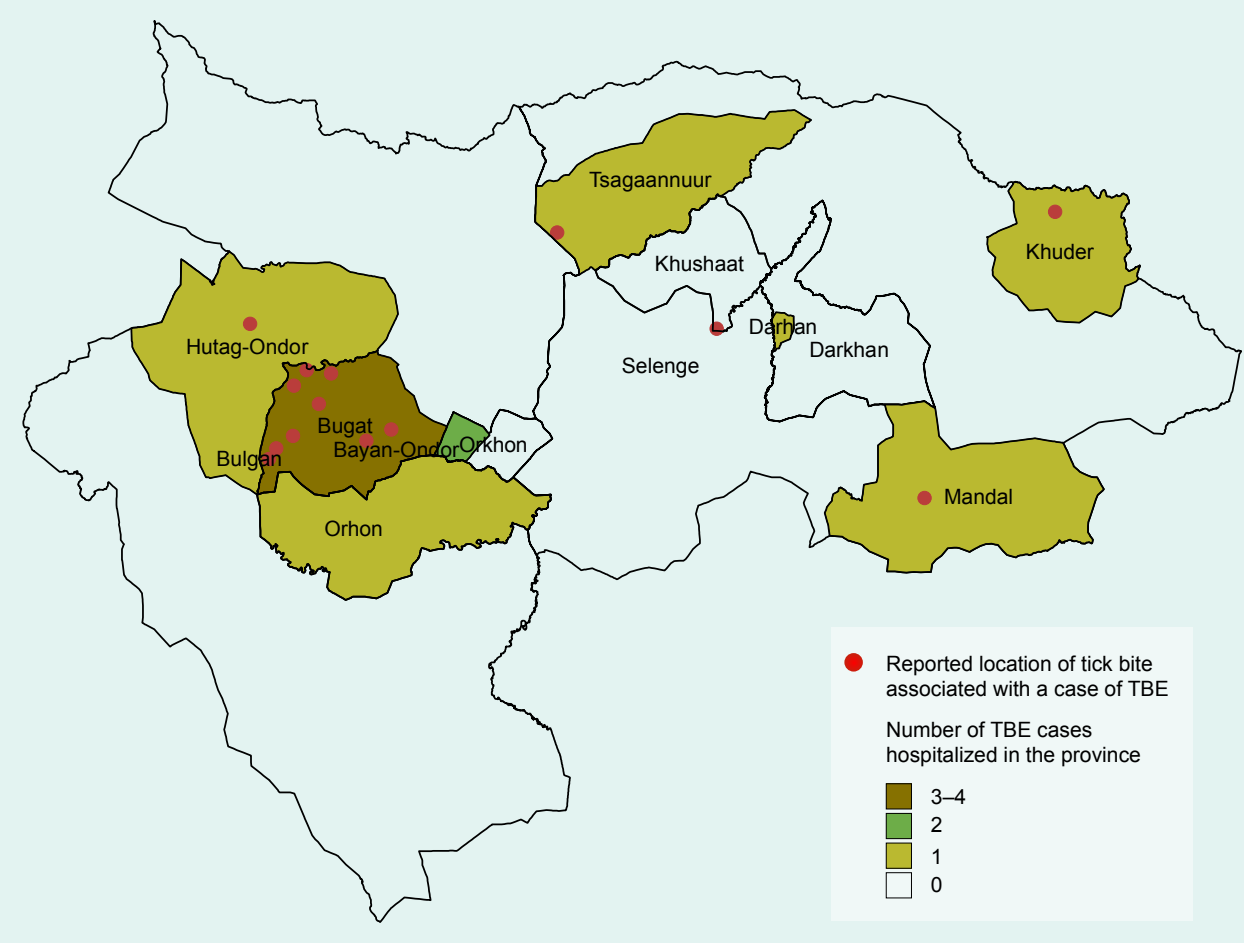

Each red dot represents the location of a tick bite associated with a case of TBE. Provinces where patients with TBE were hospitalized are shaded in green and yellow.

Table 1. Epidemiological characteristics of fatal TBE cases in Mongolia, 2008-2017

\begin{tabular}{lccc}
\hline & Characteristics & $\begin{array}{c}\text { Number of fatalities } \\
(\boldsymbol{n}=14)\end{array}$ & Percentage \\
\hline Sex & Male & 14 & 100 \\
Age group (years) & $30-39$ & 6 & 42.9 \\
& $40-49$ & 3 & 21.4 \\
& $50-59$ & 2 & 14.3 \\
Employment & Above 60 & 3 & 21.4 \\
& Herder & 5 & 35.7 \\
Exposure month & Unemployed & Driver & 28.6 \\
& Private worker & 4 & 14.3 \\
Reason for tick bite & Pensioner & 2 & 14.3 \\
& April & 2 & 7.1 \\
& May & 1 & 7.1 \\
Tick bite province & June & 1 & 64.3 \\
& Prepared wood & 9 & 28.6 \\
Diagnosis & Collected plants & 4 & 28.6 \\
& Herding livestock & 4 & 35.7 \\
& Collected horns & 5 & 7.1 \\
& Unknown & 1 & 14.3 \\
& Selenge & 2 & 14.3 \\
& Bulgan & 2 & 28.6 \\
& Meningoencephalitis & 4 & 71.4 \\
& Meningoencephalomyelitis & 10 & 85.7 \\
\hline
\end{tabular}


Table 2. Clinical symptoms of fatal TBE cases in Mongolia, 2008-2017

\begin{tabular}{|c|c|c|c|c|c|c|c|}
\hline $\begin{array}{l}\text { Province } \\
\text { of tick } \\
\text { bite }\end{array}$ & Age, sex & $\begin{array}{l}\text { Incubation } \\
\text { period } \\
\text { (days) }\end{array}$ & $\begin{array}{l}\text { Date of } \\
\text { symptom } \\
\text { onset }\end{array}$ & $\begin{array}{l}\text { Initial symptoms } \\
\text { reported }\end{array}$ & $\begin{array}{c}\text { Date of } \\
\text { hospitalization }\end{array}$ & $\begin{array}{l}\text { Signs and } \\
\text { symptoms } \\
\text { recorded }\end{array}$ & $\begin{array}{l}\text { Number of } \\
\text { days between } \\
\text { symptom } \\
\text { onset and } \\
\text { death }\end{array}$ \\
\hline \multirow[t]{4}{*}{ Selenge } & $38, \mathrm{M}$ & 6 & 22 Jun 2008 & Headache & 28 Jun 2008 & Coma & 8 \\
\hline & $66, \mathrm{M}$ & 10 & 24 May 2015 & Headache & 24 May 2015 & $\begin{array}{l}\text { Loss of conscious- } \\
\text { ness, coma, paraly- } \\
\text { sis, coxalgia }\end{array}$ & 23 \\
\hline & $34, \mathrm{M}$ & 5 & 25 Jun 2015 & $\begin{array}{l}\text { Fever, headache, } \\
\text { vomiting, stiff } \\
\text { neck }\end{array}$ & 28 Jun 2015 & $\begin{array}{l}\text { Loss of conscious- } \\
\text { ness, coma, } \\
\text { paralysis }\end{array}$ & 8 \\
\hline & $35, \mathrm{M}$ & 15 & 1 Jun 2017 & Headache & 4 Jun 2017 & $\begin{array}{l}\text { Loss of conscious- } \\
\text { ness, coma, } \\
\text { paralysis }\end{array}$ & 4 \\
\hline \multirow[t]{10}{*}{ Bulgan } & $50, \mathrm{M}$ & 8 & 20 June 2008 & $\begin{array}{l}\text { Fever, headache, } \\
\text { vomiting, stiff } \\
\text { neck }\end{array}$ & 21 Jun 2008 & $\begin{array}{l}\text { Loss of conscious- } \\
\text { ness, coma, paraly- } \\
\text { sis, rash, cough with } \\
\text { bloody mucus }\end{array}$ & 12 \\
\hline & $41, \mathrm{M}$ & 33 & 28 Jun 2013 & $\begin{array}{l}\text { Headache, } \\
\text { vomiting }\end{array}$ & 30 Jun 2013 & $\begin{array}{l}\text { Loss of conscious- } \\
\text { ness, coma, paraly- } \\
\text { sis, muscle ache }\end{array}$ & 12 \\
\hline & $46, M$ & 4 & 24 May 2013 & $\begin{array}{l}\text { Fever, headache, } \\
\text { vomiting }\end{array}$ & 24 May 2013 & $\begin{array}{l}\text { Loss of conscious- } \\
\text { ness, fever, coma, } \\
\text { facial paralysis, } \\
\text { blindness, muscle } \\
\text { ache }\end{array}$ & 5 \\
\hline & $31, \mathrm{M}$ & 15 & 20 Jun 2013 & $\begin{array}{l}\text { Fever, headache, } \\
\text { vomiting, stiff } \\
\text { neck }\end{array}$ & 22 Jun 2013 & $\begin{array}{l}\text { Loss of conscious- } \\
\text { ness, paralysis, } \\
\text { muscle ache }\end{array}$ & 3 \\
\hline & $43, M$ & 14 & 10 Jun 2016 & $\begin{array}{l}\text { Fever, headache, } \\
\text { vomiting }\end{array}$ & 12 Jun 2016 & $\begin{array}{l}\text { Paralysis, muscle } \\
\text { ache }\end{array}$ & 4 \\
\hline & $54, \mathrm{M}$ & 13 & 21 Jun 2016 & $\begin{array}{l}\text { Fever, headache, } \\
\text { vomiting, stiff } \\
\text { neck }\end{array}$ & 23 Jun 2016 & $\begin{array}{l}\text { Paralysis, muscle } \\
\text { ache }\end{array}$ & 6 \\
\hline & $34, \mathrm{M}$ & Unknown & 24 May 2017 & $\begin{array}{l}\text { Fever, vomiting, } \\
\text { stiff neck }\end{array}$ & 26 May 2017 & $\begin{array}{l}\text { Paralysis, muscle } \\
\text { ache, heartache }\end{array}$ & 5 \\
\hline & $33, \mathrm{M}$ & 16 & 25 May 2017 & $\begin{array}{l}\text { Fever, headache, } \\
\text { stiff neck }\end{array}$ & 29 May 2017 & $\begin{array}{l}\text { Loss of conscious- } \\
\text { ness, coma }\end{array}$ & 11 \\
\hline & $62, \mathrm{M}$ & 10 & 1 Jun 2017 & $\begin{array}{l}\text { Fever, headache, } \\
\text { vomiting, stiff } \\
\text { neck }\end{array}$ & 3 Jun 2017 & $\begin{array}{l}\text { Paralysis, muscle } \\
\text { ache }\end{array}$ & 5 \\
\hline & $60, M$ & 38 & 31 May 2017 & $\begin{array}{l}\text { Fever, headache, } \\
\text { vomiting, stiff } \\
\text { neck }\end{array}$ & 1 Jun 2017 & $\begin{array}{l}\text { Loss of conscious- } \\
\text { ness, coma, paraly- } \\
\text { sis, muscle ache }\end{array}$ & 7 \\
\hline
\end{tabular}

six patients who died (one in Selenge, five in Bulgan) between 2013 and 2017. By RT-PCR, the TBEV E gene was amplified from synthesized cDNA using primer sets targeting the $\mathrm{E}$ gene of TBEV that produced a 388 base pair fragment. This fragment of $E$ gene was isolated from six patients who died and two ticks. No nucleotide structures suitable for sequence analysis could be identified in either tick sample.
One fatal case from Bulgan province in 2013 had an identifiable nucleotide structure. Samples from the other five fatalities did not yield enough product for sequencing. The nucleotide sequence of the sample was most similar (90\%) to the isolate TBEV-MN-2008 (HM133639.1) according to GenBank data. ${ }^{8}$ Phylogenetic analysis showed that the isolated virus belonged to the Far-Eastern subtype (strains of the 886 and X1subtype) of TBEV. ${ }^{7,9,10}$ 


\section{DISCUSSION}

In our study, all of the TBE fatalities were men who reported tick bites during the months of April through June. In other studies, men are more affected than women by fatal TBE. ${ }^{11,12}$ The seasonal distribution of TBE cases depends on the activity of the tick species; Ixodes persulcatus generally emerge between April and May, but Ixodes ricinus activity periods may occur in April, May, October and November. ${ }^{13}$ Our study shows, Ixodes persulcatus becoming important vector of TBE in forested areas of Selenge and Bulgan provinces of Mongolia.

The CFR for TBE differs by virus subtype, including less than $2 \%$ for the European subtype, $20-40 \%$ for the Far-Eastern subtype, and $6-8 \%$ in the Siberian subtype. ${ }^{2}$ In our study, the CFR range in Bulgan province was $18.2-50 \%$, similar to that of the Far-Eastern subtype, and the CFR range in Selenge province was $5.7-10 \%$, similar to that of the Siberian subtype. In previous studies of TBEV subtypes in Mongolia, Siberian subtype was found in Ixodes persulcatus of Selenge and Bulgan provinces. ${ }^{7,14}$ Our study indicates that the Far-Eastern subtype is also present in humans in Bulgan province. This is the second confirmed case of lethal TBE caused by the Far-Eastern subtype in Bulgan province, but there has been no evidence of the Far-Eastern subtype found in ticks from Bulgan province. Despite the fatalities in northern Mongolia, few public health officials recommend expanding TBE vaccination for Selenge and Bulgan provinces. $^{3}$ Most studies, vaccination efforts and TBE trainings have focused primarily in Selenge province which has the largest population of /xodes persulcatus. ${ }^{3,4}$

We found that the Far-Eastern subtype of TBEV is the predominant virus among the fatal TBE cases in Bulgan province. Therefore, this province must increase vaccination coverage, training and education; also, it needs to conduct further comprehensive investigations in the epidemiology of TBE. More research is necessary to understand why the Far-Eastern subtype has not yet been found in Ixodes persulcatus collected in the province and whether a different species may be contributing to human disease.

This study has some limitations. The patient sample size was small, and half of the tissue samples could not be analysed. Finally, more tick samples are necessary to fully identify the subtypes circulating in ticks from these regions.

\section{CONCLUSION}

Despite these drawbacks, this study provides important epidemiological and molecular analysis of recent TBE cases and associated fatalities due to meningoencephalitis. As this tick-borne disease continues to be a public health concern to endemic provinces in Mongolia, our study can help prevent infection and subsequent serious or fatal illness. These findings support expanded vaccinations for Bulgan province and continued vaccination in Selenge province. At-risk individuals from both provinces should be targeted for education and prevention messages. More research is necessary to discover which subtypes of TBEV are circulating among tick vectors in these regions and how these subtypes may impact disease susceptibility and recovery in patients. A more coordinated effort is needed between health research and public policy officials to combat the increasing risk of TBEV transmission in Mongolia.

\section{Acknowledgement}

We would like to express our sincere thanks to Dr Nyamdorj Erdenbat and colleagues of the National Center for Zoonotic Diseases (NCZD) and Institute of Veterinary Medicine.

\section{Funding}

Dr Uyanga Baasandavga and Amber Nicole Barnes were supported in part by a grant from Fogarty International Center of the United States National Institutes of Health, 5D43TW009373 (Professor Gregory C Gray, $\mathrm{PI})$. We thank WHO colleagues for their financial support throughout the study. This research was supported by the World Health Organization in Mongolia.

\section{Conflict of interest}

The authors state no conflict of interest.

\section{References}

1. Süss J. Tick-borne encephalitis in Europe and beyond: the epidemiological situation as of 2007. Euro Surveill. 2008;13(26). pii: 18916.

2. Gritsun TS, Lashkevich VA, Gould EA. Tick-borne encephalitis. Antiviral Res. 2003;57:129-46.

3. Khasnatinova MA, Tserennorov D, Nyamdavaa P, Glushenkova T, Arbatskaya E, Bataa J, et al. Tick-borne encephalitis virus in Mongolia. Int J Infect Dis. 2010;(14):372-73. doi:10.1016/j. ijid.2010.02.449 
4. Boldbaatar B, Jiang RR, von Fricken ME, et al. Distribution and molecular characteristics of rickettsiae found in ticks across Central Mongolia. Parasit Vectors. 2017;10(1):61.

5. The history of NCZD establishment. Ulaanbaatar: National Center for Zoonotic Disease; 2018 (https://nczd.gov.mn/?page id=9295\&lang=en).

6. Johnny DH. Ixodid and argasid ticks: keys to their identification. Vet Clin North Am Small Anim Pract. 1991; 21(1):185-197.

7. Khasnatinov MA, Danchinova GA, Kulakova NV, Tungalag $K$ Arbatskaia EV, Mironova LV, et al. [Genetic characteristics of the causative agent of tick-borne encephalitis in Mongolia]. Vopr Virusol. 2010;55(3):27-32. (in Russian) pmid:20608078

8. Basic local alignment search tool. Bethesda, MD: National Center for Biotechnology Information; 2018 (http://www.ncbi.nlm.nih. gov/BLAST/)

9. Tkachev SE, Demina TV, Dzhioev Yu P, Kozlova IV, Verkhozina $\mathrm{MM}$, Doroshchenko EK, et al. Genetic studies of tick-borne encephalitis virus strains from western and eastern Siberia. In: Flavivirus Encephalitis. InTechOpen. 2011;12(3):235-54. doi: $10.5772 / 847$
10. Bertrand YJK, Johansson M, Norberg P. Revisiting recombination signal in the tick-borne encephalitis virus: a simulation approach. PLoS One. 2016 Oct 19;11(10):e0164435. doi:10.1371/journal. pone.0164435 pmid:27760182

11. Yasutaka T, Hiroaki Y, Yasunori M. Fatal meningoencephalomyetis due to the tick-borne encephalitis virus: the first detailed neurological observation in a Japanese patient from the central part of Hokkaido Island. Intern Med. 2018; 57(6): 873-76.

12. Kuivanen S, Smura T, Rantanen K, Kämppi L, Kantonen J, Kero $M$, et al. Fatal tick-borne encephalitis virus infections caused by Siberian and European subtypes, Finland, 2015. Emerg Infect Dis. 2018;24(5):946-48. doi:10.3201/eid2405.171986

13. Korenberg El. Seasonal population dynamics of ixodes ticks and tick-borne encephalitis virus. Exp Appl Acarol. 2000;24(9):66581. doi:10.1023/A:1010798518261 pmid:11227825

14. Frey S, Mossbrugger I, Altantuul D, Battsetseg J, Davaadorj R, Tserennorov $\mathrm{D}$, et al. Isolation, preliminary characterization, and full-genome analyses of tick-borne encephalitis virus from Mongolia. Virus Genes. 2012 Dec;45(3):413-25. doi:10.1007/ s11262-012-0795-9 pmid:22847274 


\title{
Missed detections of influenza
}

\section{A(H1)pdm09 by real-time RT-PCR assay due to haemagglutinin sequence mutation, December 2017 to March 2018, northern Viet Nam}

\author{
Hoang Vu Mai Phuong, ${ }^{a}$ Ung Thi Hong Trang, ${ }^{a}$ Nguyen Le Khanh Hang, ${ }^{a}$ Nguyen Thanh Thuy, Le Thi Thanh, \\ Nguyen Vu Son, ${ }^{a}$ Nguyen Phuong Anh, ${ }^{a}$ Tran Thi Thu Huong, ${ }^{a}$ Vuong Duc Cuong and Le Quynh Maia \\ Correspondence to Le Quynh Mai (email: lom9@hotmail.com or ltqm@nihe.org.vn)
}

Introduction: There are two methods of reverse transcription polymerase chain reaction (RT-PCR) that have been the common methods to detect influenza infections: conventional and real-time RT-PCR. From December 2017 to March 2018, several missed diagnoses of influenza A(H1)pdm09 using real-time RT-PCR were reported in northern Viet Nam. This study investigated how these missed detections occurred to determine their effect on the surveillance of influenza.

Methods: The haemagglutinin (HA) segments of $A(H 1 N 1) p d m 09$ from both real-time RT-PCR positive and negative samples were isolated and sequenced. The primer and probe sets in the HA gene were checked for mismatches, and phylogenetic analyses were performed to determine the molecular epidemiology of these viruses.

Results: There were 86 positive influenza A samples; 32 were $A(H 1) p d m 09$ positive by conventional RT-PCR but were negative by real-time RT-PCR. Sequencing was conducted on 23 influenza (H1N1)pdm09 isolates that were recovered from positive samples. Eight of these were negative for $\mathrm{A}(\mathrm{H} 1)$ pdm09 by real-time RT-PCR. There were two different mismatches in the probe target sites of the HA gene sequences of all isolates $(n=23)$ with additional mismatches only at position 7 (template binding site) identified for all eight negative real-time RT-PCR isolates. The prime target sites had no mismatches. Phylogenetic analysis of the HA gene showed that both the positive and negative real-time RT-PCR isolates were grouped in clade 6B.1; however, the real-time RT-PCR negative viruses were located in a subgroup that referred to substitution I295V.

Conclusion: Constant monitoring of genetic changes in the circulating influenza $A(H 1 N 1) p d m 09$ viruses is important for maintaining the sensitivity of molecular detection assays.

l nfluenza $\mathrm{A}(\mathrm{H} 1 \mathrm{~N} 1) p d m 09$ is a novel influenza detected in humans in 2009, causing the first influenza pandemic in more than 40 years. ${ }^{1}$ Since then, the virus has become a seasonal influenza virus and continues to circulate worldwide in humans and pigs. ${ }^{1,2}$ In Viet Nam, influenza $A(\mathrm{H} 1 \mathrm{~N} 1)$ pdm09 spread quickly into communities in July 2009 and predominated, comprising about $85-90 \%$ of all influenza viruses during August and September of the 2009 season. After that, influenza $\mathrm{A}(\mathrm{H} 1 \mathrm{~N} 1) p d m 02$ became endemic, co-circulating with influenza $A(H 3 N 2)$ and $B$ viruses. ${ }^{3-5}$ From December 2017 to March 2018, there was circulation of both influenza $A$ and $B$, with influenza $A(\mathrm{H} 1 \mathrm{~N} 1)$ pdm09 again predominating in Viet Nam. Influenza $A(\mathrm{H} 1 \mathrm{~N} 1) p d m 09$ was also the cause of outbreaks in other Asian countries and territories including India, Singapore, Hong Kong Special Administrative Region (SAR) and others. ${ }^{6-8}$

The gold standard assay for influenza diagnosis is the reverse transcription polymerase chain reaction (RT-PCR) assay. Of the two methods, real-time RT-PCR has many advantages over conventional RT-PCR. Most notably, it is time-saving, the data can be collected at the exponential phase of the reaction, and quality of amplification can be monitored during the run. Real-time RT-PCR can also detect a single target in a very small concentration of DNA or RNA because it uses a fluorescent dye that binds to targets. Despite these benefits, conventional RT-PCR is

\footnotetext{
National Institute of Hygiene and Epidemiology, Hanoi, Viet Nam. Submitted: 15 August 2018; Published: 31 March 2019 doi: 10.5365/wpsar.2018.9.3.003
} 
the dominant method in genetics-based diagnostic testing for influenza in Viet Nam because it is less expensive.

Sensitivity and specificity are key characteristics for diagnostic tools, and a high sensitivity is important when the test is used to identify emerging infectious diseases. Both conventional RT-PCR and real-time RTPCR assays are rapid, sensitive methods for detecting the genetic material of influenza viruses. However, mutations in the viral genome that generate novel variants cause the sensitivity of these molecular tests to decrease and may lead to false-negative results. The $\mathrm{A}(\mathrm{H} 1)$ pdm09 primers and probe used in Viet Nam were adopted from the United States Centers for Disease Control and Prevention (CDC) developed in $2009^{9,10}$ and are commonly applied in public health laboratories throughout Viet Nam.

In Viet Nam, the national sentinel influenza surveillance system, administered by the National Institute of Hygiene and Epidemiology (NIHE) of Viet Nam's Ministry of Health, comprises sentinel clinics linked to regional public health laboratories. Throat swabs collected from influenza-like illness (ILI) and severe acute respiratory infection (SARI) patients are tested for influenza using both conventional and real-time RT-PCR. ${ }^{4}$ In this study, we investigated $A(\mathrm{H} 1 \mathrm{~N} 1)$ pdm09 virus isolates that could not be subtyped using real-time RT-PCR from surveillance specimens collected in late 2017 and early 2018. These misdiagnoses may affect the sensitivity of real-time RTPCR assays used for influenza surveillance in Viet Nam.

\section{METHODS}

\section{Source of samples}

Between December 2017 and March 2018, there were 256 throat swabs collected from ILI and SARI patients according to WHO case definitions ${ }^{11}$ as part of the national sentinel influenza surveillance system. Among 256 specimens, 60 samples were from cases of ILI and 196 were cases with SARI.

\section{Viral isolation}

The respiratory swabs positive for influenza $A(H 1 N 1) p d m 09$ were inoculated on Madin-Darby Canine Kidney (MDCK) cells according to the standard operating procedures (SOPs) of the National Influenza Center (NIC) located at NIHE in Hanoi. The viruses were harvested and stored at $-80{ }^{\circ} \mathrm{C}$ until analysis.

\section{Genetic characterization}

Molecular testing assays

Ribonucleic acid (RNA) extraction was conducted on a $140 \mu \mathrm{l}$ aliquot of each sample using the QIAamp Viral RNA Mini Kit (Qiagen, Hilden, Germany) according to the manufacturer's instructions. Influenza detection was performed using both standard molecular methods (conventional RT-PCR and real-time RT-PCR), employing specific primer and probe sets targeted to the matrix, haemagglutinin ( $\mathrm{HA}$ ) gene and nucleoprotein gene according to the SOPs of the NIC at NIHE in Hanoi (Fig. 1). These primers and probes were constructed following guidelines of the CDC and the World Health Organization. ${ }^{10,12}$

\section{Nucleotide sequencing and phylogenetic analysis}

The influenza $A(\mathrm{H} 1 \mathrm{~N} 1) p d m 09$ isolates were collected after growth in MDCK cells and their identify confirmed by using haemagglutination inhibition assay kits, provided by the CDC in 2017. The isolates with HA titre of more than 8 haemagglutinating units were selected for $\mathrm{HA}$ genetic analysis. RNA extraction was conducted on a $140 \mu \mathrm{l}$ aliquot of each isolate using the viral RNA extraction kit (Qiagen, Valencia, CA, USA) according to the manufacturer's instruction. Sanger sequencing was used to determine the nucleotide sequence of the HA gene. Briefly, cDNA was first performed using the influenza A virus universal primer (Uni 12) AGC AAA AGC AGG as described (SuperScript ${ }^{\circledR}$ III First-Strand Synthesis System, Thermo Scientific, MA, USA), followed by PCR with HA specific primer (HotStar HiFidelity Polymerase Kit, Qiagen, Valencia, CA, USA). The PCR products were purified with PCR purification kits (Qiagen, Valencia, CA, USA) and sequenced using Big Dye Terminator v3.1 (Thermo Scientific, MA, USA) on an ABI 3130 automatic DNA sequencer.

\section{Analysis of nucleotide sequence data}

Sequences were assembled using DNASTAR v.8.0 ${ }^{13}$ and multiple sequences alignment by Bioedit v.7.0.5. ${ }^{14}$ The 1140 bp haemagglutinin domain 1 (HA1) sequences were constructed into a phylogenetic tree by MEGA7, using a maximum likelihood method with bootstrap supported values. ${ }^{15}$ Reference HA genes (the recent recommended vaccine strains A/California/07/2009, A/Michigan/45/2015 and others) were obtained from the National Center for Biotechnology Information in 
Fig. 1. Comparison nucleotide sequences of primer-probe sets and HA sequences of influenza A(H1N1)pdm09

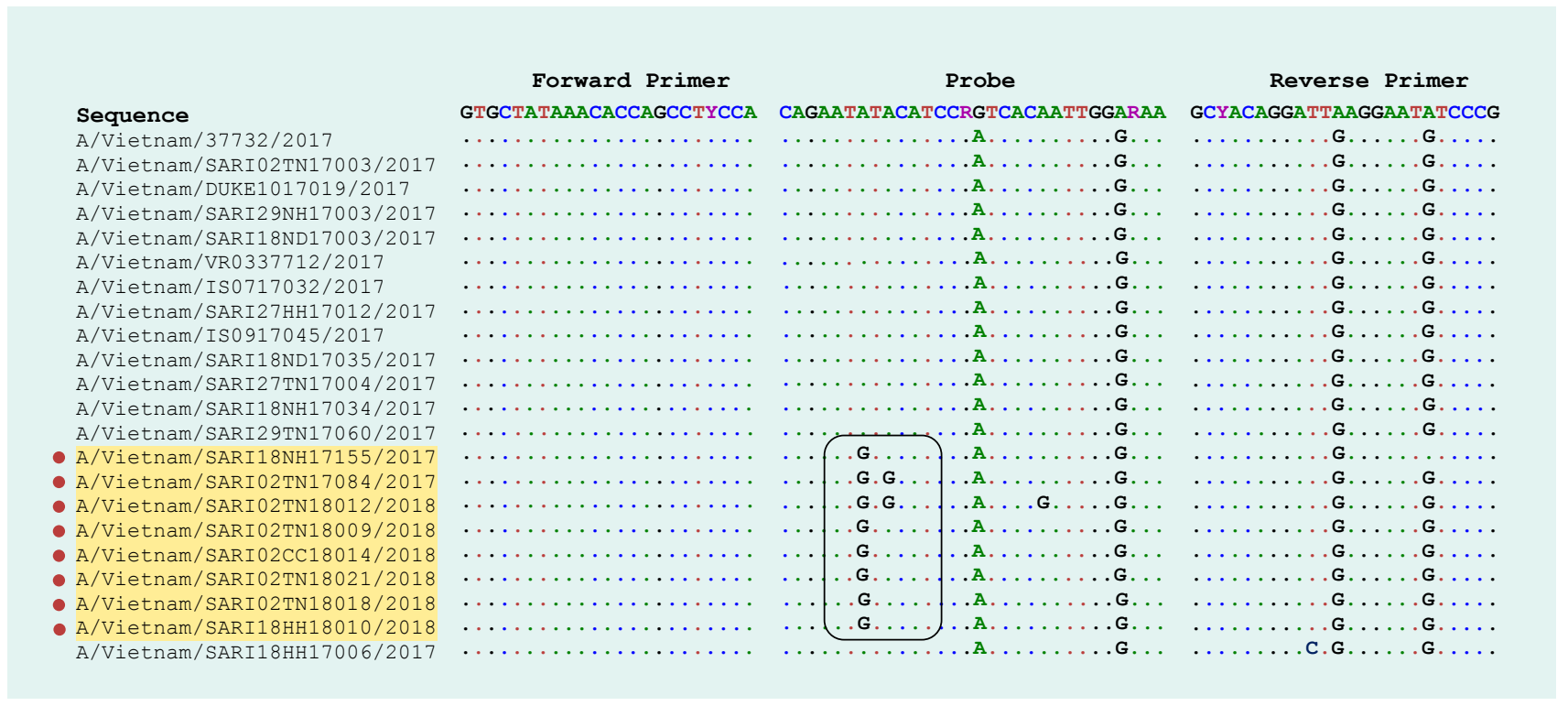

Red dots indicate identity with primer or probe sequence.

Yellow highlights indicate strains with mismatched nucleotides at position $7(A / G)$ and position $9(A / G)$ of probe.

Bethesda, MD, USA. All study sequences were deposited in Genbank (MH636827 to MH636834). ${ }^{16}$

Primer and probe binding regions were aligned with recent circulating $A(\mathrm{H} 1 \mathrm{~N} 1)$ pdm09 viruses to check for mismatches by using Geneious v.8.1.8 software. ${ }^{17}$

\section{Ethics}

The routine surveillance activities were approved by the Ethic Committee and the Scientific Committee of NIHE.

\section{RESULTS}

\section{Detection of influenza $\mathrm{A}(\mathrm{H} 1)$ pdm09 during study period}

There were 86 samples positive for influenza $A$ by both conventional RT-PCR and real-time RT-PCR during the study period (Table 1). Using conventional RT-PCR for subtyping, there were 82 samples (95.4\%) that were $\mathrm{A}(\mathrm{H} 1 \mathrm{~N} 1)$ pdm09 positive and four samples $(4.6 \%)$ that were $A(H 3)$ positive; we were able to subtype all of these samples. Using real-time RT-PCR testing, 50 samples (58.2\%) were positive for $A(H 1) p d m 09$, four samples were positive for $A(\mathrm{H} 3)(4.6 \%)$ and $32(37.2 \%)$ samples could not be subtyped (Table 1).
The distribution of subtypes by real-time RT-PCR was significantly different from that of conventional RT-PCR ( $\chi^{2}$ test $p$ value $\left.<0.05\right)$.

\section{Phylogenetic tree of HA1 gene influenza A(H1N1)pdm09}

The HA1 phylogenetic analysis compared 23 influenza $A(H 1 N 1) p d m 09$ isolates, eight of which were negative for $A(\mathrm{H} 1)$ pdm09 by real-time RT-PCR, along with other influenza $A$ viruses that circulated in Viet Nam during 2016-2018 (Fig. 2). The A(H1N1)pdm09 viruses collected before this study period (September 2016 to February 2017) were mostly in the phylogenetic clade $6 \mathrm{~B}$, whereas most of the circulating viruses in 2017 and early 2018 were from subgroup 6B.1, represented by A/ Michigan/45/2015. A small proportion of viruses were grouped in subgroup 6B.2 (Fig. 2).

All of the 23 influenza $A(\mathrm{H} 1 \mathrm{~N} 1) p d m 09$ isolates from this study belonged to subgroup 6B.1, and amino acid analysis showed differences at residues $S 84 \mathrm{~N}$, S162N and I216T in the HA protein of subgoup 6B.1 compared to those in subgroup 6B.2 (Fig. 2). These isolates were closely related to viruses circulating in Australia, the Hong Kong SAR and Singapore. The eight isolates that were positive by conventional RT-PCR but negative by real-time RT-PCR gathered in new sub- 
Table 1. Number and proportions of $\mathbf{A}(\mathrm{H} 1)$ pdm09-positive isolates by subtyping using real-time RT-PCR and conventional RT-PCR

\begin{tabular}{|c|c|c|c|c|c|c|c|}
\hline \multirow{3}{*}{ Sample source } & \multicolumn{4}{|c|}{$\begin{array}{c}\text { Real-time RT-PCR } \\
\text { Influenza A positive } n(\%)\end{array}$} & \multicolumn{3}{|c|}{$\begin{array}{c}\text { Conventional RT-PCR } \\
\text { Influenza A positive } n(\%)\end{array}$} \\
\hline & \multirow[t]{2}{*}{ Influenza A } & \multicolumn{2}{|c|}{ Subtypes } & \multirow{2}{*}{$\begin{array}{l}\text { Unable to be } \\
\text { subtyped }\end{array}$} & \multirow[t]{2}{*}{ Influenza A } & \multicolumn{2}{|c|}{ Subtypes } \\
\hline & & H1pdm09 & H3 & & & H1pdm09 & H3 \\
\hline $\begin{array}{l}\text { SARI patients } \\
n=196\end{array}$ & 52 & $\begin{array}{c}31 \\
(36.1)\end{array}$ & 3 & $\begin{array}{c}18 \\
(21)\end{array}$ & 52 & $\begin{array}{c}49 \\
(57)\end{array}$ & 3 \\
\hline $\begin{array}{l}\text { ILI patients } \\
n=60\end{array}$ & 34 & $\begin{array}{c}19 \\
(22.1)\end{array}$ & 1 & $\begin{array}{c}14 \\
(16.2)\end{array}$ & 34 & $\begin{array}{c}33 \\
(38.4)\end{array}$ & 1 \\
\hline $\begin{array}{l}\text { Total } \\
n=256\end{array}$ & $\begin{array}{c}86 \\
(100)\end{array}$ & $\begin{array}{c}50 \\
(58.2)\end{array}$ & $\begin{array}{c}4 \\
(4.6)\end{array}$ & $\begin{array}{c}32 \\
(37.2)\end{array}$ & $\begin{array}{c}86 \\
(100)\end{array}$ & $\begin{array}{c}82 \\
(95.4)\end{array}$ & $\begin{array}{c}4 \\
(4.6)\end{array}$ \\
\hline
\end{tabular}

ILI: influenza-like illness; SARI: severe acute respiratory infection

Fig. 2. HA1 phylogenetic tree of influenza $A(H 1) p d m 09$ circulating in northern Viet Nam, 2016-2018

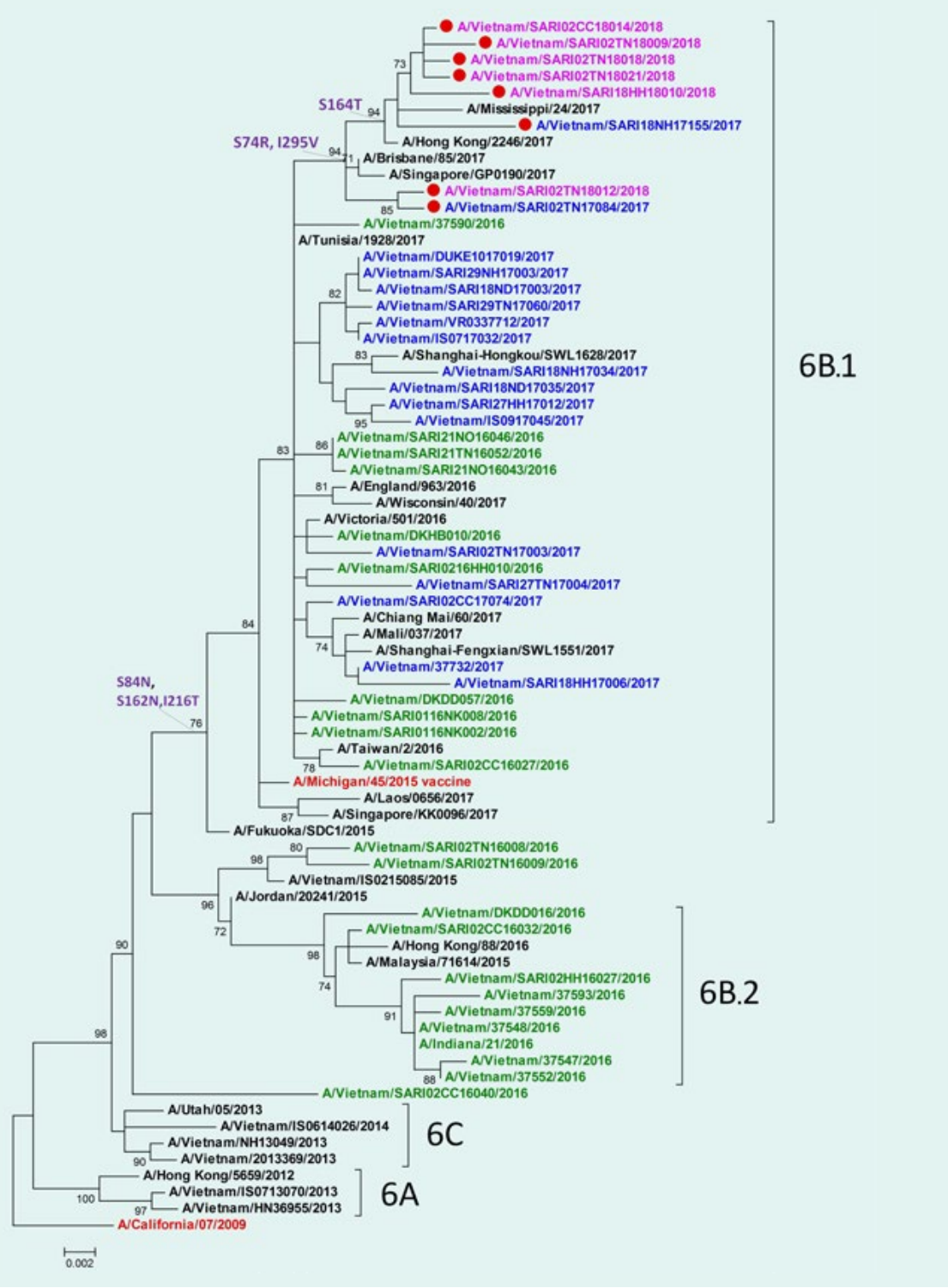

Text in pink indicates isolates in 2018. Text in blue indicates isolates in 2017. Text in green indicates isolates in 2016. Text in red indicates vaccine strains. Red dots indicate mutant isolates. 
groups that derived from 6B.1 with a change at residue S74R and I295V. The mutation S164T appeared in only six isolates of which five had been collected in early 2018.

Examining mismatches between primer and probe sequences used in the real-time RT-PCR assay and circulating $\mathrm{A}(\mathrm{H} 1 \mathrm{~N} 1) \mathrm{pdm} 09$ viruses

There were no mismatches and no significant changes in the forward and reverse primers in either the negative and positive real-time RT-PCR viruses in this study. However, three mismatches at position 7 ( $A$ to $G$ ), 9 ( $A$ to $G$ ) and 17 ( $A$ to $G$ ) at the probe's target sites were unique to the realtime RT-PCR negative viruses (Fig. 1); six of these had a mismatch at the 7th base, one had two mismatches at the 7th and 9th bases, and the other had three mismatches at the 7th, 9th and 21st bases (Fig. 1). All positive and negative influenza $A(H 1) p d m 09$ viruses by real-time RTPCR had mismatches at the 16th ( $G$ to $A$ ) and 27th ( $A$ to $G)$ bases in the probe's site, implying that the real-time RT-PCR conditions likely tolerated these mismatches.

Analysing the $H A$ protein of $A(H 1) p d m 09$ real-time RT-PCR negative isolates, the substitution I295V (HA1 numbering) referred to a single nucleotide mutation at position 7 in the probes (Fig. 3). This mutation is one of the two mutations related to new subgroups derived from group 6B.1 (Fig. 2, 3).

\section{DISCUSSION}

This study reports point mutations in the HA gene at specific probe sequence positions, which may have caused the false-negative subtyping results using real-time RT-PCR for influenza $A(\mathrm{H} 1)$ pdm09 from December 2017 to March 2018 in Viet Nam. The mutation was located at the 7th base in the probe's hybridization site that may not distinguish real-time RT-PCR negative and positive $\mathrm{A}(\mathrm{H} 1)$ pdm09 isolates and likely reduce the probe binding efficiency. All isolates with this mutation were in subgroup 6B.1, similar to $A(H 1 N 1) p d m 09$ viruses circulating worldwide recently. ${ }^{1}$ Among these mutations, substitution I295V represents a mismatch between the real-time RT-PCR probes and the HA segment. However, the mutation at position 295 in HA1 protein has minor impact on RT-PCR performance; therefore, conventional RT-PCR may be the best assay to use for influenza $A(\mathrm{H} 1)$ pdm09 detection where a new probe is being modified or developed. ${ }^{18}$

Molecular assays, such as RT-PCR, have been accepted as the gold standard diagnostic tool for the detection of influenza viruses, and real-time RT-PCR has been a key development in PCR-based technology, significantly increasing the sensitivity and reducing the turnaround time compared with conventional PCR. However, this study shows that monitoring the evolution of influenza $A$ viruses and adapting the RT-PCR probes and primers accordingly are required to minimize the risk of missed detections. ${ }^{19}$ Recently developed next-generation sequencing technology and advanced molecular assays may also be useful tools to identify virus subtypes from clinical specimens when the samples cannot be subtyped and support rapid and accurate detection of an influenza outbreak allowing for appropriate patient care and treatment. ${ }^{18-21}$

This study is limited in that it was based on samples collected from a small number of sentinel sites in northern Viet Nam with a small number of isolates $(n=23)$. Therefore the results may not be representative of all regions in Viet Nam or even of all areas in northern Viet Nam. However, that there was a mutation detected that may have resulted in the false-negative results by real-time RT-PCR demonstrates the influence of sequence variation in influenza viruses, which can result in probe mismatches on real-time RT-PCR assays for influenza detection in Viet Nam. This indicates a need for newly designed or modified primers and probes to effectively detect variant influenza viruses. To sustain sentinel influenza surveillance in Viet Nam, the evolution of influenza viruses should be monitored to determine genetic variants related to reduced sensitivity of diagnostic assays in a timely manner. This would be useful information not only for Viet Nam's national surveillance system but also for other influenza surveillance systems worldwide.

The mismatch detected at position 7 on the probe nucleotide sequence site indicates that the real-time RTPCR conditions likely tolerated these mismatches. This limits the effectiveness of real-time RT-PCR for detecting $A(H 1 N 1) p d m 09$ in clinical samples and isolates and should be monitored. Alternatively, conventional RT-PCR could be used as the preferred method or for those isolates where real-time RT-PCR cannot determine a subtype. It 
Fig. 3. The substitutions found in the HA protein of influenza $A(H 1 N 1) p d m 09$ compared to the probe sequence

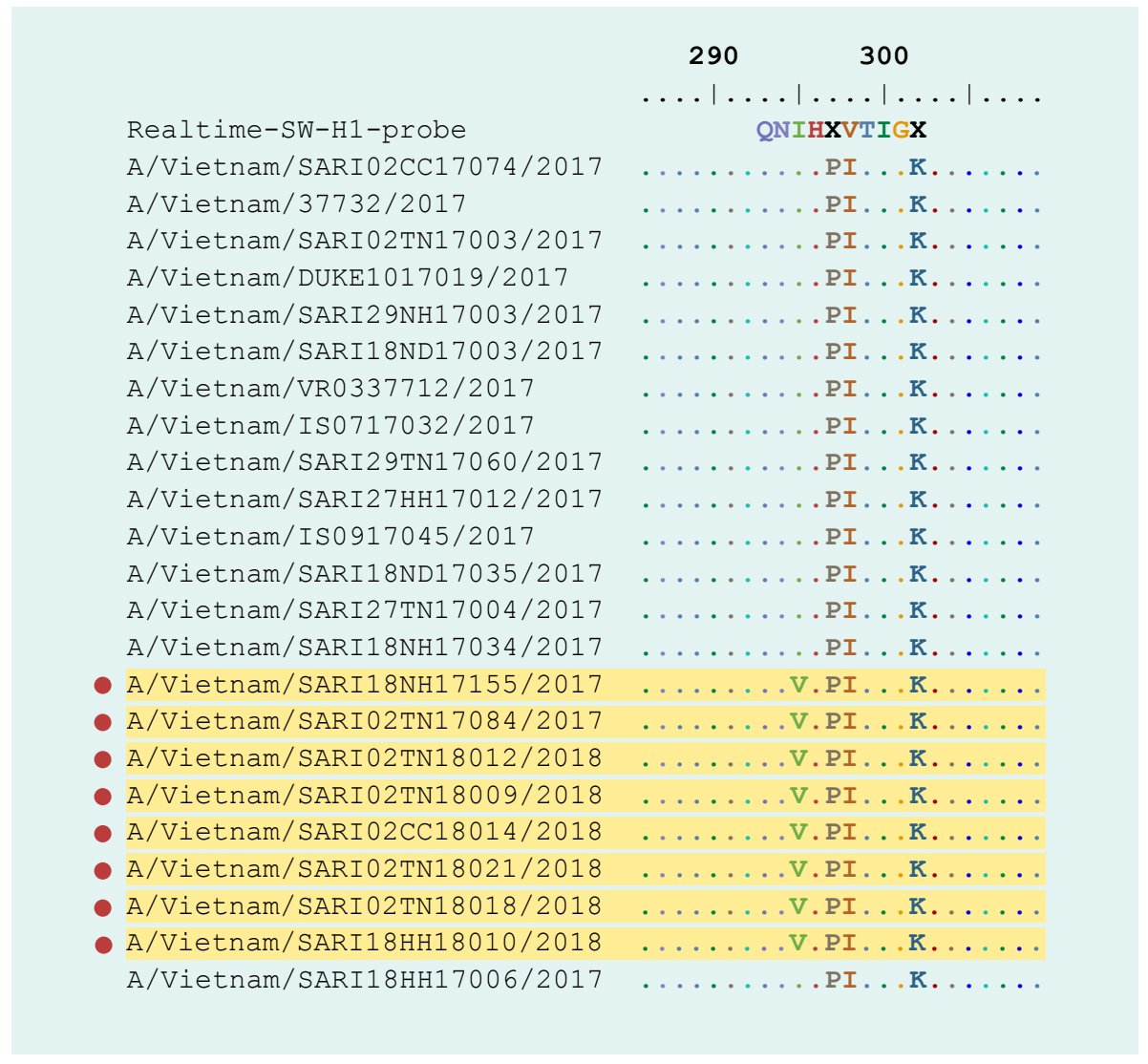

Red dots indicate identity with primer or probe sequence.

Yellow highlights indicate mismatched nucleotides at position $7(A / G)$ and position $9(A / G)$ of probe.

is also recommended that the primers and probes used be monitored and that a validation process for real-time RT-PCR primer-probe systems be developed.

\section{Acknowledgements}

We gratefully acknowledge the contribution of health workers at sentinel sites of the National Influenza Surveillance System and Acute Severe Respiratory Infection Surveillance System for sample collection.

\section{References}

1. Evolution of a pandemic. Geneva: World Health Organization; 2013 (http://www.who.int/influenza/resources/publications/evolution_pandemic_Ah1n1/en/).

2. Surveillance report: influenza virus characterisation. Solna: Health Communication Unit, European Centre for Disease Prevention and Control; 2013 (https://ecdc.europa.eu/en/publicationsdata/influenza-virus-characterisation-summary-europe-december-2013).

3. Nguyen HKL, Nguyen PTK, Nguyen TC, Hoang PVM, Le TT, Vuong
$C D$, et al. Virological characterization of influenza H1N1pdm09 in Vietnam, 2010-2013. Influenza Other Respir Viruses. 2015 Jul;9(4):216-24. doi:10.1111/irv.12323 pmid:25966032

4. Nguyen YT, Graitcer SB, Nguyen TH, Tran DN, Pham TD, Le MTQ, et al. National surveillance for influenza and influenza-like illness in Vietnam, 2006-2010. Vaccine. 2013 Sep 13;31(40):4368-74. doi:10.1016/j.vaccine.2013.07.018 pmid:23911781

5. Western Pacific Region Global Influenza Surveillance and Response System. Epidemiological and virological characteristics of influenza in the Western Pacific Region of the World Health Organization, 2006-2010. PLoS One. 2012;7(5):e37568. doi:10.1371/journal.pone.0037568 pmid:22675427

6. Influenza Update $N^{\circ} 308$. Geneva: World Health Organization; 2018 (https://www.who.int/influenza/surveillance monitoring/ updates/2018_02_05_surveillance_update_308.pdf).

7. Influenza Update $N^{\circ} 306$. Geneva: World Health Organization; 2017 (https://www.who.int/influenza/surveillance monitoring/ updates/2018_01_08_surveillance_update_306.pdf).

8. Countries in the temperate zone of the Northern Hemisphere, $\mathrm{Bi}$ weekly Influenza Situation Update. Manila: WHO Regional Office for the Western Pacific; 2016 (http://iris.wpro.who.int/bitstream/ handle/10665.1/14173/Influenza-20160621.pdf).

9. The use of PCR in the surveillance and diagnosis of influenza. Geneva: World Health Organization; 2011 (http://www.who.int/ influenza/gisrs_laboratory/final_who_pcr_meeting_report_ aug_2011_en.pdf). 
10. CDC protocol of realtime RTPCR for influenza A(H1N1). Geneva: World Health Organization; 2009 (http://www.who.int/csr/resources/publications/swineflu/CDCRealtimeRTPCR_SwineH1Assay-2009_20090430.pdf).

11. WHO surveillance case definitions for ILI and SARI. Geneva: World Health Organization; 2019 (https://www.who.int/influenza/surveillance_monitoring/ili_sari_surveillance_case_definition/en/).

12. Chen LM, Davis CT, Zhou H, Cox NJ, Donis RO. Genetic compatibility and virulence of reassortants derived from contemporary avian $\mathrm{H} 5 \mathrm{~N} 1$ and human H3N2 influenza $A$ viruses. PLoS Pathog. 200805 23;4(5):e1000072. doi:10.1371/journal.ppat.1000072 pmid: 18497857

13. Protocols for BioEdit/Mega2 Lab. Burnaby, BC: Simon Fraser University (http://www.sfu.ca/ donyang/arch335/Protocols\%20 for\%20BioEdit.pdf).

14. Software for molecular biology and sequence analysis. Madison, WI: DNASTAR (https://www.dnastar.com/workflows/molecularbiology/\#alignment).

15. Tamura K, Peterson D, Peterson N, Stecher G, Nei M, Kumar S. MEGA5: molecular evolutionary genetics analysis using maximum likelihood, evolutionary distance, and maximum parsimony methods. Mol Biol Evol. 2011;28(10):2731-9. doi:10.1093/molbev/ msr121
16. Nucleotide. Bethesda, MD: National Center for Biotechnology Information (https://www.ncbi.nlm.nih.gov/nuccore/?term=influe nza $++\mathrm{HA}++\mathrm{H} 1 \mathrm{~N} 1 \mathrm{pdm09}$ ).

17. Miller H, Olsen C, Moir R. Geneious R7: A bioinformatics platform for biologist. San Francisco, CA (https://www.scribd.com/document/232812003/Geneious-R7-A-Bioinformatics-Platform-forBiologists).

18. Mukherjee S and Chakrabarti AK. Impact of microarray technology in influenza virus research and diagnostics. J Proteomics Bioinform S6:002. doi:10.4172/jpb.S6-002

19. Tenorio-Abreu A, Eiros Bouza JM, Rodríguez Molins E, Bermejo Martín JF, Domínguez-Gil M, Vega Alonso T, et al. [Influenza surveillance by molecular diagnosis]. Rev Esp Quimioter. 2009 Dec;22(4):214-20. [Spanish] pmid:20082043

20. Van den Hoecke S, Verhelst J, Vuylsteke M, Saelens X. Analysis of the genetic diversity of influenza $A$ viruses using next-generation DNA sequencing. BMC Genomics. 2015 Feb 14;16(1):79. doi:10.1186/s12864-015-1284-z pmid:25758772

21. Kawai $Y$, Kimura $Y$, Lezhava A, Kanamori H, Usui K, Hanami T, et al. One-step detection of the 2009 pandemic influenza $A(H 1 N 1)$ virus by the RT-SmartAmp assay and its clinical validation. PLoS One. 2012;7(1):e30236. doi:10.1371/journal.pone.0030236 pmid:22295077 


\title{
Preparation for mass gathering events from the perspective of a non-host country: the experience of Japan during the 2018 PyeongChang Olympics and Paralympic Winter Games
}

\author{
Kazuaki Jindai, ${ }^{a}$ Takuya Yamagishi, ${ }^{a}$ Munehisa Fukusumi, ${ }^{a}$ Shingo Nishiki, ${ }^{b}$ Yusuke Kobayashi, ${ }^{b}$ Yusuke Matsui, \\ Tamano Matsui a and Kazunori Oishi ${ }^{\alpha}$ \\ Correspondence to Takuya Yamagishi (email: tack-8@nih.go.jp)
}

$\mathrm{T}$ he World Health Organization recommends that countries or organizations that host mass gatherings plan ahead and prepare for possible public health events to ensure a safe environment for local residents, participants and travellers. ${ }^{1}$ Public health events during mass gatherings can also affect non-host countries. There are numerous reports of the spread of infectious diseases by travellers returning from mass gatherings, ${ }^{2}$ which can potentially pose the risk of an outbreak of new infectious diseases to travellers' home countries. With more frequent travel across borders, it is prudent that non-host countries prepare for mass gathering events.

The 2018 PyeongChang Olympic Winter Games was held in the Republic of Korea between 9 February and 25 February 2018, followed by the Paralympic Games between 9 March and 18 March 2018. In both Games (hereinafter referred to as the Games), nearly 3000 athletes from 92 countries competed in 13 sports. Many travellers from Japan were expected to visit the Games. We conducted ad hoc event-based surveillance and risk assessments of Games-related public health events, especially infectious diseases outbreaks, which could affect Japanese athletes, travellers and residents in the Republic of Korea and which could have an influence on Japan. We described our methods and the lessons learnt through this project in this report.

One person was assigned to conduct event screening during weekdays using official and unofficial information sources (Fig. 1). During the Games, we identified priority infectious diseases to be monitored, such as diseases commonly seen in the Republic of Korea (e.g. mumps, hepatitis $A$ and varicella); ${ }^{3}$ diseases commonly seen in the winter in Asia (e.g. gastroenteritis and seasonal influenza); diseases that are prone to cause outbreaks during a mass gathering (e.g. meningococcal disease); and diseases with global public health significance (e.g. animal and human infection with avian influenza virus, measles, rubella and infection with multidrug-resistant bacteria). We screened reports from the media via Internet searches using the following pre-specified search terms:

Infectious disease, food poisoning, infection, Zika, Ebola, severe fever with thrombocytopenia syndrome, chikungunya, dengue, pathogen, bacteria, virus, drug resistance, influenza, yellow fever, Lassa, anthrax, MERS, outbreak, hepatitis A, hepatitis, haemorrhagic fever with renal syndrome, mumps, measles, rubella, varicella, typhoid fever, malaria, syphilis, HIV, gonorrhea, meningococcal disease or norovirus infection.

We referred to the World Animal Health Information System, ${ }^{4}$ ProMED, ${ }^{5}$ the Center for Infectious Disease Research and Policy ${ }^{6}$ and weekly reports from the Korea Centers for Disease Control and Prevention (KCDC) ${ }^{3}$ to monitor events at the Games, using web-based automatic translation if written in the Korean language. We also screened weekly reports from the National Epidemiological Surveillance of Infectious Disease (NESID) in Japan ${ }^{7}$

\footnotetext{
Infectious Disease Surveillance Center, National Institute of Infectious Diseases, Tokyo, Japan. 
Fig. 1. Algorithm of event-based surveillance and risk assessment of Games-related infectious disease events with potential impact on Japanese travellers and residents in the Republic of Korea during the 2018 PyeongChang Olympic and Paralympic Winter Games

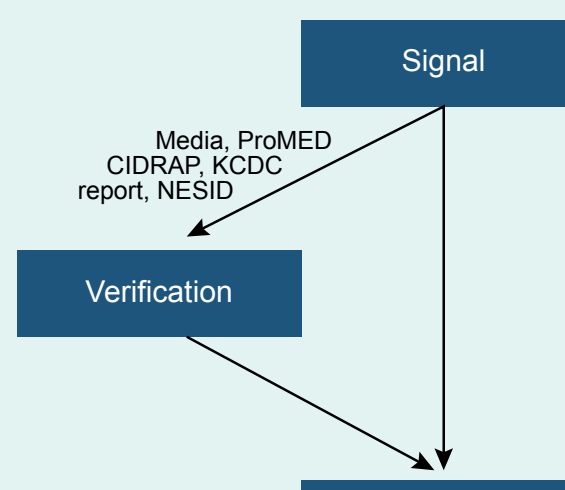

Risk assessment

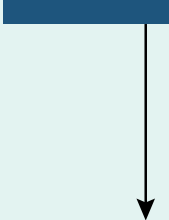

Level of the risk is

high or very high

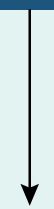

Further action
Games-related events with potential impact on Japanese athletes, travelers and residents in the Republic of Korea or Japan were screened by prespecified terms ${ }^{*}$ and identified as a signal.

* Search terms were: infectious disease, infection, outbreak, pathogen, bacteria, virus, drug resistance, food poisoning, Zika, Ebola, severe fever with

thrombocytopenia syndrome, tick-borne, chikungunya, dengue, influenza, yellow fever, Lassa, anthrax, MERS, hepatitis, haemorrhagic fever with renal syndrome, mumps, measles, rubella, varicella, typhoid fever, malaria, syphilis, HIV, gonorrhea meningococcal disease or norovirus infection

A designated person at IDSC conducted signal triaging

Priority infectious diseases were:

- diseases commonly seen in the Republic of Korea and Asia in winter;

- diseases prone to cause an outbreak during mass gatherings; and

- diseases with global public health significance.

IDSC staff and Field Epidemiology Training Program trainees assessed the likelihood and consequence of further disease spread that could potentially impact:

- Japanese athlete, travellers and residents in the

Republic of Korea; and

- the public in Japan.

Risk perceptions among the public and health officials were also assessed at the end of this process.

IDSC communicated with MHLW for further action.

CIDRAP: Center for Infectious Disease Research and Policy; IDSC: Infectious Disease Surveillance Center: National Institute of Infectious Diseases, Japan; KCDC: Korea Centers for Disease Control and Prevention; MHLW: Ministry of Health, Labour and Welfare, Japan; NESID: National Epidemiological Surveillance for Infectious Diseases, Japan.

to search for indicators of potential disease importation from the Republic of Korea or disease spread in Japan. NESID includes more than 100 notifiable diseases and diseases on its sentinel surveillance system. ${ }^{8}$ If we discovered pertinent signals, we contacted KCDC for signal verification. After verification, Infectious Disease Surveillance Center, Japan (IDSC) staff and Field Epidemiology Training Program (FETP) trainees assessed the likelihood and consequence of further spread of the event that could potentially impact on Japanese athletes, travellers, residents of the Republic of Korea and the public in Japan. The staff and trainees also assessed risk perception among Japanese nationals and among government officials of Japan to the event in the context of the Games. If the level of risk was high or very high, IDSC communicated with the Japanese Ministry of Health, Labour and Welfare (MHLW) for further action. The results were also shared with them at least weekly. We continued this activity for seven weeks: one week before, one week after and five weeks during the Games.

The mean number of signals identified per day was five. The average time required to triage all signals was 20 minutes per day. Five public health events underwent further risk assessments. One was a norovirus outbreak reported on 5 March $2018 .^{9}$ We determined that the risks of this event affecting Japanese travellers and residents in the Republic of Korea as well as spreading to Japan were low. There was a low probability that this event that would require an international response, given the low severity of the disease and quick response by the Korean Government. We also detected additional events of animal infection with avian influenza $A(\mathrm{H} 5 \mathrm{~N} 6)$ virus; however, we considered the impact to be limited 
as transmission only occurred among poultry and wild birds. These events were shared with MHLW during the routine weekly meetings.

We conducted event-based surveillance (EBS) during a mass gathering event from the perspective of a non-host country. The focus was an event or signal that could pose any health risk to Japanese travellers and residents in the Republic of Korea during the Games. We also took into consideration the potential risk of such an event being imported to and spread in Japan.

A wide variety of infectious diseases have been associated with mass gatherings. ${ }^{2}$ Diseases prone to spreading during a mass gathering should be prioritized for monitoring. The severity of diseases, the availability of treatments and public health control measures also need to be considered. The possibility of disease exportation from a non-host country to other countries is less likely in the early stage of a mass gathering event; therefore, we did not assess such risk. Instead, we highlighted attending athletes, travellers and residents in the Republic of Korea. This prioritization process required the knowledge of local context through consultation with KCDC through informal channels. Routine KCDC official reports based on existing indicator-based surveillance also provided relevant information and were helpful in understanding the situation. However, some pertinent information for events (e.g. detailed epidemiologic information of affected population) was not readily available from the reports. During the norovirus outbreak, additional detailed reports by KCDC of the outbreak played an important supplementary role in assessing the risk at the local level.

The primary concern when starting surveillance and risk assessment of the events associated with mass gathering was the burden on staff and other resources. Language barriers can lead to a greater burden on staff resources; however, we were able to reasonably understand information described in Korean through web-based automatic translation. One of our findings was that mass media in English language covered the events at the same time or quickly following reports published in the Korean media. Even if the lack of staff resources prevented close monitoring of Korean media, we believed that signals from English language media allowed the timely detection and response to events occurring at the Games. Another plausible concern for public health sectors in non-host countries is that additional time and resources are needed to implement an EBS system in another country. In this project, however, the ad hoc EBS system was an extension of an existing EBS system and did not result in additional financial and opportunity costs. ${ }^{10}$ If the host country has an established, organized indicator-based surveillance system and is willing to share information in the system with non-host countries, the burden to the non-host country would be minimal.

If an event becomes an extended and serious threat to public health, prompt upscaling of the response is warranted. ${ }^{11}$ As emphasized in the Asia Pacific Strategy for Emerging Disease and Public Health Emergencies, ${ }^{12}$ having surge capacity to expand routine EBS and risk assessment is imperative to respond to an outbreak during large mass gatherings.

It seems feasible to apply similar methods during other mass gatherings, although limitations should be considered before planning a similar EBS and risk assessment system. First, successful EBS and risk assessment depend on the infrastructure of the host country and its information-sharing system. Second, disease prioritization for EBS and risk assessment during mass gatherings needs the understanding of local disease epidemiology and the context of the host country. Third, translations by web-based automatic translation systems can be inaccurate $^{13}$ although the information in the media reports in English aligned with the original Republic of Korea reports.

We described our experience in EBS and risk assessment during a mass gathering from the perspective of a non-host country. Building in-country EBS, a risk assessment system and establishing lines of communication with host countries before the event are of critical importance for successful preparation. Regional networks can help to establish and maintain communication with host countries. Our experience could be a meaningful model for non-host countries to prepare and enhance EBS for mass gatherings held in other countries.

\section{Acknowledgement}

We thank Dr Bryan Inho Kim at KCDC for sharing useful websites for infectious diseases surveillance and reliable domestic media sources in the Republic of Korea. 


\section{Funding}

None.

\section{Conflicts of interest}

\section{None declared.}

\section{References}

1. Public health for mass gatherings: key considerations. Geneva: World Health Organization; 2015 (http://apps.who.int/iris/bitstream/10665/162109/1/WHO_HSE_GCR_2015.5_eng.pdf, accessed 15 March 2018).

2. Abubakar I, Gautret P, Brunette GW, Blumberg L, Johnson D, Poumerol G, et al. Global perspectives for prevention of infectious diseases associated with mass gatherings. Lancet Infect Dis. 2012 Jan;12(1):66-74. doi:10.1016/S1473-3099(11)70246-8 pmid:22192131

3. Infectious disease statistics system [website]. Osong: Korea Centers for Disease Control and Prevention; 2018 (https://is.cdc.go.kr/ dstat/index.jsp, accessed 10 February 2018).

4. Weekly disease information, WAHIS interface. Paris: World Organisation for Animal Health; 2018 (http://www.oie.int/wahis_2/ public/wahid.php/Diseaseinformation/WI, accessed 10 January 2019).

5. ProMED [website]. Brookline, MA: International Society for Infectious Diseases; 2019 (https://www.promedmail.org/, accessed 10 January 2019).
6. Center for Infectious Disease Research and Policy [website]. Minneapolis, MN: University of Minnesota; 2019 (http://www.cidrap. umn.edu/, accessed 10 January 2019).

7. Infectious disease weekly reports. Tokyo: National Institute of Infectious Diseases; 2018 (https://www.niid.go.jp/niid/ja/idwrdl/2018.html, accessed 12 December 2018).

8. Infectious disease surveillance system in Japan, 2018. Tokyo: National Institute of Infectious Diseases; 2018 (https://www.niid go.jp/niid/images/epi/nesid/nesid_en.pdf, accessed 12 December 2018).

9. Progress of the norovirus outbreak in the PyeongChang Olympic site. Osong: Korea Centers for Disease Control and Prevention; 2018 (http://www.cdc.go.kr/CDC/eng/info/CdcKPress. jsp? menulds $=$ HOME002-MNU0576-MNU0586\&fid $=8652 \& q$ type $=\& q$ value $=\& c i d=78462 \&$ pageNum $=1, \quad$ accessed $\quad 17$ December 2018).

10. Thackway S, Churches T, Fizzell J, Muscatello D, Armstrong P. Should cities hosting mass gatherings invest in public health surveillance and planning? Reflections from a decade of mass gatherings in Sydney, Australia. BMC Public Health. 2009 Sep 8;9(1):324. doi:10.1186/1471-2458-9-324 pmid:19735577

11. Takla A, Velasco E, Benzler J. The FIFA Women's World Cup in Germany 2011-a practical example for tailoring an event-specific enhanced infectious disease surveillance system. BMC Public Health. 2012 Jul 31;12(1):576. doi:10.1186/1471-2458-12-576 pmid:22849632

12. Asia Pacific strategy for emerging diseases and public health emergencies (APSED III). Manila: WHO Regional Office for the Western Pacific; 2017 (http://iris.wpro.who.int/handle/10665.1/13654, accessed 31 March 2018)

13. Patil S, Davies P. Use of Google Translate in medical communication: evaluation of accuracy. BMJ. 2014 Dec 15;349:g7392 doi:10.1136/bmj.g7392 pmid:25512386 
